OPEN ACCESS

Edited by:

Ghassan M. Matar,

American University of Beirut,

Lebanon

Reviewed by:

Sang Sun Yoon,

Yonsei University, South Korea

Ravi Jhaveri,

University of North Carolina Hospitals,

USA

*Correspondence:

Sang Hee Lee

sangheelee@mju.ac.kr

${ }^{\dagger}$ These authors have contributed equally to this work.

Received: 19 December 2016 Accepted: 13 February 2017

Published: 13 March 2017

Citation:

Lee C-R, Lee JH, Park M, Park KS, Bae IK, Kim YB, Cha C-J, Jeong BC and Lee SH (2017) Biology of

Acinetobacter baumannii:

Pathogenesis, Antibiotic Resistance

Mechanisms, and Prospective

Treatment Options.

Front. Cell. Infect. Microbiol. 7:55.

doi: 10.3389/fcimb.2017.00055

\section{Biology of Acinetobacter baumannii: Pathogenesis, Antibiotic Resistance Mechanisms, and Prospective Treatment Options}

\author{
Chang-Ro Lee ${ }^{1 \dagger}$, Jung Hun Lee ${ }^{1 t}$, Moonhee Park ${ }^{1,2 t}$, Kwang Seung Park ${ }^{1}$, II Kwon Bae ${ }^{3}$ \\ Young Bae Kim ${ }^{4}$, Chang-Jun Cha ${ }^{5}$, Byeong Chul Jeong ${ }^{1}$ and Sang Hee Lee ${ }^{1 *}$ \\ ${ }^{1}$ National Leading Research Laboratory of Drug Resistance Proteomics, Department of Biological Sciences, Myongji \\ University, Yongin, South Korea, ${ }^{2}$ DNA Analysis Division, Seoul Institute, National Forensic Service, Seoul, South Korea, \\ ${ }^{3}$ Department of Dental Hygiene, College of Health and Welfare, Silla University, Busan, South Korea, ${ }^{4}$ Biotechnology \\ Program, North Shore Community College, Danvers, MA, USA, ${ }^{5}$ Department of Systems Biotechnology, College of \\ Biotechnology and Natural Resources, Chung-Ang University, Anseong, South Korea
}

Acinetobacter baumannii is undoubtedly one of the most successful pathogens responsible for hospital-acquired nosocomial infections in the modern healthcare system. Due to the prevalence of infections and outbreaks caused by multi-drug resistant A. baumannii, few antibiotics are effective for treating infections caused by this pathogen. To overcome this problem, knowledge of the pathogenesis and antibiotic resistance mechanisms of $A$. baumannii is important. In this review, we summarize current studies on the virulence factors that contribute to $A$. baumannii pathogenesis, including porins, capsular polysaccharides, lipopolysaccharides, phospholipases, outer membrane vesicles, metal acquisition systems, and protein secretion systems. Mechanisms of antibiotic resistance of this organism, including acquirement of $\beta$-lactamases, up-regulation of multidrug efflux pumps, modification of aminoglycosides, permeability defects, and alteration of target sites, are also discussed. Lastly, novel prospective treatment options for infections caused by multi-drug resistant $A$. baumannii are summarized.

Keywords: antimicrobial resistance, Acinetobacter baumannii, treatment option, resistance mechanism, virulence factor

\section{INTRODUCTION}

Acinetobacter spp. are glucose-non-fermentative, non-motile, non-fastidious, catalase-positive, oxidative-negative, aerobic Gram-negative coccobacilli (Lin and Lan, 2014). Due to clusters of closely related species, it is difficult to distinguish Acinetobacter taxonomy using phenotypic traits and chemotaxonomic methods. Because antibiotic susceptibility and clinical relevance are significantly different between different genomic species, exact identification of Acinetobacter species are required (Bergogne-Berezin and Towner, 1996; Dijkshoorn et al., 1996; Houang et al., 2003; Lee et al., 2007). Many genomic fingerprinting methods have been developed, including repetitive extragenic palindromic sequence-based polymerase chain reaction (rep-PCR), pulsed-field gel electrophoresis (PFGE), matrix-assisted laser desorption ionization time-of-flight (MALDI-TOF) mass spectrometry, ribotyping, amplified ribosomal DNA restriction analysis, 
random amplified polymorphic DNA analysis, multilocus sequence typing (MLST), RNA spacer fingerprinting, amplified fragment length polymorphism analysis, and sequence analysis of 16S-23S rRNA intergene spacer regions or the $r p o B$ and $g y r B$ genes (Koeleman et al., 1998; Chang et al., 2005; La Scola et al., 2006; Croxatto et al., 2012; Higgins et al., 2012; Lee C. R. et al., 2015; Li X. M. et al., 2016).

Among Acinetobacter species, Acinetobacter baumannii is the most important member associated with hospital-acquired infections worldwide (Lin and Lan, 2014). This aerobic Gramnegative coccobacillus had been regarded as a low-grade pathogen, but it is a successful pathogen responsible for opportunistic infections of the skin, bloodstream, urinary tract, and other soft tissues (Peleg et al., 2008). Because many A. baumannii infections have suddenly been reported among veterans and soldiers who served in Iraq and Afghanistan (Centers for Disease and Prevention, 2004), A. baumannii is referred to as "Iraqibacter." Multidrug-resistant (MDR) A. baumannii has spread to civilian hospitals in part by crossinfection of injured military patients repatriated from war zones (Peleg et al., 2008). Most A. baumannii infections occur in critically ill patients in the intensive care unit (ICU) setting (Fournier and Richet, 2006) and account for up to $20 \%$ of infections in ICUs worldwide (Vincent et al., 2009). Furthermore, the frequency of community-acquired A. baumannii infections has been increasing gradually (Lin and Lan, 2014). Several virulence factors have been identified by genomic and phenotypic analyses, including outer membrane porins, phospholipases, proteases, lipopolysaccharides (LPS), capsular polysaccharides, protein secretion systems, and iron-chelating systems (Antunes et al., 2011; McConnell et al., 2013; Lin and Lan, 2014).

Many reports have shown that $A$. baumannii rapidly develops resistance to antimicrobials, and multidrug-resistant strains have been isolated (McConnell et al., 2013). The WHO declared that A. baumannii is one of the most serious ESKAPE organisms (Enterococcus faecium, Staphylococcus aureus, Klebsiella pneumoniae, A. baumannii, Pseudomonas aeruginosa, and Enterobacter species) that effectively escape the effects of antibacterial drugs (Boucher et al., 2009). A number of $A$. baumannii resistance mechanisms are known, including enzymatic degradation of drugs, target modifications, multidrug efflux pumps, and permeability defects (Gordon and Wareham, 2010; Kim et al., 2012; Lin and Lan, 2014). In this review, we summarize the virulence factors of $A$. baumannii, antibiotic resistance mechanisms, and the therapeutic options available for treating A. baumannii infections. Figure 1 depicts all the features described in this review.

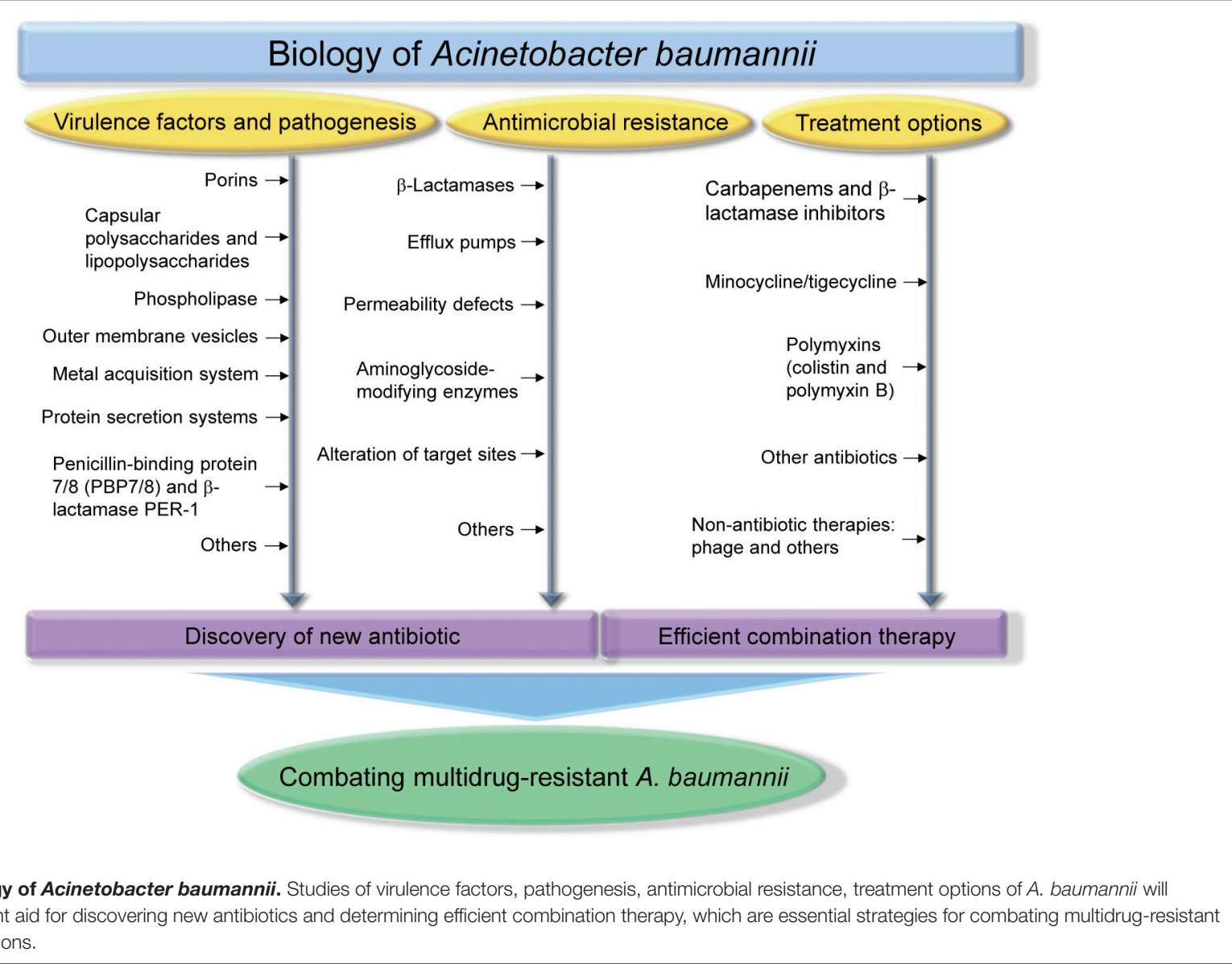




\section{ACINETOBACTER BAUMANNII VIRULENCE FACTORS AND PATHOGENESIS}

Although recent genomic and phenotypic analyses of A. baumannii have identified several virulence factors responsible for its pathogenicity, relatively few virulence factors have been identified in A. baumannii, compared to those in other Gram-negative pathogens (McConnell et al., 2013). The proposed A. baumannii virulence factors are summarized in Table 1.

\section{Porins}

Porins are outer membrane proteins associated with modulating cellular permeability. OmpA is a $\beta$-barrel porin and one of the most abundant porins in the outer membrane. In A. baumannii,
OmpA is the very well-characterized virulence factor with a variety of interesting biological properties identified in in vitro model systems (Smith et al., 2007; McConnell et al., 2013). A random mutagenesis screen showed that the A. baumannii ompA mutant is defective in inducing apoptosis in human epithelial cells (Choi et al., 2005). Purified OmpA binds host epithelial cells, targets mitochondria, and induces apoptosis by releasing proapoptotic molecules, such as cytochrome $\mathrm{c}$ and apoptosisinducing factor (Choi et al., 2005; Lee et al., 2010). Another study showed that OmpA translocates to the nucleus by a novel monopartite nuclear localization signal and induces cell death (Choi et al., 2008a). OmpA also plays a major role in adherence and invasion of epithelial cells by interacting with fibronectin (Choi et al., 2008b; Gaddy et al., 2009; Smani et al., 2012), and binds to factor $\mathrm{H}$ in human serum (Kim et al., 2009), which may allow A. baumannii to avoid complement-mediated killing. The

TABLE 1 | Identified virulence factors of Acinetobacter baumannii.

\begin{tabular}{|c|c|c|}
\hline Virulence factor & Proposed role in pathogenesis & References \\
\hline $\begin{array}{l}\text { Porin (OmpA, Omp33-36, Omp22, CarO, } \\
\text { OprD-like) }\end{array}$ & $\begin{array}{l}\text { Adherence and invasion, induction of apoptosis, serum resistance, } \\
\text { biofilm formation, persistence }\end{array}$ & $\begin{array}{l}\text { Choi et al., 2005, 2008b; Gaddy et al., 2009; Kim } \\
\text { et al., 2009; Lee et al., 2010; Fernandez-Cuenca } \\
\text { et al., 2011; Smani et al., 2012, 2013; Rumbo et al., } \\
\text { 2014; Wang et al., 2014; Huang et al., } 2016\end{array}$ \\
\hline Capsular polysaccharide & Growth in serum, survival in tissue infection, biofilm formation & $\begin{array}{l}\text { Russo et al., 2010; Iwashkiw et al., 2012; } \\
\text { Lees-Miller et al., } 2013\end{array}$ \\
\hline Lipopolysaccharide (LPS) & $\begin{array}{l}\text { Serum resistance, survival in tissue infection, evasion of the host } \\
\text { immune response }\end{array}$ & $\begin{array}{l}\text { Luke et al., 2010; Lin et al., 2012; McQueary et al., } \\
\text { 2012; McConnell et al., } 2013\end{array}$ \\
\hline Phospholipase (PLC and PLD) & Serum resistance, invasion, in vivo survival & $\begin{array}{l}\text { Camarena et al., 2010; Jacobs et al., 2010; Stahl } \\
\text { et al., 2015; Fiester et al., } 2016\end{array}$ \\
\hline Outer membrane vesicle (OMV) & $\begin{array}{l}\text { Delivery of virulence factors, horizontal transfer of antibiotic } \\
\text { resistance gene }\end{array}$ & $\begin{array}{l}\text { Kwon et al., 2009; Jin et al., 2011; Rumbo et al., } \\
\text { 2011; Moon et al., 2012; Jun et al., 2013; Li Z. T. } \\
\text { et al., } 2015\end{array}$ \\
\hline $\begin{array}{l}\text { Iron acquisition system (acinetobactin and } \\
\text { NfuA) }\end{array}$ & In vivo survival, persistence, killing of host cells & $\begin{array}{l}\text { Gaddy et al., 2012; Penwell et al., 2012; Zimbler } \\
\text { et al., 2012; Fiester et al., 2016; Megeed et al., } 2016\end{array}$ \\
\hline Zinc acquisition system (ZnuABC and ZigA) & In vivo survival & Hood et al., 2012; Nairn et al., 2016 \\
\hline $\begin{array}{l}\text { Manganese acquisition system (MumC and } \\
\text { MumT) }\end{array}$ & In vivo survival & Juttukonda et al., 2016 \\
\hline Type II protein secretion system & In vivo survival & $\begin{array}{l}\text { Johnson et al., 2015; Elhosseiny et al., 2016; } \\
\text { Harding et al., } 2016\end{array}$ \\
\hline Type VI protein secretion system & Killing of competing bacteria, host colonization & $\begin{array}{l}\text { Carruthers et al., 2013; Wright et al., 2014; Jones } \\
\text { et al., 2015; Repizo et al., 2015; Ruiz et al., } 2015\end{array}$ \\
\hline Type V protein secretion system & Biofilm formation, adherence & Bentancor et al., 2012b \\
\hline $\begin{array}{l}\text { Penicillin-binding protein } 7 / 8 \text { and } \beta \text {-lactamase } \\
\text { PER-1 }\end{array}$ & Serum resistance, in vivo survival, adherence & Sechi et al., 2004; Russo et al., 2009 \\
\hline СipA & Serum resistance, invasion & Koenigs et al., 2016 \\
\hline Tuf & Serum resistance & Koenigs et al., 2015 \\
\hline RecA & In vivo survival & Aranda et al., 2011 \\
\hline SurA1 & Serum resistance, in vivo survival & Liu D. et al., 2016 \\
\hline GigABCD & In vivo survival, killing of host cells & Gebhardt et al., 2015 \\
\hline UspA & In vivo survival, killing of host cells & Elhosseiny et al., 2015; Gebhardt et al., 2015 \\
\hline GacS and PaaE & Neutrophil influx & $\begin{array}{l}\text { Cerqueira et al., 2014; Gebhardt et al., 2015; } \\
\text { Bhuiyan et al., } 2016\end{array}$ \\
\hline Pili & Adherence, biofilm formation & Tomaras et al., 2003, 2008 \\
\hline OmpR/EnvZ & Killing of host cells & Tipton and Rather, 2016 \\
\hline FhaBC & Adherence, killing of host cells & Perez et al., 2016 \\
\hline AbeD & Killing of host cells & Srinivasan et al., 2015 \\
\hline
\end{tabular}


ompA gene is necessary for persistence of $A$. baumannii in the mouse lung (Wang et al., 2014).

Furthermore, OmpA is also involved in antimicrobial resistance of A. baumannii (Sugawara and Nikaido, 2012; Smani et al., 2014). The major A. baumannii porin is OmpA, which has 70-fold lower pore-forming activity than that of OmpF (Sugawara and Nikaido, 2012). Furthermore, disrupting the ompA gene significantly decreases the minimal inhibitory concentrations (MICs) of several antibiotics (chloramphenicol, aztreonam, and nalidixic acid), suggesting that OmpA participates in the extrusion of antibiotics from the periplasmic space through the outer membrane and couples with inner membrane efflux systems (Smani et al., 2014). OmpA enhances survival and persistence of $A$. baumannii by facilitating surface motility and biofilm formation (Gaddy et al., 2009; Clemmer et al., 2011; McConnell et al., 2013). OmpA also regulates biogenesis of outer membrane vesicles (Moon et al., 2012). These results suggest that the OmpA protein is an attractive target for developing novel antibiotics and prevention strategies. Two recent reports based on immuno-proteomics and reverse vaccinology suggested that OmpA is a potential vaccine candidate against A. baumannii (Fajardo Bonin et al., 2014; Hassan et al., 2016). Actually, the OmpA protein is immunogenic in healthy individuals and patients with $A$. baumannii invasive infections (Zhang et al., 2016). In a mouse model of $A$. baumannii infection, mice immunized with OmpA had a significantly higher survival rate than that of control mice (Luo et al., 2012; Lin L. et al., 2013; Zhang et al., 2016).

The 33- to 36-kDa Omp protein (Omp33-36), which acts as a water passage channel, is another outer membrane porin associated with A. baumannii cytotoxicity (Smani et al., 2013; Rumbo et al., 2014). The omp33-36 deletion strain significantly reduces adherence and invasion of human lung epithelial cells and cytotoxicity to these cells (Smani et al., 2013). Deletion of the omp33-36 gene in a murine sepsis model attenuates lethality and reduces bacterial concentrations in the spleen and lungs (Smani et al., 2013). One study showed that purified Omp33-36 induces apoptosis in several different cell types, including immune and connective tissue cells, by activating caspases and modulating autophagy (Rumbo et al., 2014). Omp33-36 is also involved in antibiotic resistance. A. baumannii strain JC10/01 resistant to carbapenem antibiotics (imipenem and meropenem) exhibits loss of Omp33-36 and episomal expression of Omp33-36 in this strain clearly reduces the MICs of imipenem and meropenem (del Mar Tomas et al., 2005).

Omp22 has also been identified as a novel, conserved, and safe antigen for developing effective vaccines to control A. baumannii infections (Huang et al., 2016), although the contribution of Omp22 to A. baumannii pathogenicity has not been determined. Both active and passive immunizations with Omp22 increase the survival rates of mice, suppress bacterial burdens in the organs and peripheral blood, and reduce serum levels of inflammatory cytokines and chemokines (Huang et al., 2016). Other porins, such as carbapenemassociated outer membrane protein (CarO) and OprD-like, are also virulence-related factors associated with attenuated virulence in a mouse model (Fernandez-Cuenca et al., 2011).

\section{Capsular Polysaccharides and Lipopolysaccharides (LPS)}

Beyond OmpA, the A. baumannii envelope is associated with many factors that contribute to pathogenicity. Among these, capsular exopolysaccharides and LPS are A. baumannii pathogenicity factors. Notably, many isolates from patients with A. baumannii infections express surface capsular polysaccharides and contain a conserved gene cluster, called the $\mathrm{K}$ locus, which may determine production of capsular polysaccharides (Koeleman et al., 2001; Hu et al., 2013; Kenyon and Hall, 2013; Geisinger and Isberg, 2015). A random transposon screening to identify genes essential for growth in an inflammatory exudative fluid lead to the identification of the $p t k$ and epsA genes, which are predicted to be required for capsule polymerization and assembly (Russo et al., 2010). The ptk and epsA mutants are deficient in capsule production and have a growth defect in human serum, resulting in a highly significant decrease in survival in soft tissue infection sites (Russo et al., 2010). Mutation in the $p g l C$ or $p g l L$ gene, which is responsible for synthesis of the $O$-pentasaccharide found on glycoproteins and capsular polysaccharides, also attenuate lethality in a mouse septicemia model and form abnormal biofilm structures (Iwashkiw et al., 2012; Lees-Miller et al., 2013). Therefore, capsular polysaccharides have been proposed to be a target for protective antibody-based interventions (passive immunization; Russo et al., 2013).

One study showed that capsular polysaccharides are involved in antimicrobial resistance of $A$. baumannii (Geisinger and Isberg, 2015). Mutants deficient in capsular polysaccharides have lower intrinsic resistance to peptide antibiotics. In addition, the presence of antibiotics induces hyperproduction of capsular polysaccharides (Geisinger and Isberg, 2015). Antibiotic-induced production of capsular polysaccharides increases resistance to killing by host complement and increases virulence in a mouse model of systemic infection (Geisinger and Isberg, 2015). That study also demonstrated that increased capsule production after exposure to an antibiotic depends on transcriptional increases in $\mathrm{K}$ locus gene expression, and that expression of $\mathrm{K}$ locus genes is regulated by the $b f m R S$ two-component regulatory system (Geisinger and Isberg, 2015). bfmR is a gene essential for growth in human ascites, which is an ex vivo medium that reflects the infection environment (Umland et al., 2012), and is important for persistence in the lung in a murine pneumonia model (Wang et al., 2014). BfmS is also a virulence factor that plays an important role in biofilm formation, adherence to eukaryotic cells, and resistance to human serum (Liou et al., 2014). On report showed BfmR-mediated resistance to complementmediated bactericidal activity and resistance to the clinically important antimicrobials (meropenem and colistin; Russo et al., 2016). However, that study suggested that BfmR effects are independent of capsular polysaccharide production. Therefore, the relationship between BfmRS and capsular polysaccharides must be described in more detail. 
LPS is the major component of the outer leaflet of the outer membrane in most Gram-negative bacteria and is an immunoreactive molecule that induces release of tumor necrosis factor and interleukin 8 from macrophages in a Toll-like receptor 4 (TLR4)-dependent manner (Erridge et al., 2007). LPS is composed of an endotoxic lipid A moiety, an oligosaccharide core, and a repetitive O-antigen (Lee et al., 2013b). In A. baumannii, LPS plays a major role in virulence and survival of A. baumannii (Luke et al., 2010; Lin et al., 2012; McQueary et al., 2012). Mutant cell lacking LpsB glycotransferase have a highly truncated LPS glycoform containing only two carbohydrate residues bound to lipid A, resulting in decreased resistance to human serum and decreased survival in a rat model of soft tissue infection (Luke et al., 2010; McConnell et al., 2013). Inhibiting LpxC, an enzyme involved in the lipid A biosynthesis, dose not inhibit growth of the bacterium, but suppresses A. baumannii LPS-mediated activation of TLR4 (Lin et al., 2012). Inhibition of LpxC in mouse model enhances clearance of A. baumannii by enhancing opsonophagocytic killing and reduces serum LPS concentration and inflammation, which completely protects mice from lethal infection (Lin et al., 2012; Lee et al., 2013b). These results indicate that blocking LPS synthesis is a powerful strategy for discovering novel antibiotics. Modification of LPS contributes to resistance to antimicrobials. Many studies have shown that modifications in LPS decrease the susceptibility of A. baumannii to many clinical important antibiotics, such as colistin (Moffatt et al., 2010; Arroyo et al., 2011; Beceiro et al., 2011; Pelletier et al., 2013; Boll et al., 2015; Chin et al., 2015).

\section{Phospholipase}

Phospholipase is a lipolytic enzyme essential for phospholipid metabolism and is a virulence factor in many bacteria, such as $P$. aeruginosa, Legionella monocytogenes, and Clostridium perfringens (Camarena et al., 2010; Flores-Diaz et al., 2016). Three classes of phospholipases, such as phospholipase A (PLA), phospholipase C (PLC), and phospholipase D (PLD) have been defined based on the cleavage site. PLA hydrolyzes fatty acids from the glycerol backbone, whereas PLC cleaves the phosphorylated head group from the phospholipid. PLD is a transphosphatidylase that only cleaves off the head group. Degradation of phospholipids affects the stability of host cell membranes, and the cleaved head group can interfere with cellular signaling, resulting in changes in the host immune response (Songer, 1997; Flores-Diaz et al., 2016). PLC and PLD have been identified as virulence factors in A. baumannii (Camarena et al., 2010; Jacobs et al., 2010; Stahl et al., 2015). Acinetobacter baumannii ATCC17978 has two PLCs (A1S_0043 and A1S_2055) and inactivation of the A1S_0043 gene leads to a modest reduction in the cytotoxic effect of $A$. baumannii on epithelial cells compared to that of the parental strain (Camarena et al., 2010; Fiester et al., 2016). Disrupting one (A1S_2989) of the two PLD genes present in A. baumannii strain 98-37-09 results in reduced resistance to human serum, decreased capacity for invading epithelial cells, and decreased virulence in a murine model of pneumonia (Jacobs et al., 2010). Another report showed that A. baumannii ATCC 19606 has three PLD genes and all three play important roles in virulence and host cell invasion in a concerted manner (Stahl et al., 2015). These results suggest that phospholipase enzymes are important virulence factors in $A$. baumannii pathogenesis.

\section{Outer Membrane Vesicles (OMVs)}

OMVs are spherical, 20-200 nm diameter vesicles secreted by the outer membranes of various Gram-negative pathogenic bacteria (Kulp and Kuehn, 2010). They are composed of LPS, outer membrane and periplasmic proteins, phospholipids, and DNA or RNA, and are recognized as delivery vehicles for bacterial effectors to host cells (Ellis and Kuehn, 2010). OMVs deliver diverse virulence factors to the interior of host cells simultaneously and allow the pathogens to interact with the host without close contact between bacteria and host cells (Jun et al., 2013). Many A. baumannii strains secrete OMVs containing various virulence factors, including OmpA (Kwon et al., 2009; Jin et al., 2011; Moon et al., 2012), proteases (Kwon et al., 2009), and phospholipases (Kwon et al., 2009). OMVs derived from $A$. baumannii interact with host cells and deliver bacterial effectors to host cells via lipid rafts, resulting in cytotoxicity (Jin et al., 2011). Purified OMVs of A. baumannii ATCC 19606 induce expression of pro-inflammatory cytokine genes in epithelial cells in a dose-dependent manner (Jun et al., 2013). Notably, OMVs treated with proteinase do not induce a significant increase in the expression of pro-inflammatory cytokine genes, suggesting that the membrane proteins in OMVs are responsible for eliciting a potent innate immune response (Jun et al., 2013). One study supports the role of OMVs in A. baumannii pathogenesis. An A. baumannii strain that produces abundant OMVs with more virulence factors induces a stronger innate immune response and is more cytotoxic compared with those of a strain producing fewer OMVs (Li Z. T. et al., 2015).

Due to the importance of OMVs in A. baumannii virulence, several reports have shown that $A$. baumannii OMVs could be used as an acellular vaccine to elevate protective immunity (McConnell et al., 2011; Huang et al., 2014). In a mouse model of disseminated sepsis, vaccination with A. baumannii ATCC 19606 strain OMVs protects mice from challenge with homologous bacteria and provides protection against other clinical isolates (McConnell et al., 2011). Similar results were obtained in a pneumonia mouse model. Bacterial burden, inflammatory cell infiltration, and inflammatory cytokine accumulation in the pneumonia model were significantly suppressed by both active and passive immunization with OMVs (Huang et al., 2014). These results indicate that A. baumannii OMVs can be used as an acellular vaccine to effectively control $A$. baumannii infections. Interestingly, $A$. baumannii OMVs are also related with the spread of antibiotic resistance and induce the horizontal transfer of the OXA-24 carbapenemase gene (Rumbo et al., 2011).

\section{Metal Acquisition System}

Although iron is one of the most abundant elements in environmental and biological systems, ferric iron is relatively unavailable to bacteria in the preferred state, because of its poor solubility $\left(10^{-17} \mathrm{M}\right.$ solubility limit for ferric iron) under aerobic and neutral $\mathrm{pH}$ conditions as well as due to chelation by lowmolecular-weight compounds, such as heme, or high-affinity 
iron-binding compounds, such as lactoferrin and transferrin (Rakin et al., 2012; Saha et al., 2013). To overcome this iron limitation, most aerobic bacteria produce a high-affinity iron chelator known as a siderophore (Saha et al., 2013). Siderophores are low molecular weight compounds $(400-1,000 \mathrm{kDa})$ with high affinity for iron. The range of $\mathrm{Fe}^{3+}$-siderophore association constants is $10^{12}-10^{52}$ (Saha et al., 2013). Siderophores have been classified into catecholates, hydroxymates, and a mixed type based on the moiety that donates oxygen ligands to coordinate $\mathrm{Fe}^{3+}$ (Saha et al., 2013). Acinetobacter baumannii also has iron siderophores and acinetobactin, the best-characterized A. baumannii siderophore, is a mixed type siderophore with an oxazoline ring derived from threonine (McConnell et al., 2013). Acinetobactin is an A. baumannii virulence factor (Gaddy et al., 2012; Penwell et al., 2012; Megeed et al., 2016). Impaired acinetobactin biosynthesis and transport functions significantly reduce the ability of A. baumannii ATCC 19606 cells to persist within epithelial cells and cause cell damage and animal death (Gaddy et al., 2012). Mutation in the entA gene, which is essential for biosynthesis of the acinetobactin precursor 2,3dihydroxybenzoic acid, also significantly reduces the capacity of A. baumannii ATCC 19606 cells to persist within human alveolar epithelial cells and diminishes the ability to infect and kill Galleria mellonella larvae (Penwell et al., 2012). One study showed that acinetobactin production occurs significantly more frequently in MDR A. baumannii isolates than that in avirulent isolates (Megeed et al., 2016).

The A. baumannii NfuA Fe-S scaffold protein, that participates in the formation of $\mathrm{Fe}-\mathrm{S}$ clusters and plays a role in cell responses to iron chelation and oxidative stress, has also been identified as a virulence factor (Zimbler et al., 2012). The $n f u A$ mutant is more sensitive to reactive oxygen species (ROS), such as hydrogen peroxide and cumene hydroperoxide, and shows significantly reduced growth in human epithelial cells. In addition, a G. mellonella infection model showed that more than $50 \%$ of injected G. mellonella larvae die 6 days after infection with the parental strain, whereas less than $30 \%$ of the larvae die when infected with the $n f u A$ mutant (Zimbler et al., 2012). One report showed that iron starvation increases production of PLCs, which increase hemolytic activity of $A$. baumannii (Fiester et al., 2016). These reports indicate that iron acquisition functions play a critical role in A. baumannii virulence.

The innate immune metal-chelating protein calprotectin inhibits bacterial growth by host-mediated chelation of metals, such as zinc $\left(\mathrm{Zn}^{2+}\right.$ and $\left.\mathrm{Zn}\right)$ and manganese $\left(\mathrm{Mn}^{2+}\right.$ and $\left.\mathrm{Mn}\right)$ (Corbin et al., 2008). However, A. baumannii can cause disease in the presence of this nutritional immune protein in vivo (Juttukonda et al., 2016). To combat the zinc limitation, A. baumannii uses a zinc acquisition system (ZnuABC), which is up-regulated under $\mathrm{Zn}$-limiting conditions, and the $z n u B$ mutant strain experiences $\mathrm{Zn}$ starvation at higher $\mathrm{Zn}$ concentrations than that of the wild-type (Hood et al., 2012). ZnuB contributes to the pathogenesis of A. baumannii pulmonary infections. Notably, a zinc limitation reduces the imipenem MIC of MDR A. baumannii to below the clinical breakpoint for imipenem resistance in A. baumannii (Hood et al., 2012), possibly because many carbapenemases are metalloenzymes that require $\mathrm{Zn}$ for their hydrolyzing activity. Besides the ZnuABC system, the novel $\mathrm{Zn}$ metallochaperone ZigA has been characterized in $A$. baumannii (Nairn et al., 2016). ZigA tightly interacts with Zn, which is required for bacterial growth under $\mathrm{Zn}$ starvation conditions and for disseminated infection in mice (Nairn et al., 2016).

The mechanism employed by A. baumannii to overcome a Mn limitation has been identified. Calprotectin induces $\mathrm{Mn}$ starvation in A. baumannii, which increases transcription of an NRAMP (Natural Resistance-Associated Macrophage Proteins) family $\mathrm{Mn}$ transporter and a urea carboxylase to resist the antimicrobial activities of calprotectin (Juttukonda et al., 2016). A urea carboxylase enzyme (MumC) is important for growth of $A$. baumannii in the presence of calprotectin and an NRAMP family transporter (MumT) contributes to the fitness of $A$. baumannii in a murine pneumonia model (Juttukonda et al., 2016), suggesting that the two proteins are virulence factors. Acinetobacter baumannii can utilize urea as a sole nitrogen source, and this urea utilization is required for MumC (Juttukonda et al., 2016). Based on the contribution of MumC to A. baumannii resistance to calprotectin, the authors suggest a connection between metal starvation and metabolic stress, such as nitrogen starvation.

\section{Protein Secretion Systems}

Several protein secretion systems have been identified in $A$. baumannii (Weber et al., 2015a). The most recently described $A$. baumannii secretion system is a type II secretion system (T2SS) (Johnson et al., 2015). The T2SS is a multi-protein complex that is structurally very similar to type IV pili systems, which is an appendage that is commonly found in Gram-negative bacteria (Korotkov et al., 2012). T2SS translocates a wide range of proteins from the periplasmic space to the extracellular milieu out of the cell or the outer membrane surface. The T2SS is composed of 12-15 proteins comprised of four subassemblies: a pseudopilus, a cytoplasmic secretion ATPase, an inner-membrane platform assembly, and a dodecameric outermembrane complex (Korotkov et al., 2012; Harding et al., 2016). Secretion by T2SS is a two-step process. The target proteins are first translocated to the periplasm by the general secretory (Sec) system or the twin arginine transport (Tat) system, where the target proteins are then secreted out of the cell through the T2SS (Korotkov et al., 2012). Deleting A. baumannii genes for the T2SS components, $g s p D$ or $g s p E$, results in loss of LipA secretion, indicating that LipA is a T2SS substrate (Johnson et al., 2015). Because LipA is a lipase that breaks down long-chain fatty acids, lipA, $g s p D$, and $g s p E$ mutant strains are incapable of growing on long-chain fatty acids as a sole carbon source and are defective in in vivo growth in a neutropenic murine model of bacteremia (Johnson et al., 2015). The role of a functional T2SS for full virulence of A. baumannii has been shown in G. mellonella and murine pulmonary infection models (Harding et al., 2016). Lipases (LipA, LipH, and LipAN) and the metallopeptidase CpaA have been identified as T2SS substrates (Elhosseiny et al., 2016; Harding et al., 2016). Notably, two proteins (LipA and CpaA) among these secreted proteins require specific chaperones for 
secretion. These chaperones are encoded adjacently to their cognate effector, and their inactivation abolishes secretion of LipA and CpaA (Harding et al., 2016).

Acinetobacter baumannii also has a type VI secretion system (T6SS). The T6SS was first identified in Vibrio cholera and P. aeruginosa (Mougous et al., 2006; Pukatzki et al., 2006). Many bacteria use the T6SS to inject effector proteins, providing a colonization advantage during infection of eukaryotic hosts (Mougous et al., 2006) or to kill competing bacteria (Basler et al., 2013). The T6SS leads to DNA release and horizontal gene transfer in $V$. cholera, which may contribute to spread of antibiotic resistance (Borgeaud et al., 2015). The T6SS is composed of many conserved structural proteins and accessory factors, and bears a contractile bacteriophage sheath-like structure forming a needle or spike structure used to penetrate the target cell (Shneider et al., 2013). Hcp is a structural protein forming a polymerized tubular structure that is secreted out of the cell, and VgrGs are involved in attaching effector domains to the spike, and a proline-alanine-alanine-arginine (PAAR) repeat protein forms the sharp tip of the distinctive needle-like structure (Shneider et al., 2013; Zoued et al., 2014).

The presence of T6SS in A. baumannii was initially predicted by bioinformatic analysis (Weber et al., 2013). Although the role of T6SS in A. baumannii ATCC 17978 has not been determined (Weber et al., 2013), research on A. baumannii strain M2 showed that this strain produces a functional T6SS and that the T6SS mediates killing of competing bacteria (Carruthers et al., 2013). Another study showed that the T6SS is active in six pathogenic strains of A. baumannii (Ruiz et al., 2015). However, the T6SS seems to play an important role in A. baumannii virulence in a strain-specific manner (Repizo et al., 2015). They compared T6SS functionality of several A. baumannii strains, including ATCC17978 (a type strain), various MDR strains implicated in hospital outbreaks (Ab242, Ab244, and Ab825), and DSM30011 (a non-clinical isolate). Although the T6SS genomic locus is present in all of these strains, only DSM30011 has a fully active T6SS that mediates E. coli killing (Repizo et al., 2015). In addition, the T6SS of DSM30011 is required for host colonization of the G. mellonella model organism (Repizo et al., 2015). Similar results were obtained from a comparative analysis of the genomes of MDR A. baumannii clinical strains (Wright et al., 2014; Jones et al., 2015). A. baumannii isolates of a particular clade exhibit complete loss of the T6SS genomic locus. Therefore, these results suggest that more extensive investigations are required to analyze the role of T6SS in A. baumannii virulence, even though this system seems to play an important role in A. baumannii virulence in some strains. Notably, one study showed that several MDR A. baumannii strains have a large, selftransmissible plasmid that carries negative regulators for T6SS (Weber et al., 2015b). The T6SS is silenced in plasmid-containing, antibiotic-resistant cells, whereas plasmid-losing cells have an active T6SS. Although plasmid-losing cells are capable of T6SSmediated killing of competing bacteria, they become susceptible to antibiotics (Weber et al., 2015b). This result suggests a molecular switch between T6SS and antibiotic resistance.

The type $\mathrm{V}$ system autotransporter Ata has also been characterized in A. baumannii (Bentancor et al., 2012a).
This is a trimeric membrane protein that mediates biofilm formation, adherence to extracellular matrix components such as collagen I, III, and IV, and virulence in a murine systemic model of Acinetobacter infection (Bentancor et al., 2012a). Another experiment using a pneumonia model of infection in immunocompetent and immunocompromised mice showed that Ata is a vaccine candidate against A. baumannii infections (Bentancor et al., 2012b). A type IV secretion system present in the plasmid was bioinformatically identified in A. baumannii (Liu C. C. et al., 2014), but no experimental evidence describing its function has been presented.

\section{Penicillin-Binding Protein 7/8 (PBP7/8) and $\beta$-Lactamase PER-1}

Although PBPs are commonly involved in resistance to $\beta$ lactam antibiotics, PBP7/8 encoded by the $p b p G$ gene is a virulence factor in A. baumannii. The $p b p G$ mutant strain grows similar to its wild-type strain in Luria-Bertani medium, but the mutant shows reduced growth in human serum and its survival significantly decreases in rat soft-tissue infection and pneumonia models (Russo et al., 2009). An investigation of bacterial morphology using electron microscopy suggested that loss of PBP7/8 may have affected peptidoglycan structure, which may affect susceptibility to host defense factors (Russo et al., 2009).

Interestingly, $\beta$-lactamase PER-1 has been suggested to be an A. baumannii virulence factor. PER-1 is an extended-spectrum$\beta$-lactamase (ESBL), but this gene is associated with cell adhesion (Sechi et al., 2004). Nine PER-1-producing strains adhere to the Caco2 cell lines, whereas all PER-1-negative strains are negative for cell adhesion (Sechi et al., 2004). Notably, many $\beta$-lactamases are associated with virulence in various pathogenic bacteria, such as E. coli (Dubois et al., 2009), P. aeruginosa (Moya et al., 2008), and K. pneumoniae (Sahly et al., 2008). However, no general mechanisms have been proposed (Beceiro et al., 2013).

\section{Others}

Acinetobacter baumannii CipA is a novel plasminogen binding and complement inhibitory protein that mediates serum resistance (Koenigs et al., 2016). CipA-binding plasminogen is converted to active plasmin that degrades fibrinogen and complement $\mathrm{C} 3 \mathrm{~b}$, which contributes to serum resistance of $A$. baumannii. Therefore, the cipA mutant strain is efficiently killed by human serum and also shows a defect in the penetration of endothelial monolayers (Koenigs et al., 2016). Similar to CipA, the A. baumannii translation elongation factor Tuf is also a plasminogen-binding protein. Tuf-binding plasminogen can be converted to active plasmin, which proteolytically degrades fibrinogen as well as component C3b (Koenigs et al., 2015). RecA, which is involved in homologous recombination and the SOS response, has been identified as an $A$. baumannii virulence factor. The recA mutant shows significantly reduced survival within macrophages and decreases lethality in a mouse model of systemic infection (Aranda et al., 2011). The surface antigen protein 1 (SurA1) plays an important role in fitness and virulence of A. baumannii (Liu D. et al., 2016). Serum resistance of the surA1 mutant significantly decreases compared with that of 
the wild-type strain CCGGD201101. In the G. mellonella insect model, a surA1 mutant strain exhibits a lower survival rate and decreased dissemination (Liu D. et al., 2016).

A growth analysis of 250,000 A. baumannii transposon mutants within G. mellonella larvae identified 300 genes required for survival or growth of $A$. baumannii inside $G$. mellonella larvae (Gebhardt et al., 2015). The 300 genes were classified into six categories of micronutrient acquisition, cysteine metabolism/sulfur assimilation, aromatic hydrocarbon metabolism, cell envelope/membrane/wall, stress response genes, antibiotic resistance, and transcriptional regulation. Among them, four transcriptional regulators required for growth in G. mellonella larvae were called the gig (growth in Galleria) genes. Loss of these genes (gigA-D) led to a significant defect in both growth within and killing of G. mellonella larvae (Gebhardt et al., 2015). This study identified stress proteins, such as UspA, as factors required for growth in G. mellonella. Another study showed that UspA is essential for pneumonia and sepsis pathogenesis of $A$. baumannii (Elhosseiny et al., 2015). Among the 300 genes, several genes are involved in aromatic hydrocarbon metabolism (Gebhardt et al., 2015). Another study showed that GacS, which is a transcriptional factor that regulates expression of genes, such as paaE, and is responsible for the phenylacetic acid catabolic pathway, affects $A$. baumannii virulence (Cerqueira et al., 2014). Experiments using a paaE deletion mutant confirmed the role of aromatic hydrocarbon metabolism in A. baumannii virulence (Cerqueira et al., 2014), but its molecular mechanism remains unknown. Interestingly, a recent report showed that accumulation of phenylacetate in A. baumannii induces rapid neutrophil influx to a localized site of infection and increases bacterial clearance (Bhuiyan et al., 2016). They suggested that phenylacetate is a neutrophil chemoattractant inducing bacterialguided neutrophil chemotaxis. This report may reveal a novel molecular mechanism about the role of the phenylacetic acid catabolic pathway in A. baumannii virulence.

Biofilm formation plays an important role in immune evasion by $A$. baumannii (de Breij et al., 2010), and pili are essential for A. baumannii adherence to and biofilm formation on abiotic surfaces as well as virulence (Tomaras et al., 2003, 2008). Notably, imipenem treatment of the imipenem-resistant A. baumannii isolate induces expression of important genes responsible for synthesis of type IV pili (Dhabaan et al., 2015), suggesting that the ability to overproduce pili confers a biological advantage to A. baumannii.

Other virulence-related proteins have been identified, including OmpR/EnvZ (Tipton and Rather, 2016), FhaBC (Perez et al., 2016), and the resistance-nodulation-division-type membrane transporter AbeD (Srinivasan et al., 2015), but their molecular mechanisms remain unknown.

\section{ANTIMICROBIAL RESISTANCE OF A. BAUMANNII}

Acinetobacter baumannii has become one of the most successful pathogens in modern healthcare because of its amazing ability to acquire antimicrobial resistance. Several strains of A. baumannii are highly resistant to most clinically available antibiotics (Lin and Lan, 2014). A. baumannii has a number of resistance mechanisms, including $\beta$-lactamases, aminoglycoside-modifying enzymes, efflux pumps, permeability defects, and modifications of target sites. The accumulation of several resistance mechanisms in A. baumannii has gradually decreased the number of antibiotic classes available to treat A. baumannii infections in clinical practice. Table 2 shows the antibiotic resistance mechanisms found in A. baumannii. We will discuss the details below.

\section{$\beta$-Lactamases}

Inactivation of $\beta$-lactams by $\beta$-lactamases is a major antibiotic resistance mechanism in $A$. baumannii. Based on sequence homology, $\beta$-lactamases are grouped into molecular classes, A, B, C, and D (Jeon et al., 2015). All four classes of $\beta$ lactamases were identified in A. baumannii. Recent studies have shown that A. baumannii has natural competence to incorporate exogenous DNA and its genome has foreign DNA at high frequencies, implying frequent horizontal gene transfer in this pathogen (Ramirez et al., 2010a; Touchon et al., 2014; Traglia et al., 2014). Additionally, albumin, a main protein in blood, enhances natural competence of A. baumannii (Traglia et al., 2016). Therefore, natural competence of A. baumannii may contribute to identification of a large number of $\beta$-lactamases in this threatening human pathogen.

Class A $\beta$-lactamases inhibited by clavulanate hydrolyze penicillins and cephalosporins more efficiently than carbapenems, except for some KPC type enzymes (Jeon et al., 2015). A number of class A $\beta$-lactamases, including TEM, SHV, GES, CTX-M, SCO, PER, VEB, KPC, and CARB, have been identified in A. baumannii (Table 2). Some of these enzymes, such as TEM-1, CARB-4, and SCO-1, are narrow-spectrum $\beta$-lactamases, whereas other enzymes (e.g., PER-1, TEM-92, CARB-10, SHV-5, PER-2, CTX-M-2, CTX-M-15, VEB-1, GES-14, and PER-7) are ESBLs. Some carbapenemases, such as GES-14 and KPC-2, have been detected in A. baumannii (Moubareck et al., 2009; Bogaerts et al., 2010).

Unlike the serine-dependent $\beta$-lactamases (classes $A, C$, and D), class B $\beta$-lactamases are metallo- $\beta$-lactamases (MBLs) that require zinc or another heavy metal for catalysis (Jeon et al., 2015). Due to a broad substrate spectrum, MBLs catalyze the hydrolysis of virtually all $\beta$-lactam antibiotics including carbapenems, but not monobactams (Jeon et al., 2015). A variety of class B $\beta$-lactamases have been identified in A. baumannii (Table 2).

Class C $\beta$-lactamases pose therapeutic problems because they can confer resistance to cephamycins (cefoxitin and cefotetan), penicillins, cephalosporins, and $\beta$-lactamase inhibitor combinations, but are not significantly inhibited by clinically used $\beta$-lactamase inhibitors, such as clavulanic acid (Jeon et al., 2015). Acinetobacter baumannii has an intrinsic AmpC cephalosporinase (Gordon and Wareham, 2010). An analysis of 23 MDR A. baumannii clinical isolates in Taiwan showed that all isolates had AmpC-type $\beta$-lactamases (Lin et al., 2011a). Several clinical isolates of $A$. baumannii have the ampC gene transcribed 
TABLE 2 | Resistance mechanisms in Acinetobacter baumannii.

\begin{tabular}{|c|c|c|c|}
\hline Resistance mechanism & Class/subgroup & Protein & References \\
\hline \multirow[t]{42}{*}{$\beta$-Lactamases } & Class A & TEM-1 & Chen et al., 2006; Adams et al., 2008; Krizova et al., 2013 \\
\hline & & TEM-92 & Endimiani et al., 2007 \\
\hline & & GES-1 & Al-Agamy et al., 2016 \\
\hline & & GES-5 & Al-Agamy et al., 2016 \\
\hline & & GES-11 & Moubareck et al., 2009; Bogaerts et al., 2010; Chihi et al., 2016 \\
\hline & & GES-12 & Bogaerts et al., 2010 \\
\hline & & GES-14 & Bogaerts et al., 2010 \\
\hline & & PER-1 & Jeong et al., 2005; Poirel et al., 2005a; Aly et al., 2016 \\
\hline & & PER-2 & Pasteran et al., 2006 \\
\hline & & PER-7 & Bonnin et al., 2011b \\
\hline & & CTX-M-2 & Nagano et al., 2004 \\
\hline & & CTX-M-15 & Potron et al., 2011 \\
\hline & & $\mathrm{SCO}-1$ & Poirel et al., 2007 \\
\hline & & VEB-1 & $\begin{array}{l}\text { Fournier et al., 2006; Naas et al., 2006; Pasteran et al., 2006; } \\
\text { Adams et al., 2008; Poirel et al., } 2009\end{array}$ \\
\hline & & KPC-2 & Martinez et al., 2016 \\
\hline & & $\mathrm{KPC}-10$ & Robledo et al., 2010 \\
\hline & & CARB-4 & Ramirez et al., 2010b \\
\hline & & CARB-10 & Potron et al., 2009 \\
\hline & Class B & IMP-1 & Tognim et al., 2006 \\
\hline & & IMP-2 & Riccio et al., 2000 \\
\hline & & IMP-4 & Chu et al., 2001 \\
\hline & & IMP-5 & Koh et al., 2007 \\
\hline & & IMP-6 & Gales et al., 2003 \\
\hline & & IMP-8 & Lee M. F. et al., 2008 \\
\hline & & IMP-11 & Yamamoto et al., 2011 \\
\hline & & IMP-19 & Yamamoto et al., 2011 \\
\hline & & IMP-24 & Lee M. F. et al., 2008 \\
\hline & & $\mathrm{VIM}-1$ & Tsakris et al., 2006, 2008; Papa et al., 2009 \\
\hline & & $\mathrm{VIM}-2$ & Yum et al., 2002; Lee M. F. et al., 2008 \\
\hline & & VIM-3 & Lee M. F. et al., 2008 \\
\hline & & VIM-4 & Tsakris et al., 2008; Papa et al., 2009 \\
\hline & & VIM-11 & Lee M. F. et al., 2008 \\
\hline & & NDM-1 & $\begin{array}{l}\text { Chen et al., 2011; Pfeifer et al., 2011; Bonnin et al., 2012; } \\
\text { Voulgari et al., } 2016\end{array}$ \\
\hline & & NDM-2 & Espinal et al., 2011 \\
\hline & & NDM-3 & Kumar, 2016 \\
\hline & & SIM-1 & Lee et al., 2005 \\
\hline & Class C & AmpC & $\begin{array}{l}\text { Bou and Martinez-Beltran, 2000; Corvec et al., 2003; Segal } \\
\text { et al., 2004; Hujer et al., 2005; Heritier et al., 2006; Liu and Liu, } \\
2015\end{array}$ \\
\hline & Class D & & \\
\hline & OXA-2 subgroup & OXA-21 & Vila et al., 1997 \\
\hline & OXA-10 subgroup & OXA-128 & Giannouli et al., 2009 \\
\hline & OXA-20 subgroup & OXA-37 & Navia et al., 2002 \\
\hline & OXA-23 subgroup & OXA-23 & $\begin{array}{l}\text { Heritier et al., 2005b; Naas et al., 2005; Corvec et al., 2007; } \\
\text { Koh et al., 2007; Perez et al., 2007; Valenzuela et al., 2007; } \\
\text { Wang et al., 2007; Adams et al., 2008; Stoeva et al., 2008; } \\
\text { Kohlenberg et al., 2009; Kuo et al., 2010; Mugnier et al., 2010; } \\
\text { Bonnin et al., 2011a; Lee et al., 2011; Lin et al., 2011b; Koh } \\
\text { et al., 2012; Mosqueda et al., 2013; Chagas et al., 2014; } \\
\text { Principe et al., 2014; Li Y. et al., 2015 }\end{array}$ \\
\hline
\end{tabular}


TABLE 2 | Continued

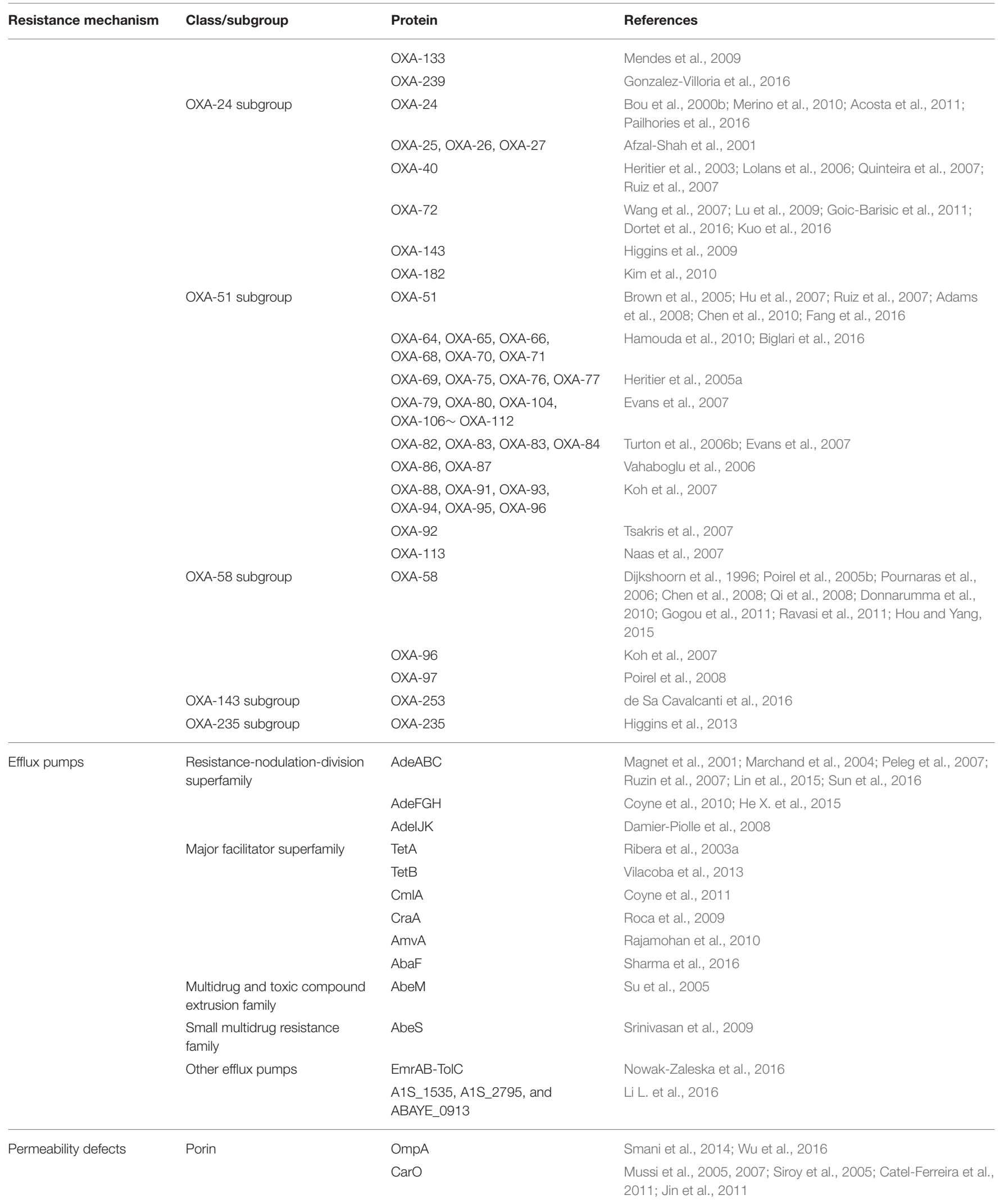




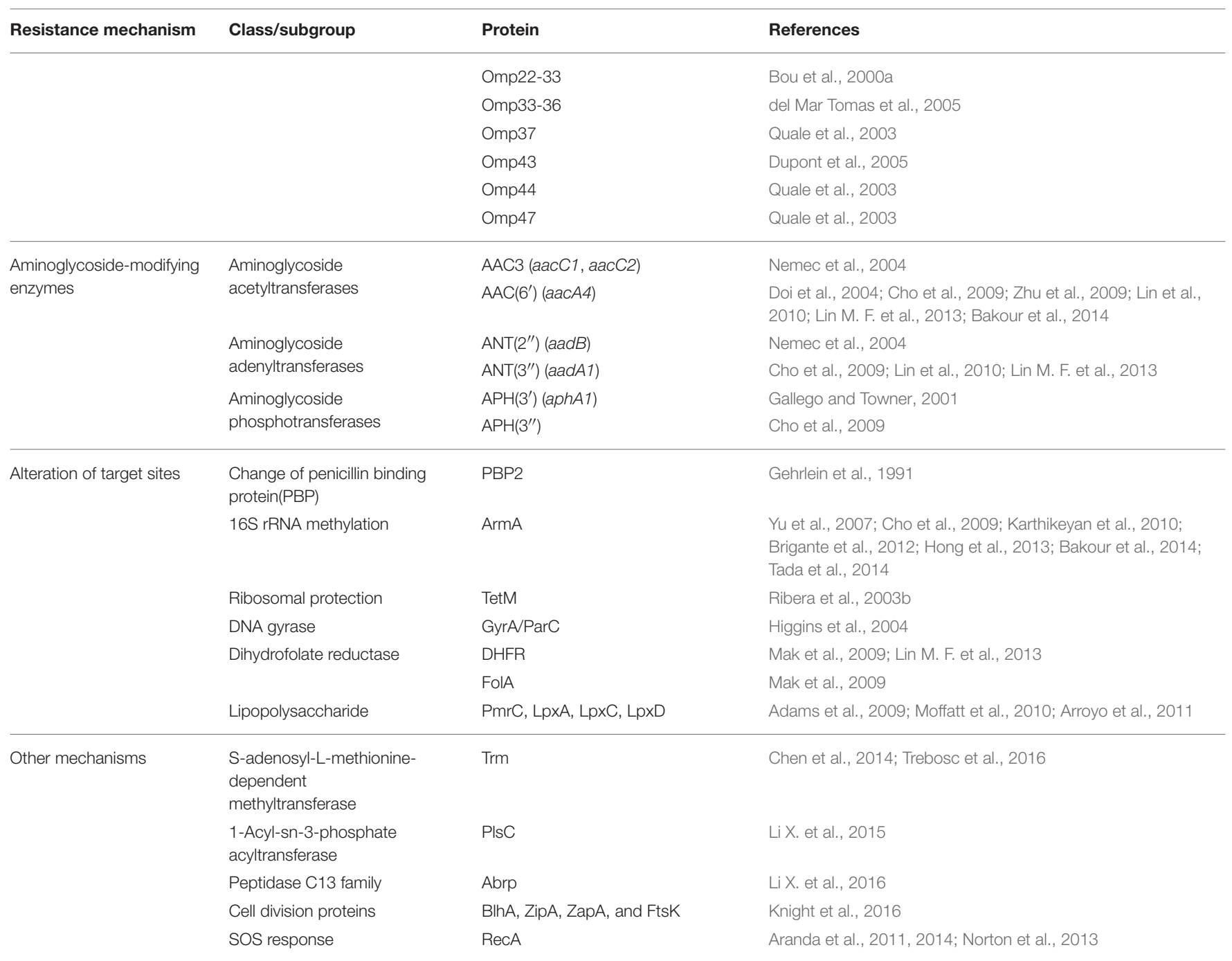

from a strong promoter contained within a putative insertion sequence element (ISAba1-like sequence), which results in high resistance to ceftazidime (Corvec et al., 2003; Segal et al., 2004). This sequence has been identified in ceftazidime-resistant $A$. baumannii isolates, but is absent in ceftazidime-susceptible $A$. baumannii isolates (Heritier et al., 2006).

Class D $\beta$-lactamases are called OXAs (oxacillinases), because they commonly hydrolyze isoxazolylpenicillin oxacillin much faster than benzylpenicillin (Jeon et al., 2015). More than 400 OXA-type enzymes have been identified and many variants actually possess carbapenemase activity. The presence of carbapenem-hydrolyzing class D $\beta$-lactamases or MBLs is one of the major carbapenem resistance mechanisms in A. baumannii (Lin and Lan, 2014). The subgroups of carbapenem-hydrolyzing OXAs, such as the OXA-23, OXA-24, OXA-51, and OXA-58 subgroups, are prevalent in A. baumannii (Table 2). The OXA23 enzyme was first identified in an A. baumannii isolate in the United Kingdom in 1985 (Perez et al., 2007). The bla $a_{\text {OXA-23 }}$ gene has been disseminated worldwide, and the frequency of
OXA-23-producing A. baumannii strains is significantly high (Mugnier et al., 2010; Al-Agamy et al., 2016). One recent report from Lebanon showed $76.5 \%$ of 119 A. baumannii isolates are resistant to carbapenems, and OXA-23 $\beta$-lactamases have been found in 82 isolates ( $\mathrm{Al}$ Atrouni et al., 2016). Insertion of ISAbal in the bla $a_{\mathrm{OXA}-23}$ promoter sequence has been reported to be associated with overexpression of bla $a_{\mathrm{OXA}-23}, b l a_{\mathrm{OXA}-51}$, or bla $a_{\mathrm{OXA}-58}$ in A. baumannii (Turton et al., 2006a). One report from India showed that $b l a_{\mathrm{OXA}-51}$ and $b l a_{\mathrm{OXA}-23}$ were present in all 103 carbapenem-resistant A. baumannii isolates and almost $80 \%$ of the isolates had ISAbal upstream of the bla $a_{\text {OXA-23 gene, }}$ indicating the prevalence of the ISAbal insertion (Vijayakumar et al., 2016).

\section{Efflux Pumps}

Efflux pumps are associated with resistance against many different classes of antibiotics, such as imipenem ( $\mathrm{Hu}$ et al., 2007) and tigecycline (Peleg et al., 2007; Ruzin et al., 2007), in A. baumannii. Reversal of antibiotic resistance by 
efflux pump inhibitors, such as 1-(1-naphthylmethyl)-piperazine and carbonyl cyanide 3-chlorophenyl-hydrazone, supports the importance of efflux pumps in A. baumannii antibiotic resistance (Pannek et al., 2006; Deng et al., 2014). Four categories of efflux pumps, such as the resistance-nodulation-division superfamily, the multidrug and toxic compound extrusion family, the major facilitator superfamily, and the small multidrug resistance family transporters, are related to antimicrobial resistance in $A$. baumannii (Table 2; Lin and Lan, 2014).

AdeABC in the resistance-nodulation-division superfamily is associated with aminoglycoside resistance (Magnet et al., 2001) and with decreasing susceptibility to tigecycline (Ruzin et al., 2007) and non-fluoroquinolone antibiotics (Higgins et al., 2004). AdeABC seems to be cryptic in wild-type $A$. baumannii because of stringent control by the AdeRS twocomponent system (Marchand et al., 2004), but point mutations or insertion of the ISAbal sequence in the adeS gene leads to overexpression of AdeABC (Marchand et al., 2004; Sun et al., 2012, 2016; Hammerstrom et al., 2015). Cell density (Fernando and Kumar, 2012) and the BaeSR two-component system (Lin et al., 2014, 2015), which is involved in an envelope stress response, also seem to regulate transcription of the adeA gene and thus affect tigecycline susceptibility. Other resistancenodulation-division type efflux pumps, such as AdeFGH and AdeIJK, are synergistically associated with tigecycline resistance (Damier-Piolle et al., 2008). AdeFGH and AdeIJK expression is regulated by the LysR-type transcriptional regulator AdeL and the TetR-type transcriptional regulator AdeN (Coyne et al., 2010; Rosenfeld et al., 2012).

Acinetobacter baumannii clinical isolates possess a strong ability to form biofilms (Rodriguez-Bano et al., 2008). Notably, the subinhibitory concentrations of antibiotics encountered by low-dose therapy seem to strongly induce biofilm formation (Kaplan, 2011). A recent result revealed the mechanism. Overexpression of the AdeFGH efflux pump by low-dose antimicrobial therapy increases the synthesis and transport of autoinducer molecules, which induce biofilm formation ( $\mathrm{He} \mathrm{X}$. et al., 2015). These results suggest a link between low-dose antimicrobial therapy and a high risk for biofilm infections caused by $A$. baumannii.

$\mathrm{CmlA}$ and CraA are major facilitator superfamily efflux pumps related with chloramphenicol (Fournier et al., 2006; Roca et al., 2009), and TetA is associated with tetracycline resistance (Ribera et al., 2003a). The novel efflux pump AmvA mediates resistance to different classes of antibiotics, disinfectants, detergents, and dyes, such as erythromycin, acriflavine, benzalkonium chloride, and methyl viologen (Rajamohan et al., 2010). AbaF was recently identified as a novel efflux pump associated with fosfomycin resistance (Sharma et al., 2016).

AbeM is in the multidrug and toxic compound extrusion family and confers resistance to imipenem and fluoroquinolones (Su et al., 2005). AbeS is the small multidrug resistance family transporter and affects resistance to various antimicrobial compounds. Deletion of the abeS gene results in increased susceptibility to various antimicrobial compounds, such as chloramphenicol, nalidixic acid, and erythromycin (Srinivasan et al., 2009).
Some other efflux pumps, such as MacAB-TolC (Kobayashi et al., 2001) and EmrAB-TolC (Lomovskaya and Lewis, 1992), have been well described in E. coli, but their role in A. baumannii has been recently explored. The EmrAB-TolC efflux pump is also present in A. baumannii where it conferred resistance to netilmicin, tobramycin, and imipenem (Nowak-Zaleska et al., 2016). Another report identified three novel efflux pumps (A1S_1535, A1S_2795, and ABAYE_0913) in A. baumannii using multiplexed phenotypic screening (Li L. et al., 2016). A1S_1535 confers resistance to various antibiotics, including gentamicin, kanamycin, chloroxylenol, oxytetracycline, 1,10-phenanthroline, and chloramphenicol (Li L. et al., 2016). A1S_2795 is the first major facilitator superfamily efflux pump found to confer resistance to the sulphonamide sulfathiazole, and ABAYE_0913 is associated with resistance to chloramphenicol and fusidic acid (Li L. et al., 2016).

\section{Permeability Defects}

A change in envelope permeability can influence antibiotic resistance. For example, porins form channels that allow transport of molecules across the outer membrane and play a significant role in A. baumannii virulence (Table 1). Because porins affect membrane permeability, they also play a significant role in the mechanism of resistance. Reduced expression of some porins, including CarO (Mussi et al., 2005, 2007; Siroy et al., 2005; Catel-Ferreira et al., 2011; Jin et al., 2011), Omp22-33 (Bou et al., 2000a), Omp33-36 (del Mar Tomas et al., 2005; Hood et al., 2010), Omp37 (Quale et al., 2003), Omp43 (Dupont et al., 2005), Omp44 (Quale et al., 2003), and Omp47 (Quale et al., 2003), is associated with carbapenem resistance in A. baumannii. Loss of Omp29 in A. baumannii producing OXA-51-like or OXA-23-like carbapenemases results in increased imipenem resistance (Jeong et al., 2009; Fonseca et al., 2013). OmpA is also related with resistance to aztreonam, chloramphenicol, and nalidixic acid (Smani et al., 2014). One study showed that OmpA and CarO physically interact with OXA-23 carbapenemase, and these interactions are associated with antibiotic resistance (Wu et al., 2016). These results provide a novel view to increase understanding of bacterial antibiotic resistance mechanisms.

Besides outer membrane proteins, envelope components, such as LPS and peptidoglycans, also affects antibiotic resistance of A. baumannii. Loss or modification of LPS decreases membrane integrity and increases colistin resistance in $A$. baumannii (Adams et al., 2009; Moffatt et al., 2010).

\section{Aminoglycoside-Modifying Enzymes}

Aminoglycoside-modifying enzymes are the major mechanism by which $A$. baumannii confers resistance to aminoglycosides. Aminoglycoside-modifying enzymes can be classified into acetyltransferases, adenyltransferases, and phosphotransferases. These enzymes are typically present on transposable elements and are transferred among pathogenic bacteria (Lin and Lan, 2014). Several reports show that many MDR A. baumannii isolates produce a combination of aminoglycoside-modifying enzymes (Gallego and Towner, 2001; Nemec et al., 2004). A study from China identified a MDR A. baumannii strain carrying four aminoglycoside-modifying enzymes (Zhu et al., 2009). Another 
study from Greece reported that all A. baumannii strains contain aminoglycoside-modifying enzymes (Ploy et al., 1994), indicating the high prevalence of these enzymes in A. baumannii.

\section{Alteration of Target Sites}

Modifications in antibiotic target sites for antibiotics can induce antibiotic resistance in $A$. baumannii. In the absence of other known resistance mechanisms, only overexpression of altered PBPs with a low affinity for imipenem induce imipenem resistance (Gehrlein et al., 1991). Quinolone resistance is associated with modifications in GyrA (one subunit of DNA gyrase) and ParC (one subunit of topoisomerase IV) in epidemiologically unrelated A. baumannii isolates (Vila et al., 1995). Acinetobacter baumannii TetM, which has $100 \%$ homology with S. aureus TetM, has been proposed to be associated with tetracycline resistance through ribosomal protection (Ribera et al., 2003b). Similar to other pathogenic bacteria, dihydrofolate reductases (DHFR and FolA) responsible for trimethoprim resistance have been found in nosocomial MDR A. baumannii isolates (Mak et al., 2009; Lin M. F. et al., 2013; Taitt et al., 2014). The 16 S rRNA methylase ArmA responsible for aminoglycoside resistance is also found in many A. baumannii strains and always coexists with OXA type carbapenemases such as OXA-23 (Yu et al., 2007; Cho et al., 2009; Karthikeyan et al., 2010; Brigante et al., 2012; Hong et al., 2013; Bakour et al., 2014; Tada et al., 2014; Hasani et al., 2016). As described above, many studies have shown that modifications or/and loss of LPS decrease the susceptibility of A. baumannii to many clinical important antibiotics, such as colistin.

\section{Others}

AdeABC is associated with decreased susceptibility to tigecycline (Ruzin et al., 2007). However, some clinical isolates without overexpressed AdeABC, AdeFGH, and AdeIJK have decreased susceptibility to tigecycline. Several reports have suggested the mechanism. One study analyzed eight $A$. baumannii clinical isolates and revealed that the deletion mutation in the trm gene, which encodes S-adenosyl-L-methionine-dependent methyltransferase, decreases susceptibility to tigecycline (Chen et al., 2014). The same result was reported using a highly efficient and versatile genome-editing platform enabling markerless modification of the A. baumannii genome. Deletion of AdeR, a transcription factor that regulates AdeABC efflux pump expression in tigecycline-resistant $A$. baumannii, reduces the MIC of tigecycline. However, $60 \%$ of the clinical isolates remained nonsusceptible to tigecycline after the adeR deletion according to a highly efficient and versatile genome-editing platform (Trebosc et al., 2016). Whole-genome sequencing in two tigecycline-resistant $a d e R$ deletion strains revealed that a mutation in the trm gene makes the adeR mutant resistant to tigecycline. In addition, a trm disruption was identified in most tigecycline-resistant clinical isolates (Trebosc et al., 2016). However, its exact mechanism was not determined. Another study revealed that a frameshift mutation in $p l s C$, encoding 1acyl-sn-glycerol-3-phosphate acyltransferase, is associated with decreased susceptibility to tigecycline (Li X. et al., 2015).
The abrp gene, which encodes the peptidase C13 family, is associated with decreased susceptibility to tetracycline, minocycline, doxycycline, tigecycline, chloramphenicol, and fosfomycin ( $\mathrm{Li} \mathrm{X}$. et al., 2016). Deletion of abrp increases cell membrane permeability, displays slower cell growth rate, and confers reduced susceptibility to these antibiotics (Liu X. et al., 2016). However, its exact mechanism was not determined. Some genes involved in cell division, including $b \operatorname{lh} A, z i p A, z a p A$, and $f t s K$, are associated with intrinsic $\beta$-lactam resistance in $A$. baumannii (Knight et al., 2016).

Increased expression of mutagenesis-related genes, such as the SOS response genes, is a well-understood mechanism of $E$. coli and other bacteria to obtain antibiotic resistance (Cirz and Romesberg, 2007). Acinetobacter baumannii also seems to have an inducible DNA damage response in which RecA plays a major regulatory role and seems to acquire antibiotic resistances under clinically relevant DNA-damaging conditions (Aranda et al., 2011, 2014; Norton et al., 2013). Furthermore, RecA is involved in the A. baumannii pathogenicity (Aranda et al., 2011).

\section{PROSPECTIVE TREATMENT OPTIONS}

Although carbapenems are effective antibiotics to treat $A$. baumannii infections (Cisneros and Rodríguez-Baño, 2002; Turner et al., 2003), the rate of carbapenem-resistant $A$. baumannii isolates has been increasing gradually (Mendes et al., 2010; Kuo et al., 2012; Su et al., 2012). Only a few effective antibiotic options are available to treat MDR A. baumannii infections (Gordon and Wareham, 2009; Lee J. H. et al., 2015, 2016). To combat MDR or pandrugresistant (PDR) A. baumannii, which are resistant to all available antibiotics, combination therapies, including colistin/imipenem, colistin/meropenem, colistin/rifampicin, colistin/tigecycline, colistin/sulbactam, colistin/teicoplanin, and imipenem/sulbactam, have been extensively studied. Prospective treatment options of Acinetobacter baumannii infections are summarized in Table 3. We will discuss the most recent published reports.

\section{Carbapenems and $\beta$-Lactamase Inhibitors}

Carbapenems, including imipenem, meropenem, and doripenem, have generally been considered the agents to treat $A$. baumannii infections, due to their effective activity against this organism and their favorable safety (Doi et al., 2015). However, the decreased susceptibility of A. baumannii to carbapenems has forced clinicians and researchers to explore alternative therapeutic approaches (Doi et al., 2015). Because carbapenem-resistant $A$. baumannii strains are often resistant to all other commonly used antibiotics as well, these strains remain susceptible to only limited antibiotics, such as minocycline/tigecycline and polymyxins (colistin and polymyxin B; Lin and Lan, 2014; Doi et al., 2015). Carbapenem therapies combined with a few effective antibiotics was extensively tested and many cases showed a synergistic effect against $A$. baumannii infections (Table 3). However, recent increase of tigecyclineor colistin-resistant $A$. baumannii increasingly poses a serious 


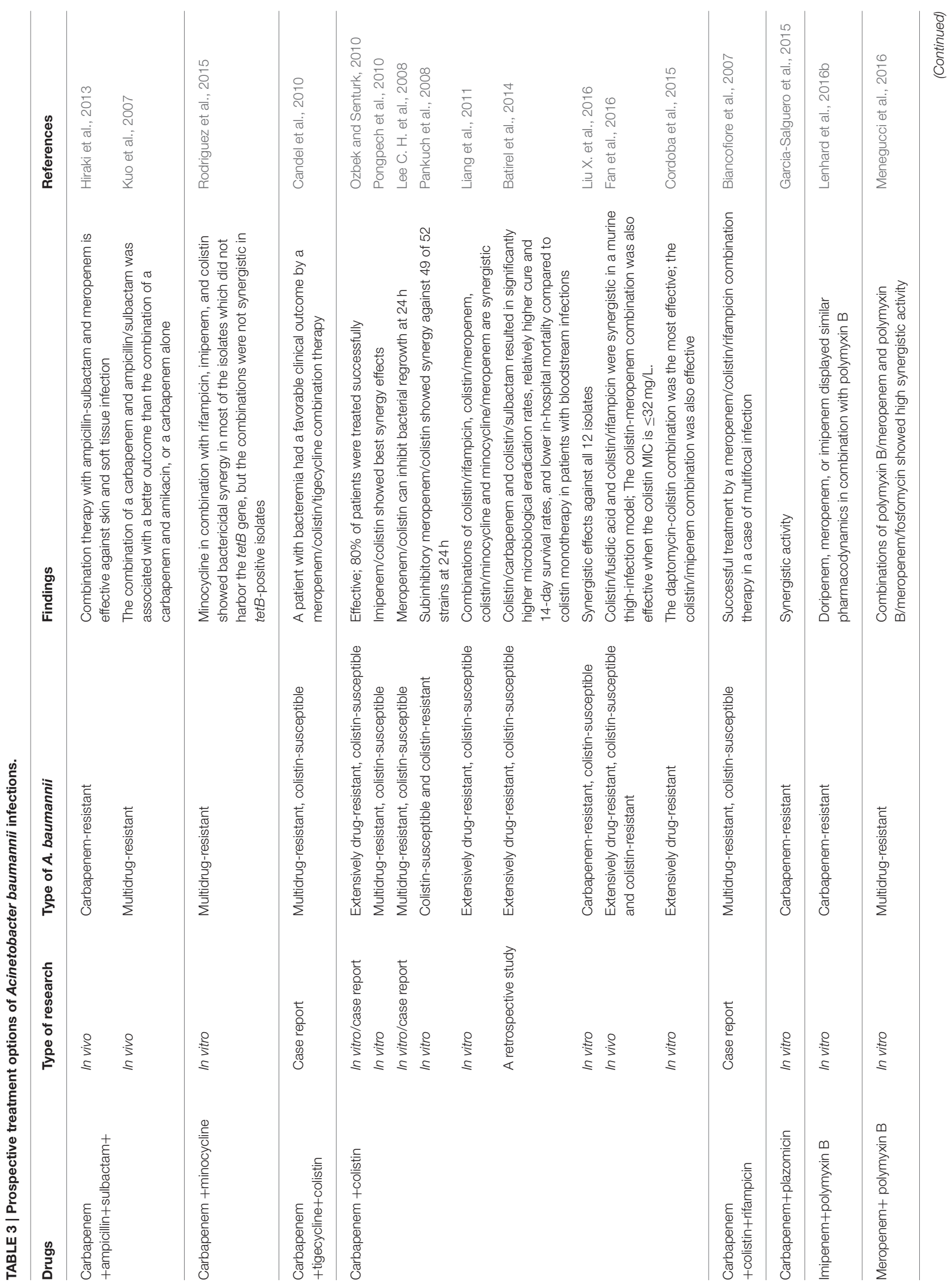




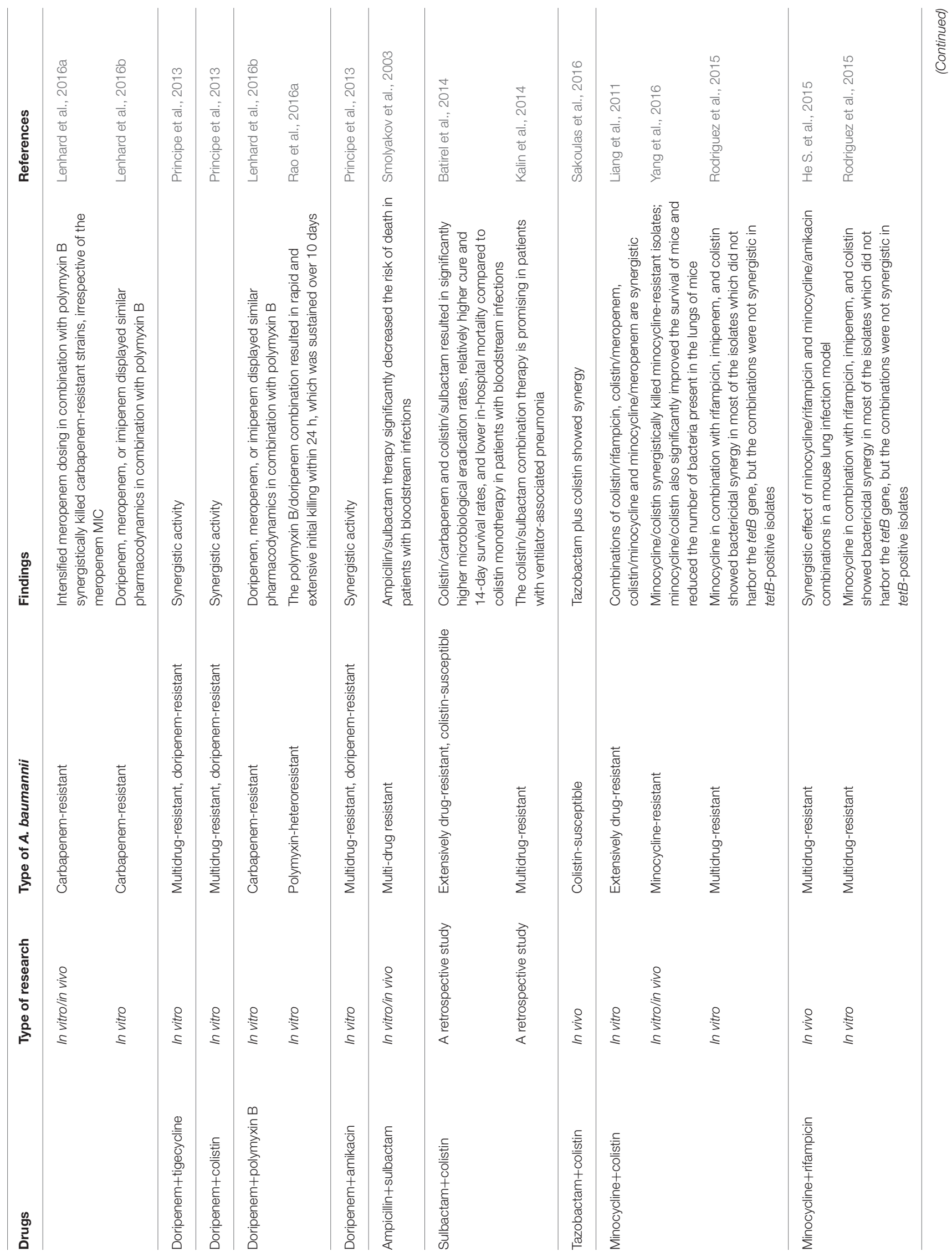




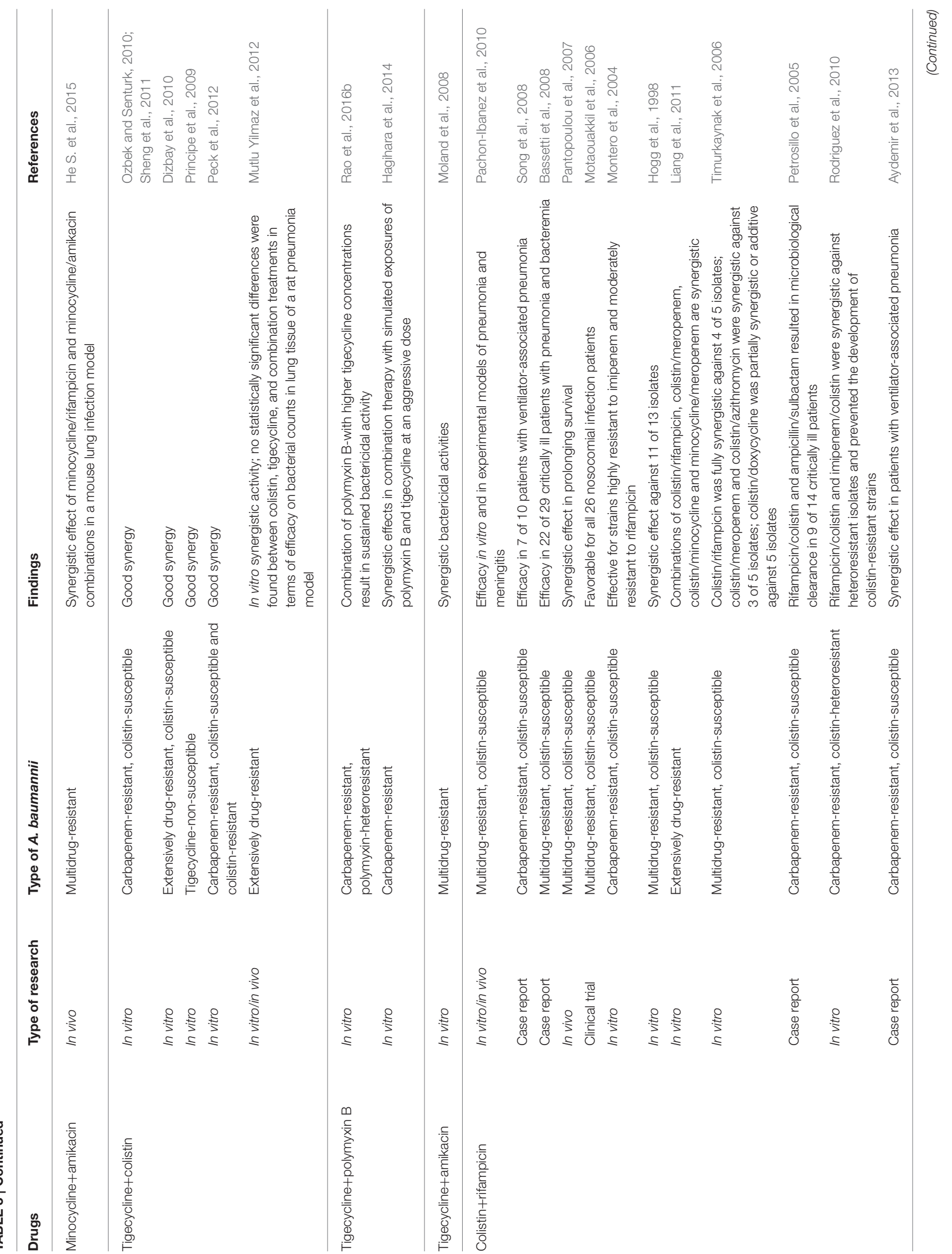




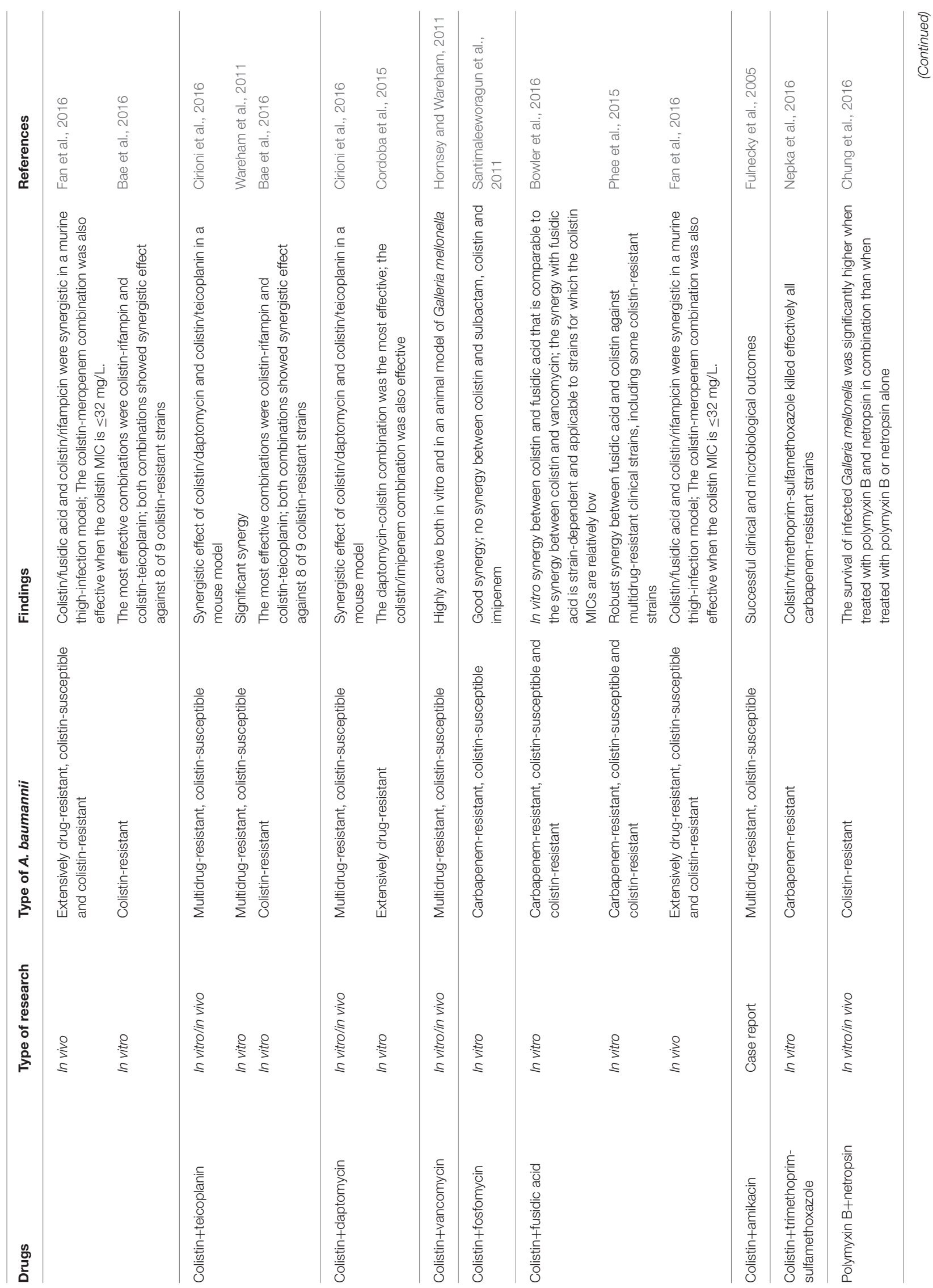




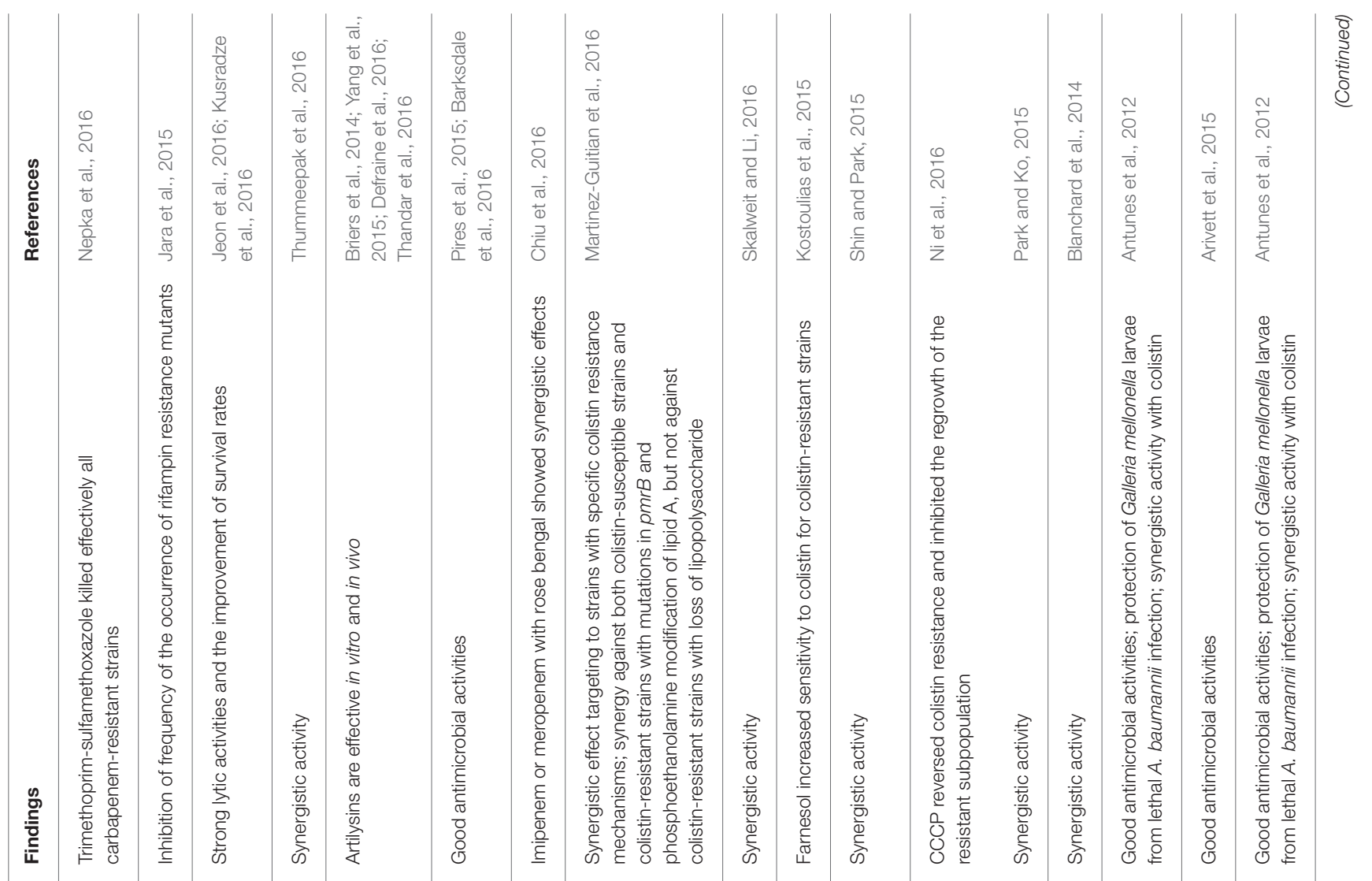


threat to public health worldwide (Peleg et al., 2007; Hornsey et al., 2010; Cai et al., 2012).

Sulbactam is a $\beta$-lactamase inhibitor and also has affinity for penicillin-binding proteins of $A$. baumannii (Rafailidis et al., 2007; Doi et al., 2015). Combined therapy of ampicillin with sulbactam is effective for treating bloodstream infections due to MDR A. baumannii (Smolyakov et al., 2003). Ampicillin/sulbactam/carbapenem combination therapy is also effective for treating MDR A. baumannii bacteremia (Kuo et al., 2007) and skin and soft tissue infection of carbapenem-resistant A. baumannii (Hiraki et al., 2013), but not in ventilatorassociated pneumonia (Kalin et al., 2014). The population pharmacokinetics and pharmacodynamics of sulbactam were determined in critically ill patients with severe sepsis caused by A. baumannii (Jaruratanasirikul et al., 2016) and in patients with impaired renal function (Yokoyama et al., 2015). Another $\beta$ lactamase inhibitor tazobactam increases the activity of peptide antibiotics, such as colistin and daptomycin, in a murine model of A. baumannii pneumonia (Sakoulas et al., 2016). The authors suggested that $\beta$-lactamase inhibitors may exert similar effects in potentiating peptide antibiotics, because of structural similarities between $\beta$-lactamase inhibitors and peptide antibiotics (Sakoulas et al., 2016).

\section{Minocycline/Tigecycline}

Minocycline, is a broad-spectrum tetracycline antibiotic that has been proposed for treating drug-resistant $A$. baumannii based on its high degree of susceptibility to this drug and its favorable pharmacokinetic profile (Ritchie and GaravagliaWilson, 2014). The mean susceptibility rate of $A$. baumannii to minocycline is approximately $80 \%$ worldwide (Castanheira et al., 2014). Therefore, minocycline therapy has high treatment success rates and good tolerability (Ritchie and Garavaglia-Wilson, 2014). However, since the introduction of minocycline, approximately $20 \%$ of A. baumannii isolates are not susceptible to minocycline. The TetB efflux pump is the main determinants of minocycline resistance (Vilacoba et al., 2013). Minocycline therapy combined with colistin is effective for treating minocycline-resistant $A$. baumannii infections (Yang et al., 2016), and minocycline therapy combined with rifampicin, colistin, or imipenem has a synergistic effect in most of isolates without the tet $B$ gene, but combined therapies are not synergistic in isolates with the tet $B$ gene (Rodriguez et al., 2015).

Tigecycline is the first glycylcycline class antibiotic that exhibits bacteriostatic activity by binding to the $30 \mathrm{~S}$ ribosomal subunit, and is active against A. baumannii infections (PachonIbanez et al., 2004; Anthony et al., 2008; Koomanachai et al., 2009). Tigecycline shows a synergistic effect with some classes of antibiotics, such as amikacin (Moland et al., 2008) and colistin (Mutlu Yilmaz et al., 2012). However, limitations of tigecycline use have emerged with its increasing use. Tigecycline is less effective than imipenem to treat pneumonia in a murine pneumonia model (Pichardo et al., 2010). $\beta$-Lactam or carbapenem instead of tigecycline was recommended for $A$. baumannii infections with tigecycline MIC of more than $2 \mathrm{mg} / \mathrm{L}$, due to high mortality from the tigecycline treatment (Curcio and Fernandez, 2008). In a study of 266 patients with MDR 
A. baumannii infections, tigecycline-based therapy was not more effective than non-tigecycline-based therapies (Lee Y. T. et al., 2013). Tigecycline resistance associated with overexpression of efflux pumps, such as AdeABC, has been reported in clinical isolates of A. baumannii (Peleg et al., 2007; Ruzin et al., 2007; Hornsey et al., 2010, 2011). Multiple MDR A baumannii clones resistant to tigecycline have been reported in many medical centers (Navon-Venezia et al., 2007). Therefore, tigecycline can only be used in limited cases for treating A. baumannii infections.

\section{Polymyxins (Colistin and Polymyxin B)}

Polymyxins are a group of polycationic peptide antibiotics that were discovered more than 60 years ago and exhibit potent efficacy against most Gram-negative bacteria (Liu Q. et al., 2014; Lee C. R. et al., 2016). Among all five polymyxins (A$\mathrm{E})$, only polymyxin $\mathrm{B}$ and $\mathrm{E}$ (colistin) with a one amino acid difference are used clinically. Colistin is a key component of combination therapies used to treat MDR A. baumannii infections (Cai et al., 2012). The rate of colistin resistance (10.4\%) in MDR A. baumannii isolates is lower than that of rifampicin (47.8\%) or tigecycline (45.5\%) resistance (Chang et al., 2012). Similar results were reported in another study (Muthusamy et al., 2016). Therefore, colistin seems to be the only effective antimicrobial agent against MDR A. baumannii infections. Many colistin-based combined therapies, including colistin/rifampicin (Liang et al., 2011; Aydemir et al., 2013), colistin/minocycline (Liang et al., 2011), colistin/carbapenem (Liang et al., 2011; Batirel et al., 2014; Liu X. et al., 2016), colistin/sulbactam (Batirel et al., 2014), colistin/tigecycline (Principe et al., 2009; Ozbek and Senturk, 2010; Sheng et al., 2011; Peck et al., 2012), colistin/daptomycin (Cirioni et al., 2016), colistin/fusidic acid (Bowler et al., 2016; Fan et al., 2016), and colistin/teicoplanin (Wareham et al., 2011; Cirioni et al., 2016), are synergistic in vivo or in vitro against A. baumannii infections. Colistin therapy combined with rifampin or fusidic acid seems to be the most effective for treating a MDR A. baumannii in a murine thigh-infection model (Fan et al., 2016). Another report comparing colistin/daptomycin, colistin/imipenem, and imipenem/ertapenem showed that the daptomycin-colistin combination was the most effective (Cordoba et al., 2015).

Unfortunately, the emergence of colistin-resistant $A$. baumannii strains has increased worldwide (Cai et al., 2012). The mechanisms of colistin resistance include loss of LPS (Moffatt et al., 2010) and the addition of phosphoethanolamine to LPS by the PmrAB two-component system (Adams et al., 2009). Mutations in $p m r A$ and $p m r B$ activate $p m r C$, which adds phosphoethanolamine to the hepta-acylated form of lipid A (Beceiro et al., 2011). Interestingly, an investigation of the in vitro activities of various antimicrobial combinations against colistin-resistant A. baumannii showed that the most effective combinations against colistin-resistant $A$. baumannii are colistinrifampin and colistin-teicoplanin, indicating that colistin is the most common constituent of antimicrobial combinations even against colistin-resistant A. baumannii (Bae et al., 2016). Similarly, minocycline therapy in combination with colistin is effective to treat infections caused by minocycline-resistant A. baumannii. Minocycline/colistin therapy significantly improves survival of mice infected with minocycline-resistant $A$. baumannii and reduces the number of bacteria present in the lungs of mice (Yang et al., 2016).

A urinary tract Enterococcus faecalis isolate that apparently requires vancomycin to grow was reported in 1994, and this phenomenon is called "antimicrobial agent dependence." Colistin dependence was reported in an $A$. baumannii-A. calcoaceticus complex (Hawley et al., 2007). Partial colistin dependence has been detected in several LPS-deficient strains with mutations in $l p x A, l p x C$, and $l p x D$ (Garcia-Quintanilla et al., 2015). Many colistin-susceptible A. baumannii isolates develop colistin dependence in vitro after exposure to colistin (Hong et al., 2016). Although the clinical implication of colistin dependence and its molecular mechanism remain unclear, it is interesting that patients with colistin-dependent A. baumannii isolates show a high rate of treatment failure (Hong et al., 2016).

Unlike colistin, polymyxin B is not converted from a prodrug form into an active form; thus, plasma concentrations of polymyxin B more quickly reach target levels (Sandri et al., 2013). In addition, polymyxin B is available for direct parenteral administration (Zavascki et al., 2007). Despite the favorable pharmacokinetics of polymyxin $\mathrm{B}$, dose-related nephrotoxicity limits the concentration of polymyxin B used in combination therapy (Dubrovskaya et al., 2015). Therefore, almost all studies on polymyxins are carried out for colistin. However, because some carbapenems have comparatively safer dose modulation to optimize killing during combination therapy (Cannon et al., 2014), several studies have analyzing the pharmacodynamics of carbapenems in combination with polymyxin B (Lenhard et al., 2016a,b; Rao et al., 2016a). One study showed that intensified meropenem dosing combined with polymyxin B is a good strategy to treat carbapenem-resistant $A$. baumannii, regardless of the meropenem MIC (Lenhard et al., 2016a). Combination therapy with doripenem and polymyxin B also showed similar results. Early aggressive dosing of doripenem combined with polymyxin $\mathrm{B}$ is effective for treating heteroresistant $A$. baumannii infections (Rao et al., 2016a). A combined pharmacodynamics analysis of four different carbapenems with polymyxin B showed that doripenem, meropenem, or imipenem display similar pharmacodynamics in combination, and the decision to use carbapenem in combination with polymyxin B is usually based on toxicodynamic profiles (Lenhard et al., 2016b). Polymyxin $\mathrm{B}$ also shows good bactericidal activity in combination with high tigecycline concentrations (Hagihara et al., 2014; Rao et al., 2016b). Therefore, polymyxin B combination therapies seem to be one of the most promising options for minimizing the emergence of polymyxin resistance. Increasing the dose intensity of polymyxin $\mathrm{B}$ amplifies polymyxin $\mathrm{B}$ resistance in $A$. baumannii (Cheah et al., 2016; Tsuji et al., 2016). In conclusion, although polymyxin B displays dose-related nephrotoxicity, it is a potential therapeutic alternative to colistin when use together with intensified doses of other antibiotics. Large-scale screening of Streptomyces secondary metabolites was performed to develop a novel combination therapy using minimal concentrations of polymyxin $\mathrm{B}$, and the reliable polymyxin synergist netropsin was identified (Chung et al., 2016). Survival of G. mellonella 
infected with colistin-resistant clinical A. baumannii isolates is significantly higher when treated with polymyxin B combined with netropsin than when treated with polymyxin B or netropsin alone (Chung et al., 2016).

\section{Other Antibiotics}

Trimethoprim-sulfamethoxazole is a two antibiotics combination that exerts a synergistic effect by inhibiting successive steps in the folate synthesis pathway against a number of bacteria (Wormser et al., 1982). The in vitro killing activity of trimethoprim-sulfamethoxazole against carbapenem-resistant A. baumannii was recently studied. Trimethoprim-sulfamethoxazole alone effectively kills all carbapenem-resistant A. baumannii strains and trimethoprimsulfamethoxazole combined with colistin also rapidly kills all strains for up to $24 \mathrm{~h}$ (Nepka et al., 2016). These results suggest that trimethoprim-sulfamethoxazole might be an effective therapy for severe carbapenem-resistant A. baumannii infections. Plazomicin is a next-generation aminoglycoside synthetically derived from sisomicin that enhances activity against many MDR Gram-negative bacteria (Garcia-Salguero et al., 2015). A synergistic effect was observed with carbapenems along with plazomicin during treatment of A. baumannii infections (Garcia-Salguero et al., 2015), indicating the potential utility of plazomicin combined with carbapenems.

The inducible DNA damage response in A. baumannii plays an important role in acquiring antibiotic resistance under clinically relevant DNA-damaging conditions (Aranda et al., 2011, 2014; Norton et al., 2013). The aminocoumarin novobiocin is a well-established antimicrobial agent that inhibits the DNA damage response in Gram-positive bacteria by interfering with ATPase activity of DNA gyrase (Schroder et al., 2013). One study showed that novobiocin also inhibits acquisition of antimicrobial resistance in MDR A. baumannii through DNA damage-induced mutagenesis (Jara et al., 2015).

\section{Non-antibiotic Therapies: Phage and Others}

The worldwide spread of MDR pathogens has renewed interest in the therapy using bacteriophage, which is a virus that infects and lyses bacteria. Various lytic A. baumannii bacteriophages, such as $v B \_A b-M-G 7$ (Kusradze et al., 2016) and B $\phi$-C62 (Jeon et al., 2016), have been used to treat infections caused by MDR A. baumannii. Bacteriophage-encoded endolysin has also received attention. Endolysin is a lytic enzyme that degrades the cell wall of bacterial hosts and shows promise as a novel class of antibacterials with a unique mode of action (Defraine et al., 2016). For example, endolysin from A. baumannii bacteriophage $\varnothing$ ABP-01 degrades the crude cell wall of A. baumannii strains and elevates antibacterial activity when combined with colistin (Thummeepak et al., 2016). However, most Gram-negative pathogens are generally not susceptible to endolysins, due to their protective outer membrane (Lee et al., 2013a). To overcome this problem, endolysins have recently been engineered with specific outer membrane-destabilizing peptides to obtain the ability to penetrate outer membrane and these engineered endolysins are called "artilysins" (Rodriguez-Rubio et al., 2016). Several engineered artilysins have been developed to combat MDR A. baumannii and show highly effective antimicrobial activity against A. baumannii (Briers et al., 2014; Yang et al., 2015; Defraine et al., 2016; Thandar et al., 2016). These results suggest that artilysins can be a treatment option for MDR A. baumannii. The diversity of the phage population was determined by analysis of viromes, endolysins, and CRISPR spacers (Davison et al., 2016). These results can be used to assist in finding an effective endolysin for combating MDR A. baumannii. Various peptides, such as American alligator plasma peptide (Barksdale et al., 2016) and antimicrobial peptide dendrimer G3KL (Pires et al., 2015), have in vitro antimicrobial activity against MDR A. baumannii. However, the use of antimicrobial enzymes or peptides also has some important problems, such as their short half-life in serum and high production costs compared with those of smaller molecules.

An in silico analysis predicted that OXA-58, OXA-23, and OXA-83 are translocated to the periplasm via the Sec system (Liao et al., 2015; Chiu et al., 2016). A SecA inhibitor (rose bengal) inhibits periplasmic translocation of these carbapenemhydrolyzing class D $\beta$-lactamases, indicating that these $\beta$ lactamases are selectively released via a Sec-dependent system (Liao et al., 2015; Chiu et al., 2016). Imipenem or meropenem combined with rose bengal shows synergistic effects for carbapenem-resistant A. baumannii clinical isolates (Chiu et al., 2016). Similarly, $\beta$-aminoketone (MD3), an inhibitor of bacterial type I signal peptidases that cleaves the amino-terminal signal peptides of translocated proteins, shows a synergistic effect when combined with colistin against colistin-resistant A. baumannii strains (Martinez-Guitian et al., 2016).

Bulgecin $\mathrm{A}$ is a natural product of $P$. mesoacidophila and a lytic transglycosylase inhibitor that works synergistically with $\beta$-lactams (Skalweit and Li, 2016). Bulgecin A restores the efficacy of meropenem in suppressing growth of carbapenemresistant $A$. baumannii strains, suggesting that Bulgecin A may be an adjunctive compound to extend the life of carbapenems against A. baumannii infections (Skalweit and Li, 2016). Similarly, farnesol, a natural product of Candida albicans for quorum-sensing, disrupts A. baumannii cell membrane integrity, alters cell morphology, and increases sensitivity of MDR A. baumannii strains to colistin (Kostoulias et al., 2015). Many herbal active compounds have potent antibacterial activities against many bacteria including carbapenem-resistant A. baumannii (Lin et al., 2015). For example, oleanolic acid is a triterpenoid compound that widely exists in food, medicinal herbs, and many plants and can potently inhibit various pathogenic bacteria. One study showed that oleanolic acid increases aminoglycoside uptake by changing membrane permeability and energy metabolism in A. baumannii (Shin and Park, 2015).

Cyanide 3-chlorophenylhydrazone (CCCP) is an efflux pump inhibitor that decreases the MIC of colistin in colistin-susceptible and colistin-resistant A. baumannii strains (Park and Ko, 2015; $\mathrm{Ni}$ et al., 2016). Other efflux pump inhibitors, such as ABEPI1 and ABEPI2, inhibit efflux-mediated minocycline tolerance of 
A. baumannii. Adding these compounds during growth in human serum leads to the accumulation of minocycline within A. baumannii and inhibits efflux potential of the bacterium (Blanchard et al., 2014).

Gallium is a semi-metallic element in group 13 of the periodic table that binds to biological complexes containing $\mathrm{Fe}^{3+}$ and disrupts essential redox-driven biological processes (Bernstein, 1998). Gallium has been used as a simple inorganic or organic salt or complexed with organic compounds. Several studies have shown that gallium nitrate or gallium protoporphyrin IX could be a viable therapeutic option for treating MDR A. baumannii (Antunes et al., 2012; Arivett et al., 2015). Some D-amino acids, such as D-His and D-Cys, inhibit bacterial growth, biofilm formation, and adherence to eukaryotic cells in A. baumannii (Rumbo et al., 2016).

Probiotics are "live microorganisms that confer a health benefit on the host when administered in adequate amounts" (Reid et al., 2005) and assist in protecting against MDR A. baumannii infections. For example, the ability of the probiotic Bifidobacterium breve to protect against MDR A. baumannii infections has been investigated (Asahara et al., 2016). This probiotic markedly potentiates protection against fatal intestinal infections caused by MDR A. baumannii (Asahara et al., 2016). With probiotics, immunomodulators, such as lysophosphatidylcholine (Parra Millan et al., 2016) and macrolide antibiotics such as clarithromycin (Konstantinidis et al., 2016), can reduce A. baumannii infection severity by stimulating the immune response, when combined with antibiotics such as colistin, tigecycline, or imipenem.

\section{CONCLUSION}

The number of studies about A. baumannii is increasing dramatically because of its increasing clinical importance. Use of animal models has produced important data regarding virulence factors that contribute to A. baumannii pathogenesis. Notably, some studies on metal acquisition and protein secretion systems are interesting. Besides iron acquisition systems such as acinetobactin, the discovery of zinc and manganese acquisition systems in $A$. baumannii broadens our understanding of $A$. baumannii pathogenesis. More extensive studies on various protein secretion systems present in A. baumannii are required. About 300 genes required for in vivo survival of $A$. baumannii were identified using transposon screening in G. mellonella larvae (Gebhardt et al., 2015). Because many of these genes were not known to be associated with A. baumannii pathogenesis, more detailed studies are required to determine whether these genes are related to the pathogenesis of $A$. baumannii. In addition, transposon screening in other model animals will provide novel insight into A. baumannii pathogenesis. Knowledge of virulence factors responsible for $A$. baumannii pathogenicity will be the cornerstone for developing novel antibiotics. For example, LPS is an important virulence factor and LpxC inhibitor, which inhibits LPS synthesis, completely protects mice from lethal infection (Lin et al., 2012). These results indicate that blocking LPS synthesis is a powerful strategy for discovering novel antibiotics. However, despite recent extensive studies about A. baumannii pathogenesis, the toxicity and pathogenicity of $A$. baumannii remain unclear.

Recent interest about A. baumannii is mostly due to its seemingly endless capacity to acquire antibiotic resistance. $A$. baumannii has almost all bacterial resistance mechanisms. All class $\beta$-lactamases have been detected in A. baumannii and the frequency of carbapenem-resistant $A$. baumannii isolates is very high. Furthermore, almost all $A$. baumannii contain aminoglycoside-modifying enzymes and many efflux pumps responsible for resistance to various clinically important antibiotics have been identified in A. baumannii. Due to these abilities, available antibiotics to treat $A$. baumannii infections are significantly limited. Colistin is used as the antibiotic treatment of last resort, due to its relatively low resistance rate. However, emergence of colistin-resistant A. baumannii strains has increased worldwide with increasing use of colistin. Notably, some more recent studies have proposed that another polymyxin antibiotic, polymyxin $\mathrm{B}$, is a potential therapeutic alternative to colistin (Lenhard et al., 2016a,b; Rao et al., 2016a; Repizo et al., 2015). Polymyxin B has not been a good antibiotic owing to dose-dependent nephrotoxicity, but recent reports show that a novel combination therapy with carbapenems or tigecycline using minimal concentrations of polymyxin B can be a good strategy to treat carbapenem-resistant A. baumannii infections. These results indicate the requirement for extensive studies that analyze the pharmacodynamics of polymyxin B in combination therapy.

Various trials to identify a novel alternative to carbapenem or colistin have been performed. Among them, engineered endolysins (artilysins) are particularly interesting, despite evident defects. A lytic enzyme degrading peptidoglycan of bacteria is a promising novel class of antimicrobial agents due to its unique mode of action. Similar to $\beta$-lactam antibiotics that are one of the most successful antibiotics, inhibition of peptidoglycan synthesis is a promising target of antimicrobial agents. Because lytic enzymes directly degrade peptidoglycans, but not proteins, the possibility of the emergence of a resistance mechanism is relatively low. In addition, enzymes with relatively high molecular weight are not inhibited by efflux pumps. If the short stability of artilysin in serum and high cost in its production compared with small molecules can be resolved, the improved artilysin can be a good treatment option for carbapenem- or colistin-resistant A. baumannii infections. In conclusion, novel, rationally designed strategies and screening-based approaches are required to discover new classes of antibiotics. If we continue to take all efforts at maintaining the effectiveness of antibiotics and developing novel antibiotics, effective control of A. baumannii infections can be successful.

\section{AUTHOR CONTRIBUTIONS}

CL, JL, MP, and SL contributed to the conception and the design of the review and $\mathrm{CL}, \mathrm{JL}, \mathrm{MP}, \mathrm{KP}, \mathrm{IB}, \mathrm{YK}, \mathrm{CC}, \mathrm{BJ}$, and SL researched and wrote the review. 


\section{FUNDING}

This review was supported by the Cooperative Research Program for Agriculture Science and Technology Development (No. PJ01103103) of Rural Development Administration in Republic

\section{REFERENCES}

Acosta, J., Merino, M., Viedma, E., Poza, M., Sanz, F., Otero, J. R., et al. (2011). Multidrug-resistant Acinetobacter baumannii Harboring OXA-24 carbapenemase, Spain. Emerg. Infect Dis. 17, 1064-1067. doi: 10.3201/eid/ 1706.091866

Adams, M. D., Goglin, K., Molyneaux, N., Hujer, K. M., Lavender, H., Jamison, J. J., et al. (2008). Comparative genome sequence analysis of multidrug-resistant Acinetobacter baumannii. J. Bacteriol. 190, 8053-8064. doi: 10.1128/JB.00834-08

Adams, M. D., Nickel, G. C., Bajaksouzian, S., Lavender, H., Murthy, A. R., Jacobs, M. R., et al. (2009). Resistance to colistin in Acinetobacter baumannii associated with mutations in the PmrAB two-component system. Antimicrob. Agents Chemother. 53, 3628-3634. doi: 10.1128/AAC.00284-09

Afzal-Shah, M., Woodford, N., and Livermore, D. M. (2001). Characterization of OXA-25, OXA-26, and OXA-27, molecular class D $\beta$-lactamases associated with carbapenem resistance in clinical isolates of Acinetobacter baumannii. Antimicrob. Agents Chemother. 45, 583-588. doi: 10.1128/AAC.45.2.583-588.2001. [Epub ahead of print].

Al-Agamy, M. H., Jeannot, K., El-Mahdy, T. S., Shibl, A. M., Kattan, W., Plesiat, P., et al. (2016). First Detection of GES-5 Carbapenemase-Producing Acinetobacter baumannii Isolate. Microb. Drug Resist. doi: 10.1089/mdr.2016.0152. [Epub ahead of print].

Al Atrouni, A., Hamze, M., Jisr, T., Lemarie, C., Eveillard, M., Joly-Guillou, M. L., et al. (2016). Wide spread of OXA-23-producing carbapenem-resistant Acinetobacter baumannii belonging to clonal complex II in different hospitals in Lebanon. Int. J. Infect. Dis. 52, 29-36. doi: 10.1016/j.ijid.2016.09.017

Aly, M. M., Abu Alsoud, N. M., Elrobh, M. S., Al Johani, S. M., and Balkhy, H. H. (2016). High prevalence of the PER-1 gene among carbapenem-resistant Acinetobacter baumannii in Riyadh, Saudi Arabia. Eur. J. Clin. Microbiol. Infect Dis. 35, 1759-1766. doi: 10.1007/s10096-016-2723-8

Anthony, K. B., Fishman, N. O., Linkin, D. R., Gasink, L. B., Edelstein, P. H., and Lautenbach, E. (2008). Clinical and microbiological outcomes of serious infections with multidrug-resistant gram-negative organisms treated with tigecycline. Clin. Infect. Dis. 46, 567-570. doi: 10.1086/526775

Antunes, L. C., Imperi, F., Carattoli, A., and Visca, P. (2011). Deciphering the multifactorial nature of Acinetobacter baumannii pathogenicity. PLoS ONE 6:e22674. doi: 10.1371/journal.pone.0022674

Antunes, L. C., Imperi, F., Minandri, F., and Visca, P. (2012). In vitro and in vivo antimicrobial activities of gallium nitrate against multidrug-resistant Acinetobacter baumannii. Antimicrob. Agents Chemother. 56, 5961-5970. doi: 10.1128/AAC.01519-12

Aranda, J., Bardina, C., Beceiro, A., Rumbo, S., Cabral, M. P., Barbe, J., et al. (2011). Acinetobacter baumannii RecA protein in repair of DNA damage, antimicrobial resistance, general stress response, and virulence. J. Bacteriol. 193, 3740-3747. doi: 10.1128/JB.00389-11

Aranda, J., Lopez, M., Leiva, E., Magan, A., Adler, B., Bou, G., et al. (2014). Role of Acinetobacter baumannii UmuD homologs in antibiotic resistance acquired through DNA damage-induced mutagenesis. Antimicrob. Agents Chemother. 58, 1771-1773. doi: 10.1128/AAC.02346-13

Arivett, B. A., Fiester, S. E., Ohneck, E. J., Penwell, W. F., Kaufman, C. M., Relich, R. F., et al. (2015). Antimicrobial activity of Gallium Protoporphyrin IX against Acinetobacter baumannii strains displaying different antibiotic resistance phenotypes. Antimicrob. Agents Chemother. 59, 7657-7665. doi: 10.1128/AAC.01472-15

Arroyo, L. A., Herrera, C. M., Fernandez, L., Hankins, J. V., Trent, M. S., and Hancock, R. E. (2011). The $p m r C A B$ operon mediates polymyxin resistance in Acinetobacter baumannii ATCC 17978 and clinical isolates through phosphoethanolamine modification of lipid A. Antimicrob. Agents Chemother. 55, 3743-3751. doi: 10.1128/AAC.00256-11 of Korea; the Environmental Health Action Program (No. 2016001350004) funded by the Ministry of Environment (MOE) in Republic of Korea; and the National Research Foundation of the Ministry of Education, Republic of Korea (NRF2015R1C1A1A02037470).

Asahara, T., Takahashi, A., Yuki, N., Kaji, R., Takahashi, T., and Nomoto, K. (2016). Protective effect of a synbiotic against multidrug-resistant Acinetobacter baumannii in a Murine Infection Model. Antimicrob. Agents Chemother. 60, 3041-3050. doi: 10.1128/AAC.02928-15

Aydemir, H., Akduman, D., Piskin, N., Comert, F., Horuz, E., Terzi, A., et al. (2013). Colistin vs. the combination of colistin and rifampicin for the treatment of carbapenem-resistant Acinetobacter baumannii ventilator-associated pneumonia. Epidemiol. Infect. 141, 1214-1222. doi: 10.1017/S095026881200194X

Bae, S., Kim, M. C., Park, S. J., Kim, H. S., Sung, H., Kim, M. N., et al. (2016). In vitro synergistic activity of antimicrobial agents in combination against clinical isolates of colistin-resistant Acinetobacter baumannii. Antimicrob. Agents Chemother. 60, 6774-6779. doi: 10.1128/AAC.00839-16

Bakour, S., Alsharapy, S. A., Touati, A., and Rolain, J. M. (2014). Characterization of Acinetobacter baumannii clinical isolates carrying bla $a_{\mathrm{OXA}-23}$ carbapenemase and 16S rRNA methylase armA genes in Yemen. Microb. Drug Resist. 20, 604-609. doi: 10.1089/mdr.2014.0018

Barksdale, S. M., Hrifko, E. J., Chung, E. M., and van Hoek, M. L. (2016) Peptides from American alligator plasma are antimicrobial against multidrug resistant bacterial pathogens including Acinetobacter baumannii. BMC Microbiol. 16:189. doi: 10.1186/s12866-016-0799-z

Basler, M., Ho, B. T., and Mekalanos, J. J. (2013). Tit-for-tat: type VI secretion system counterattack during bacterial cell-cell interactions. Cell 152, 884-894. doi: 10.1016/j.cell.2013.01.042

Bassetti, M., Repetto, E., Righi, E., Boni, S., Diverio, M., Molinari, M. P., et al. (2008). Colistin and rifampicin in the treatment of multidrug-resistant Acinetobacter baumannii infections. J. Antimicrob. Chemother. 61, 417-420. doi: $10.1093 / \mathrm{jac} / \mathrm{dkm} 509$

Batirel, A., Balkan, I. I., Karabay, O., Agalar, C., Akalin, S., Alici, O., et al. (2014). Comparison of colistin-carbapenem, colistin-sulbactam, and colistin plus other antibacterial agents for the treatment of extremely drug-resistant Acinetobacter baumannii bloodstream infections. Eur. J. Clin. Microbiol. Infect. Dis. 33, 1311-1322. doi: 10.1007/s10096-0142070-6

Beceiro, A., Llobet, E., Aranda, J., Bengoechea, J. A., Doumith, M., Hornsey, M., et al. (2011). Phosphoethanolamine modification of lipid A in colistinresistant variants of Acinetobacter baumannii mediated by the pmrAB twocomponent regulatory system. Antimicrob. Agents Chemother. 55, 3370-3379. doi: 10.1128/AAC.00079-11

Beceiro, A., Tomas, M., and Bou, G. (2013). Antimicrobial resistance and virulence: a successful or deleterious association in the bacterial world? Clin. Microbiol. Rev. 26, 185-230. doi: 10.1128/CMR.00059-12

Bentancor, L. V., Camacho-Peiro, A., Bozkurt-Guzel, C., Pier, G. B., and Maira-Litran, T. (2012a). Identification of Ata, a multifunctional trimeric autotransporter of Acinetobacter baumannii. J. Bacteriol. 194, 3950-3960. doi: 10.1128/JB.06769-11

Bentancor, L. V., Routray, A., Bozkurt-Guzel, C., Camacho-Peiro, A., Pier, G. B., and Maira-Litran, T. (2012b). Evaluation of the trimeric autotransporter Ata as a vaccine candidate against Acinetobacter baumannii infections. Infect. Immun. 80, 3381-3388. doi: 10.1128/IAI.06096-11

Bergogne-Berezin, E., and Towner, K. J. (1996). Acinetobacter spp. as nosocomial pathogens: microbiological, clinical, and epidemiological features. Clin. Microbiol Rev. 9, 148-165.

Bernstein, L. R. (1998). Mechanisms of therapeutic activity for gallium. Pharmacol. Rev. 50, 665-682.

Bhuiyan, M. S., Ellett, F., Murray, G. L., Kostoulias, X., Cerqueira, G. M., Schulze, K. E., et al. (2016). Acinetobacter baumannii phenylacetic acid metabolism influences infection outcome through a direct effect on neutrophil chemotaxis. Proc. Natl. Acad. Sci. U.S.A. 113, 9599-9604. doi: 10.1073/pnas.15231 16113 
Biancofiore, G., Tascini, C., Bisa, M., Gemignani, G., Bindi, M. L., Leonildi, A., et al. (2007). Colistin, meropenem and rifampin in a combination therapy for multi-drug-resistant Acinetobacter baumannii multifocal infection. A case report. Minerva. Anestesiol. 73, 181-185.

Biglari, S., Hanafiah, A., Mohd Puzi, S., Ramli, R., Rahman, M., and Lopes, B. S. (2016). Antimicrobial resistance mechanisms and genetic diversity of multidrug-resistant Acinetobacter baumannii isolated from a teaching hospital in Malaysia. Microb. Drug Resist. doi: 10.1089/mdr.2016.0130. [Epub ahead of print].

Blanchard, C., Barnett, P., Perlmutter, J., and Dunman, P. M. (2014). Identification of Acinetobacter baumannii serum-associated antibiotic efflux pump inhibitors. Antimicrob. Agents Chemother. 58, 6360-6370. doi: 10.1128/AAC.03535-14

Bogaerts, P., Naas, T., El Garch, F., Cuzon, G., Deplano, A., Delaire, T., et al. (2010). GES extended-spectrum $\beta$-lactamases in Acinetobacter baumannii isolates in Belgium. Antimicrob. Agents Chemother. 54, 4872-4878. doi: 10.1128/AAC.00871-10

Boll, J. M., Tucker, A. T., Klein, D. R., Beltran, A. M., Brodbelt, J. S., Davies, B. W., et al. (2015). Reinforcing lipid A acylation on the cell surface of Acinetobacter baumannii promotes cationic antimicrobial peptide resistance and desiccation survival. MBio 6, e00478-e00415. doi: 10.1128/mBio.00478-15

Bonnin, R. A., Poirel, L., Licker, M., and Nordmann, P. (2011a). Genetic diversity of carbapenem-hydrolysing $\beta$-lactamases in Acinetobacter baumannii from Romanian hospitals. Clin. Microbiol. Infect. 17, 1524-1528. doi: 10.1111/j.1469-0691.2011.03622.x

Bonnin, R. A., Poirel, L., Naas, T., Pirs, M., Seme, K., Schrenzel, J., et al. (2012). Dissemination of New Delhi metallo- $\beta$-lactamases-1-producing Acinetobacter baumannii in Europe. Clin. Microbiol. Infect. 18, E362-E365. doi: 10.1111/j.1469-0691.2012.03928.x

Bonnin, R. A., Potron, A., Poirel, L., Lecuyer, H., Neri, R., and Nordmann, P. (2011b). PER-7, an extended-spectrum $\beta$-lactamases with increased activity toward broad-spectrum cephalosporins in Acinetobacter baumannii. Antimicrob. Agents Chemother. 55, 2424-2427. doi: 10.1128/AAC. 01795-10

Borgeaud, S., Metzger, L. C., Scrignari, T., and Blokesch, M. (2015). The type VI secretion system of Vibrio cholerae fosters horizontal gene transfer. Science. 347, 63-67. doi: 10.1126/science.1260064

Bou, G., Cervero, G., Dominguez, M. A., Quereda, C., and Martinez-Beltran, J. (2000a). Characterization of a nosocomial outbreak caused by a multiresistant Acinetobacter baumannii strain with a carbapenem-hydrolyzing enzyme: highlevel carbapenem resistance in A. baumannii is not due solely to the presence of $\beta$-lactamases. J. Clin. Microbiol. 38, 3299-3305.

Bou, G., and Martinez-Beltran, J. (2000). Cloning, nucleotide sequencing, and analysis of the gene encoding an AmpC $\beta$-lactamases in Acinetobacter baumannii. Antimicrob. Agents Chemother. 44, 428-432. doi: 10.1128/AAC.44.2.428-432.2000

Bou, G., Oliver, A., and Martinez-Beltran, J. (2000b). OXA-24, a novel class D $\beta$-lactamases with carbapenemase activity in an Acinetobacter baumannii clinical strain. Antimicrob. Agents Chemother. 44, 1556-1561. doi: 10.1128/AAC.44.6.1556-1561.2000

Boucher, H. W., Talbot, G. H., Bradley, J. S., Edwards, J. E., Gilbert, D., Rice, L. B., et al. (2009). Bad bugs, no drugs: no ESKAPE! An update from the Infectious Diseases Society of America. Clin. Infect. Dis. 48, 1-12. doi: 10.1086/ 595011

Bowler, S. L., Spychala, C. N., McElheny, C. L., Mettus, R. T., and Doi, Y. (2016). In vitro activity of fusidic acid-containing combinations against carbapenem-resistant Acinetobacter baumannii clinical strains. Antimicrob. Agents Chemother. 60, 5101. doi: 10.1128/AAC.01124-16

Briers, Y., Walmagh, M., Van Puyenbroeck, V., Cornelissen, A., Cenens, W., Aertsen, A., et al. (2014). Engineered endolysin-based "Artilysins" to combat multidrug-resistant gram-negative pathogens. MBio 5, e01379-14. doi: $10.1128 / \mathrm{mBio} .01379-14$

Brigante, G., Migliavacca, R., Bramati, S., Motta, E., Nucleo, E., Manenti, M., et al. (2012). Emergence and spread of a multidrug-resistant Acinetobacter baumannii clone producing both the carbapenemase OXA23 and the 16S rRNA methylase ArmA. J. Med. Microbiol. 61, 653-661. doi: 10.1099/jmm.0.040980-0

Brown, S., Young, H. K., and Amyes, S. G. (2005). Characterisation of OXA-51, a novel class D carbapenemase found in genetically unrelated clinical strains of Acinetobacter baumannii from Argentina. Clin. Microbiol. Infect. 11, 15-23. doi: 10.1111/j.1469-0691.2004.01016.x
Cai, Y., Chai, D., Wang, R., Liang, B., and Bai, N. (2012). Colistin resistance of Acinetobacter baumannii: clinical reports, mechanisms and antimicrobial strategies. J. Antimicrob. Chemother. 67, 1607-1615. doi: 10.1093/jac/dks084

Camarena, L., Bruno, V., Euskirchen, G., Poggio, S., and Snyder, M. (2010). Molecular mechanisms of ethanol-induced pathogenesis revealed by RNAsequencing. PLoS Pathog. 6:e1000834. doi: 10.1371/journal.ppat.1000834

Candel, F. J., Calvo, N., Head, J., Sanchez, A., Matesanz, M., Culebras, E., et al. (2010). A combination of tigecycline, colistin, and meropenem against multidrug-resistant Acinetobacter baumannii bacteremia in a renal transplant recipient: pharmacodynamic and microbiological aspects. Rev. Esp. Quimioter. 23, 103-108.

Cannon, J. P., Lee, T. A., Clark, N. M., Setlak, P., and Grim, S. A. (2014). The risk of seizures among the carbapenems: a meta-analysis. J. Antimicrob. Chemother. 69, 2043-2055. doi: 10.1093/jac/dku111

Carruthers, M. D., Nicholson, P. A., Tracy, E. N., and Munson, R. S. Jr. (2013). Acinetobacter baumannii utilizes a type VI secretion system for bacterial competition. PLoS ONE 8:e59388. doi: 10.1371/journal.pone.0059388

Castanheira, M., Mendes, R. E., and Jones, R. N. (2014). Update on Acinetobacter species: mechanisms of antimicrobial resistance and contemporary in vitro activity of minocycline and other treatment options. Clin. Infect. Dis. 59 (Suppl. 6), S367-S373. doi: 10.1093/cid/ciu706

Catel-Ferreira, M., Coadou, G., Molle, V., Mugnier, P., Nordmann, P., Siroy, A., et al. (2011). Structure-function relationships of CarO, the carbapenem resistance-associated outer membrane protein of Acinetobacter baumannii. J. Antimicrob. Chemother. 66, 2053-2056. doi: 10.1093/jac/dkr267

Centers for Disease and Prevention (2004). Acinetobacter baumannii infections among patients at military medical facilities treating injured U.S. service members, 2002-2004. MMWR Morb. Mortal. Wkly. Rep. 53, 1063-1066.

Cerqueira, G. M., Kostoulias, X., Khoo, C., Aibinu, I., Qu, Y., Traven, A., et al. (2014). A global virulence regulator in Acinetobacter baumannii and its control of the phenylacetic acid catabolic pathway. J. Infect. Dis. 210, 46-55. doi: 10.1093/infdis/jiu024

Chagas, T. P., Carvalho, K. R., de Oliveira Santos, I. C., Carvalho-Assef, A. P., and Asensi, M. D. (2014). Characterization of carbapenem-resistant Acinetobacter baumannii in Brazil (2008-2011): countrywide spread of OXA23-producing clones (CC15 and CC79). Diagn. Microbiol. Infect. Dis. 79, 468-472. doi: 10.1016/j.diagmicrobio.2014.03.006

Chang, H. C., Wei, Y. F., Dijkshoorn, L., Vaneechoutte, M., Tang, C. T., and Chang, T. C. (2005). Species-level identification of isolates of the Acinetobacter calcoaceticus-Acinetobacter baumannii complex by sequence analysis of the 16S-23S rRNA gene spacer region. J. Clin. Microbiol. 43, 1632-1639. doi: 10.1128/JCM.43.4.1632-1639.2005

Chang, K. C., Lin, M. F., Lin, N. T., Wu, W. J., Kuo, H. Y., Lin, T. Y., et al. (2012). Clonal spread of multidrug-resistant Acinetobacter baumannii in eastern Taiwan. J. Microbiol. Immunol. Infect. 45, 37-42. doi: 10.1016/j.jmii.2011.09.019

Cheah, S. E., Li, J., Tsuji, B. T., Forrest, A., Bulitta, J. B., and Nation, R. L. (2016). Colistin and polymyxin B dosage regimens against Acinetobacter baumannii: differences in activity and the emergence of resistance. Antimicrob. Agents Chemother. 60, 3921-3933. doi: 10.1128/AAC.02927-15

Chen, C. H., Young, T. G., and Huang, C. C. (2006). Predictive biomarkers for drug-resistant Acinetobacter baumannii isolates with bla ${ }_{\mathrm{TEM}-1}$, AmpC-type bla and integrase 1 genotypes. J. Microbiol. Immunol. Infect. 39, 372-379.

Chen, Q., Li, X., Zhou, H., Jiang, Y., Chen, Y., Hua, X., et al. (2014). Decreased susceptibility to tigecycline in Acinetobacter baumannii mediated by a mutation in trm encoding SAM-dependent methyltransferase. J. Antimicrob. Chemother. 69, 72-76. doi: 10.1093/jac/dkt319

Chen, T. L., Lee, Y. T., Kuo, S. C., Hsueh, P. R., Chang, F. Y., Siu, L. K., et al. (2010). Emergence and distribution of plasmids bearing the bla $a_{\mathrm{OXA}-51^{-}}$ like gene with an upstream ISAbal in carbapenem-resistant Acinetobacter baumannii isolates in Taiwan. Antimicrob. Agents Chemother. 54, 4575-4581. doi: 10.1128/AAC.00764-10

Chen, T. L., Wu, R. C., Shaio, M. F., Fung, C. P., and Cho, W. L. (2008). Acquisition

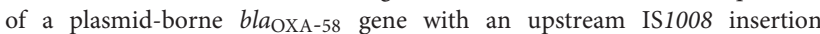
conferring a high level of carbapenem resistance to Acinetobacter baumannii. Antimicrob. Agents Chemother. 52, 2573-2580. doi: 10.1128/AAC.00393-08

Chen, Y., Zhou, Z., Jiang, Y., and Yu, Y. (2011). Emergence of NDM-1-producing Acinetobacter baumannii in China. J. Antimicrob. Chemother. 66, 1255-1259. doi: $10.1093 / \mathrm{jac} / \mathrm{dkr} 082$

Chihi, H., Bonnin, R. A., Bourouis, A., Mahrouki, S., Besbes, S., Moussa, M. B., et al. (2016). GES-11-producing Acinetobacter baumannii clinical 
isolates from Tunisian hospitals: long-term dissemination of GES-type carbapenemases in North Africa. J. Glob. Antimicrob. Resist. 5, 47-50. doi: 10.1016/j.jgar.2016.03.005

Chin, C. Y., Gregg, K. A., Napier, B. A., Ernst, R. K., and Weiss, D. S. (2015). A PmrB-regulated deacetylase required for lipid A modification and polymyxin resistance in Acinetobacter baumannii. Antimicrob. Agents Chemother. 59, 7911-7914. doi: 10.1128/AAC.00515-15

Chiu, C. H., Liu, Y. H., Wang, Y. C., Lee, Y. T., Kuo, S. C., Chen, T. L., et al. (2016). In vitro activity of SecA inhibitors in combination with carbapenems against carbapenem-hydrolysing class D $\beta$-lactamase-producing Acinetobacter baumannii. J. Antimicrob. Chemother. 71, 3441-3448. doi: 10.1093/jac/dkw331

Cho, Y. J., Moon, D. C., Jin, J. S., Choi, C. H., Lee, Y. C., and Lee, J. C. (2009). Genetic basis of resistance to aminoglycosides in Acinetobacter spp. and spread of armA in Acinetobacter baumannii sequence group 1 in Korean hospitals. Diagn. Microbiol. Infect. Dis. 64, 185-190. doi: 10.1016/j.diagmicrobio.2009.02.010

Choi, C. H., Hyun, S. H., Lee, J. Y., Lee, J. S., Lee, Y. S., Kim, S. A., et al. (2008a). Acinetobacter baumannii outer membrane protein A targets the nucleus and induces cytotoxicity. Cell. Microbiol. 10, 309-319. doi: 10.1111/j.1462-5822.2007.01041.x

Choi, C. H., Lee, E. Y., Lee, Y. C., Park, T. I., Kim, H. J., Hyun, S. H., et al. (2005). Outer membrane protein 38 of Acinetobacter baumannii localizes to the mitochondria and induces apoptosis of epithelial cells. Cell Microbiol. 7, 1127-1138. doi: 10.1111/j.1462-5822.2005.00538.x

Choi, C. H., Lee, J. S., Lee, Y. C., Park, T. I., and Lee, J. C. (2008b). Acinetobacter baumannii invades epithelial cells and outer membrane protein A mediates interactions with epithelial cells. BMC Microbiol. 8:216. doi: 10.1186/1471-2180-8-216

Chu, Y. W., Afzal-Shah, M., Houang, E. T., Palepou, M. I., Lyon, D. J., Woodford, N., et al. (2001). IMP-4, a novel metallo- $\beta$-lactamase from nosocomial Acinetobacter spp. collected in Hong Kong between 1994 and 1998. Antimicrob. Agents Chemother. 45, 710-714. doi: 10.1128/AAC.45.3.710-714.2001

Chung, J. H., Bhat, A., Kim, C. J., Yong, D., and Ryu, C. M. (2016). Combination therapy with polymyxin B and netropsin against clinical isolates of multidrugresistant Acinetobacter baumannii. Sci. Rep. 6:28168. doi: 10.1038/srep28168

Cirioni, O., Simonetti, O., Pierpaoli, E., Barucca, A., Ghiselli, R., Orlando, F., et al. (2016). Colistin enhances therapeutic efficacy of daptomycin or teicoplanin in a murine model of multiresistant Acinetobacter baumannii sepsis. Diagn. Microbiol. Infect. Dis. 86, 392-398. doi: 10.1016/j.diagmicrobio.2016.09.010

Cirz, R. T., and Romesberg, F. E. (2007). Controlling mutation: intervening in evolution as a therapeutic strategy. Crit. Rev. Biochem. Mol. Biol. 42, 341-354. doi: 10.1080/10409230701597741

Cisneros, J. M., and Rodríguez-Baño, J. (2002). Nosocomial bacteremia due to Acinetobacter baumannii: epidemiology, clinical features and treatment. Clin. Microbiol. Infect. 8, 687-693. doi: 10.1046/j.1469-0691.2002.00487.x

Clemmer, K. M., Bonomo, R. A., and Rather, P. N. (2011). Genetic analysis of surface motility in Acinetobacter baumannii. Microbiology 157, 2534-2544. doi: 10.1099/mic.0.049791-0

Corbin, B. D., Seeley, E. H., Raab, A., Feldmann, J., Miller, M. R., Torres, V. J., et al. (2008). Metal chelation and inhibition of bacterial growth in tissue abscesses. Science 319, 962-965. doi: 10.1126/science.1152449

Cordoba, J., Coronado-Alvarez, N. M., Parra, D., and Parra-Ruiz, J. (2015). In vitro activities of novel antimicrobial combinations against extensively drug-resistant Acinetobacter baumannii. Antimicrob. Agents Chemother. 59, 7316-7319. doi: 10.1128/AAC.00493-15

Corvec, S., Caroff, N., Espaze, E., Giraudeau, C., Drugeon, H., and Reynaud, A. (2003). AmpC cephalosporinase hyperproduction in Acinetobacter baumannii clinical strains. J. Antimicrob. Chemother. 52, 629-635. doi: 10.1093/jac/ dkg407

Corvec, S., Poirel, L., Naas, T., Drugeon, H., and Nordmann, P. (2007). Genetics and expression of the carbapenem-hydrolyzing oxacillinase gene bla $a_{\mathrm{OXA}-23}$ in Acinetobacter baumannii. Antimicrob. Agents Chemother. 51, 1530-1533. doi: 10.1128/AAC.01132-06

Coyne, S., Courvalin, P., and Perichon, B. (2011). Efflux-mediated antibiotic resistance in Acinetobacter spp. Antimicrob. Agents Chemother. 55, 947-953. doi: 10.1128/AAC.01388-10

Coyne, S., Rosenfeld, N., Lambert, T., Courvalin, P., and Perichon, B. (2010). Overexpression of resistance-nodulation-cell division pump AdeFGH confers multidrug resistance in Acinetobacter baumannii. Antimicrob. Agents Chemother. 54, 4389-4393. doi: 10.1128/AAC.00155-10
Croxatto, A., Prod'hom, G., and Greub, G. (2012). Applications of MALDI-TOF mass spectrometry in clinical diagnostic microbiology. FEMS Microbiol. Rev. 36, 380-407. doi: 10.1111/j.1574-6976.2011.00298.x

Curcio, D., and Fernandez, F. (2008). Tigecycline for Acinetobacter baumannii infection: other considerations. Clin. Infect. Dis. 46, 1797-1798; author reply 1798-1799. doi: 10.1086/588051

Damier-Piolle, L., Magnet, S., Bremont, S., Lambert, T., and Courvalin, P. (2008). AdeIJK, a resistance-nodulation-cell division pump effluxing multiple antibiotics in Acinetobacter baumannii. Antimicrob. Agents Chemother. 52, 557-562. doi: 10.1128/AAC.00732-07

Davison, M., Treangen, T. J., Koren, S., Pop, M., and Bhaya, D. (2016). Diversity in a polymicrobial community revealed by analysis of viromes, endolysins and CRISPR spacers. PLoS ONE 11:e0160574. doi: 10.1371/journal.pone.0160574

de Breij, A., Dijkshoorn, L., Lagendijk, E., van der Meer, J., Koster, A., Bloemberg, G., et al. (2010). Do biofilm formation and interactions with human cells explain the clinical success of Acinetobacter baumannii? PLoS ONE 5:e10732. doi: 10.1371/journal.pone.0010732

Defraine, V., Schuermans, J., Grymonprez, B., Govers, S. K., Aertsen, A., Fauvart, M., et al. (2016). Efficacy of artilysin Art-175 against resistant and persistent Acinetobacter baumannii. Antimicrob. Agents Chemother. 60, 3480-3488. doi: 10.1128/AAC.00285-16

del Mar Tomas, M., Beceiro, A., Perez, A., Velasco, D., Moure, R., Villanueva, R., et al. (2005). Cloning and functional analysis of the gene encoding the 33- to 36-kilodalton outer membrane protein associated with carbapenem resistance in Acinetobacter baumannii. Antimicrob. Agents Chemother. 49, 5172-5175. doi: 10.1128/AAC.49.12.5172-5175.2005

Deng, M., Zhu, M. H., Li, J. J., Bi, S., Sheng, Z. K., Hu, F. S., et al. (2014). Molecular epidemiology and mechanisms of tigecycline resistance in clinical isolates of Acinetobacter baumannii from a Chinese university hospital. Antimicrob. Agents Chemother. 58, 297-303. doi: 10.1128/AAC.01727-13

de Sa Cavalcanti, F. L., Mendes-Marques, C. L., Vasconcelos, C. R., de Lima Campos, T., Rezende, A. M., Xavier, D. E., et al. (2016). High frequency of OXA-253-producing Acinetobacter baumannii in different hospitals in Recife, Brazil: a new threat? Antimicrob. Agents Chemother. 61:e01309-16. doi: 10.1128/AAC.01309-16

Dhabaan, G. N., AbuBakar, S., Cerqueira, G. M., Al-Haroni, M., Pang, S. P., and Hassan, H. (2015). Imipenem treatment induces expression of important genes and phenotypes in a resistant Acinetobacter baumannii isolate. Antimicrob. Agents Chemother. 60, 1370-1376. doi: 10.1128/AAC.01696-15

Dijkshoorn, L., Aucken, H., Gerner-Smidt, P., Janssen, P., Kaufmann, M. E., Garaizar, J., et al. (1996). Comparison of outbreak and nonoutbreak Acinetobacter baumannii strains by genotypic and phenotypic methods. J. Clin. Microbiol. 34, 1519-1525.

Dizbay, M., Tozlu, D. K., Cirak, M. Y., Isik, Y., Ozdemir, K., and Arman, D. (2010). In vitro synergistic activity of tigecycline and colistin against XDR-Acinetobacter baumannii. J. Antibiot. (Tokyo) 63, 51-53. doi: 10.1038/ja.2009.117

Doi, Y., Murray, G. L., and Peleg, A. Y. (2015). Acinetobacter baumannii: evolution of antimicrobial resistance-treatment options. Semin. Respir. Crit. Care Med. 36, 85-98. doi: 10.1055/s-0034-1398388

Doi, Y., Wachino, J., Yamane, K., Shibata, N., Yagi, T., Shibayama, K., et al. (2004). Spread of novel aminoglycoside resistance gene aac (6' $)$-Iad among Acinetobacter clinical isolates in Japan. Antimicrob. Agents Chemother. 48, 2075-2080. doi: 10.1128/AAC.48.6.2075-2080.2004

Donnarumma, F., Sergi, S., Indorato, C., Mastromei, G., Monnanni, R., Nicoletti, P., et al. (2010). Molecular characterization of acinetobacter isolates collected in intensive care units of six hospitals in Florence, Italy, during a 3-year surveillance program: a population structure analysis. J. Clin. Microbiol. 48, 1297-1304. doi: 10.1128/JCM.01916-09

Dortet, L., Bonnin, R. A., Bernabeu, S., Escaut, L., Vittecoq, D., Girlich, D., et al. (2016). First occurrence of OXA-72-producing Acinetobacter baumannii in Serbia. Antimicrob. Agents Chemother. 60, 5724-5730. doi: 10.1128/AAC.01016-16

Dubois, D., Prasadarao, N. V., Mittal, R., Bret, L., Roujou-Gris, M., and Bonnet, R. (2009). CTX-M $\beta$-lactamase production and virulence of Escherichia coli K1. Emerg. Infect. Dis. 15, 1988-1990. doi: 10.3201/eid1512. 090928

Dubrovskaya, Y., Prasad, N., Lee, Y., Esaian, D., Figueroa, D. A., and Tam, V. H. (2015). Risk factors for nephrotoxicity onset associated with polymyxin B therapy. J. Antimicrob. Chemother. 70, 1903-1907. doi: 10.1093/jac/dkv014 
Dupont, M., Pages, J. M., Lafitte, D., Siroy, A., and Bollet, C. (2005). Identification of an OprD homologue in Acinetobacter baumannii. J. Proteome. Res. 4, 2386-2390. doi: 10.1021/pr050143q

Elhosseiny, N. M., Amin, M. A., Yassin, A. S., and Attia, A. S. (2015). Acinetobacter baumannii universal stress protein A plays a pivotal role in stress response and is essential for pneumonia and sepsis pathogenesis. Int. J. Med. Microbiol. 305, 114-123. doi: 10.1016/j.ijmm.2014.11.008

Elhosseiny, N. M., El-Tayeb, O. M., Yassin, A. S., Lory, S., and Attia, A. S. (2016). The secretome of Acinetobacter baumannii ATCC 17978 type II secretion system reveals a novel plasmid encoded phospholipase that could be implicated in lung colonization. Int. J. Med. Microbiol. 306, 633-641. doi: 10.1016/j.ijmm.2016.09.006

Ellis, T. N., and Kuehn, M. J. (2010). Virulence and immunomodulatory roles of bacterial outer membrane vesicles. Microbiol. Mol. Biol. Rev. 74, 81-94. doi: 10.1128/MMBR.00031-09

Endimiani, A., Luzzaro, F., Migliavacca, R., Mantengoli, E., Hujer, A. M., Hujer, K. M., et al. (2007). Spread in an Italian hospital of a clonal Acinetobacter baumannii strain producing the TEM-92 extended-spectrum $\beta$-lactamase. Antimicrob. Agents Chemother. 51, 2211-2214. doi: 10.1128/AAC.01139-06

Erridge, C., Moncayo-Nieto, O. L., Morgan, R., Young, M., and Poxton, I. R. (2007). Acinetobacter baumannii lipopolysaccharides are potent stimulators of human monocyte activation via Toll-like receptor 4 signalling. J. Med. Microbiol. 56, 165-171. doi: 10.1099/jmm.0.46823-0

Espinal, P., Fugazza, G., Lopez, Y., Kasma, M., Lerman, Y., Malhotra-Kumar, S., et al. (2011). Dissemination of an NDM-2-producing Acinetobacter baumannii clone in an Israeli rehabilitation center. Antimicrob. Agents Chemother. 55, 5396-5398. doi: 10.1128/AAC.00679-11

Evans, B. A., Brown, S., Hamouda, A., Findlay, J., and Amyes, S. G. (2007). Eleven novel OXA-51-like enzymes from clinical isolates of Acinetobacter baumannii. Clin. Microbiol. Infect. 13, 1137-1138. doi: 10.1111/j.1469-0691.2007.01828.x

Fajardo Bonin, R., Chapeaurouge, A., Perales, J., da Silva, J. G. Jr., do Nascimento, H. J., D'Alincourt Carvalho Assef, A. P., et al. (2014). Identification of immunogenic proteins of the bacterium Acinetobacter baumannii using a proteomic approach. Proteomics Clin. Appl. 8, 916-923. doi: $10.1002 /$ prca.201300133

Fan, B., Guan, J., Wang, X., and Cong, Y. (2016). Activity of colistin in combination with meropenem, tigecycline, fosfomycin, fusidic acid, rifampin or sulbactam against extensively drug-resistant Acinetobacter baumannii in a murine thighinfection model. PLoS ONE 11:e0157757. doi: 10.1371/journal.pone.0157757

Fang, F., Wang, S., Dang, Y. X., Wang, X., and Yu, G. Q. (2016). Molecular characterization of carbapenemase genes in Acinetobacter baumannii in China. Genet. Mol. Res. 15:gmr7432. doi: 10.4238/gmr.15017432

Fernandez-Cuenca, F., Smani, Y., Gomez-Sanchez, M. C., Docobo-Perez, F., Caballero-Moyano, F. J., Dominguez-Herrera, J., et al. (2011). Attenuated virulence of a slow-growing pandrug-resistant Acinetobacter baumannii is associated with decreased expression of genes encoding the porins CarO and OprD-like. Int. J. Antimicrob. Agents 38, 548-549. doi: 10.1016/j.ijantimicag.2011.08.002

Fernando, D., and Kumar, A. (2012). Growth phase-dependent expression of RND efflux pump- and outer membrane porin-encoding genes in Acinetobacter baumannii ATCC 19606. J. Antimicrob. Chemother. 67, 569-572. doi: $10.1093 / \mathrm{jac} / \mathrm{dkr} 519$

Fiester, S. E., Arivett, B. A., Schmidt, R. E., Beckett, A. C., Ticak, T., Carrier, M. V., et al. (2016). Iron-regulated phospholipase C activity contributes to the cytolytic activity and virulence of Acinetobacter baumannii. PLoS ONE 11:e0167068. doi: 10.1371/journal.pone.0167068

Flores-Diaz, M., Monturiol-Gross, L., Naylor, C., Alape-Giron, A., and Flieger, A. (2016). Bacterial sphingomyelinases and phospholipases as virulence factors. Microbiol. Mol. Biol. Rev. 80, 597-628. doi: 10.1128/MMBR. 00082-15

Fonseca, E. L., Scheidegger, E., Freitas, F. S., Cipriano, R., and Vicente, A. C. (2013). Carbapenem-resistant Acinetobacter baumannii from Brazil: role of carO alleles expression and bla $a_{\mathrm{OXA}-23}$ gene. BMC Microbiol. 13:245. doi: 10.1186/1471-2180-13-245

Fournier, P. E., and Richet, H. (2006). The epidemiology and control of Acinetobacter baumannii in health care facilities. Clin. Infect. Dis. 42, 692-699. doi: $10.1086 / 500202$

Fournier, P. E., Vallenet, D., Barbe, V., Audic, S., Ogata, H., Poirel, L., et al. (2006). Comparative genomics of multidrug resistance in Acinetobacter baumannii. PLoS Genet. 2:e7. doi: 10.1371/journal.pgen.0020007
Fulnecky, E. J., Wright, D., Scheld, W. M., Kanawati, L., and Shoham, S. (2005). Amikacin and colistin for treatment of Acinetobacter baumannii meningitis. J. Infect. 51, e249-e251. doi: 10.1016/j.jinf.2005.04.003

Gaddy, J. A., Arivett, B. A., McConnell, M. J., Lopez-Rojas, R., Pachon, J., and Actis, L. A. (2012). Role of acinetobactin-mediated iron acquisition functions in the interaction of Acinetobacter baumannii strain ATCC 19606T with human lung epithelial cells, Galleria mellonella caterpillars, and mice. Infect. Immun. 80, 1015-1024. doi: 10.1128/IAI.06279-11

Gaddy, J. A., Tomaras, A. P., and Actis, L. A. (2009). The Acinetobacter baumannii 19606 OmpA protein plays a role in biofilm formation on abiotic surfaces and in the interaction of this pathogen with eukaryotic cells. Infect. Immun. 77, 3150-3160. doi: 10.1128/IAI.00096-09

Gales, A. C., Tognim, M. C., Reis, A. O., Jones, R. N., and Sader, H. S. (2003). Emergence of an IMP-like metallo-enzyme in an Acinetobacter baumannii clinical strain from a Brazilian teaching hospital. Diagn. Microbiol. Infect. Dis. 45, 77-79. doi: 10.1016/S0732-8893(02)00500-X

Gallego, L., and Towner, K. J. (2001). Carriage of class 1 integrons and antibiotic resistance in clinical isolates of Acinetobacter baumannii from northern Spain. J. Med. Microbiol. 50, 71-77. doi: 10.1099/0022-1317-50-1-71

Garcia-Quintanilla, M., Carretero-Ledesma, M., Moreno-Martinez, P., MartinPena, R., Pachon, J., and McConnell, M. J. (2015). Lipopolysaccharide loss produces partial colistin dependence and collateral sensitivity to azithromycin, rifampicin and vancomycin in Acinetobacter baumannii. Int. J. Antimicrob. Agents 46, 696-702. doi: 10.1016/j.ijantimicag.2015.07.017

Garcia-Salguero, C., Rodriguez-Avial, I., Picazo, J. J., and Culebras, E. (2015). Can plazomicin alone or in combination be a therapeutic pption against carbapenem-resistant Acinetobacter baumannii? Antimicrob. Agents Chemother. 59, 5959-5966. doi: 10.1128/AAC.00873-15

Gebhardt, M. J., Gallagher, L. A., Jacobson, R. K., Usacheva, E. A., Peterson, L. R., Zurawski, D. V., et al. (2015). Joint transcriptional control of virulence and resistance to antibiotic and environmental stress in Acinetobacter baumannii. MBio 6, e01660-15. doi: 10.1128/mBio.01660-15

Gehrlein, M., Leying, H., Cullmann, W., Wendt, S., and Opferkuch, W. (1991). Imipenem resistance in Acinetobacter baumanii is due to altered penicillinbinding proteins. Chemotherapy 37, 405-412.

Geisinger, E., and Isberg, R. R. (2015). Antibiotic modulation of capsular exopolysaccharide and virulence in Acinetobacter baumannii. PLoS Pathog. 11:e1004691. doi: 10.1371/journal.ppat.1004691

Giannouli, M., Tomasone, F., Agodi, A., Vahaboglu, H., Daoud, Z., Triassi, M., et al. (2009). Molecular epidemiology of carbapenem-resistant Acinetobacter baumannii strains in intensive care units of multiple Mediterranean hospitals. J. Antimicrob. Chemother. 63, 828-830. doi: 10.1093/jac/dkp032

Gogou, V., Pournaras, S., Giannouli, M., Voulgari, E., Piperaki, E. T., Zarrilli, R., et al. (2011). Evolution of multidrug-resistant Acinetobacter baumannii clonal lineages: a 10 year study in Greece (2000-09). J. Antimicrob. Chemother. 66, 2767-2772. doi: 10.1093/jac/dkr390

Goic-Barisic, I., Towner, K. J., Kovacic, A., Sisko-Kraljevic, K., Tonkic, M., Novak, A., et al. (2011). Outbreak in Croatia caused by a new carbapenem-resistant clone of Acinetobacter baumannii producing OXA-72 carbapenemase. J. Hosp. Infect. 77, 368-369. doi: 10.1016/j.jhin.2010.12.003

Gonzalez-Villoria, A. M., Tamayo-Legorreta, E., Garza-Ramos, U., Barrios, H., Sanchez-Perez, A., Rodriguez-Medina, N., et al. (2016). A multicenter study in Mexico finds Acinetobacter baumannii clinical isolates belonging to clonal complexes 636B (113B) and 92B harboring OXA-72, OXA-239, and OXA469. Antimicrob. Agents Chemother. 60, 2587-2588. doi: 10.1128/AAC.0 2042-15

Gordon, N. C., and Wareham, D. W. (2009). A review of clinical and microbiological outcomes following treatment of infections involving multidrug-resistant Acinetobacter baumannii with tigecycline. J. Antimicrob. Chemother. 63, 775-780. doi: 10.1093/jac/dkn555

Gordon, N. C., and Wareham, D. W. (2010). Multidrug-resistant Acinetobacter baumannii: mechanisms of virulence and resistance. Int. J. Antimicrob. Agents 35, 219-226. doi: 10.1016/j.ijantimicag.2009.10.024

Hagihara, M., Housman, S. T., Nicolau, D. P., and Kuti, J. L. (2014). In vitro pharmacodynamics of polymyxin $\mathrm{B}$ and tigecycline alone and in combination against carbapenem-resistant Acinetobacter baumannii. Antimicrob. Agents Chemother. 58, 874-879. doi: 10.1128/AAC. 01624-13

Hammerstrom, T. G., Beabout, K., Clements, T. P., Saxer, G., and Shamoo, Y. (2015). Acinetobacter baumannii repeatedly evolves a hypermutator phenotype 
in response to tigecycline that effectively surveys evolutionary trajectories to resistance. PLoS ONE 10:e0140489. doi: 10.1371/journal.pone.0140489

Hamouda, A., Evans, B. A., Towner, K. J., and Amyes, S. G. (2010). Characterization of epidemiologically unrelated Acinetobacter baumannii isolates from four continents by use of multilocus sequence typing, pulsed-field gel electrophoresis, and sequence-based typing of $b l a_{\mathrm{OXA}}-51$-like genes. J. Clin. Microbiol. 48, 2476-2483. doi: 10.1128/JCM.02431-09

Harding, C. M., Kinsella, R. L., Palmer, L. D., Skaar, E. P., and Feldman, M. F. (2016). Medically relevant Acinetobacter species require a type II secretion system and specific membrane-associated chaperones for the export of multiple substrates and full virulence. PLoS Pathog. 12:e1005391. doi: 10.1371/journal.ppat.1005391

Hasani, A., Sheikhalizadeh, V., Ahangarzadeh Rezaee, M., Rahmati-Yamchi, M., Hasani, A., Ghotaslou, R., et al. (2016). Frequency of aminoglycosidemodifying enzymes and ArmA among different sequence groups of Acinetobacter baumannii in Iran. Microb. Drug Resist. 22, 347-353. doi: $10.1089 / \mathrm{mdr} .2015 .0254$

Hassan, A., Naz, A., Obaid, A., Paracha, R. Z., Naz, K., Awan, F. M., et al. (2016). Pangenome and immuno-proteomics analysis of Acinetobacter baumannii strains revealed the core peptide vaccine targets. BMC Genomics. 17:732. doi: 10.1186/s12864-016-2951-4

Hawley, J. S., Murray, C. K., and Jorgensen, J. H. (2007). Development of colistindependent Acinetobacter baumannii-Acinetobacter calcoaceticus complex. Antimicrob. Agents Chemother. 51, 4529-4530. doi: 10.1128/AAC.01115-07

He, S., He, H., Chen, Y., Chen, Y., Wang, W., and Yu, D. (2015). In vitro and in vivo analysis of antimicrobial agents alone and in combination against multi-drug resistant Acinetobacter baumannii. Front. Microbiol. 6, 507. doi: $10.3389 /$ fmicb.2015.00507

He, X., Lu, F., Yuan, F., Jiang, D., Zhao, P., Zhu, J., et al. (2015). Biofilm formation caused by clinical Acinetobacter baumannii isolates is associated with overexpression of the AdeFGH efflux pump. Antimicrob. Agents Chemother. 59, 4817-4825. doi: 10.1128/AAC.00877-15

Heritier, C., Poirel, L., Aubert, D., and Nordmann, P. (2003). Genetic and functional analysis of the chromosome-encoded carbapenem-hydrolyzing oxacillinase OXA-40 of Acinetobacter baumannii. Antimicrob. Agents Chemother. 47, 268-273. doi: 10.1128/AAC.47.1.268-273.2003

Heritier, C., Poirel, L., Fournier, P. E., Claverie, J. M., Raoult, D., and Nordmann, P. (2005a). Characterization of the naturally occurring oxacillinase of Acinetobacter baumannii. Antimicrob. Agents Chemother. 49, 4174-4179. doi: 10.1128/AAC.49.10.4174-4179.2005

Heritier, C., Poirel, L., Lambert, T., and Nordmann, P. (2005b). Contribution of acquired carbapenem-hydrolyzing oxacillinases to carbapenem resistance in Acinetobacter baumannii. Antimicrob. Agents Chemother. 49, 3198-3202. doi: 10.1128/AAC.49.8.3198-3202.2005

Heritier, C., Poirel, L., and Nordmann, P. (2006). Cephalosporinase overexpression resulting from insertion of ISAba1 in Acinetobacter baumannii. Clin. Microbiol. Infect. 12, 123-130. doi: 10.1111/j.1469-0691.2005.01320.x

Higgins, P. G., Janssen, K., Fresen, M. M., Wisplinghoff, H., and Seifert, H. (2012). Molecular epidemiology of Acinetobacter baumannii bloodstream isolates obtained in the United States from 1995 to 2004 using rep-PCR and multilocus sequence typing. J. Clin. Microbiol. 50, 3493-3500. doi: 10.1128/JCM. 01759-12

Higgins, P. G., Perez-Llarena, F. J., Zander, E., Fernandez, A., Bou, G., and Seifert, H. (2013). OXA-235, a novel class D $\beta$-lactamase involved in resistance to carbapenems in Acinetobacter baumannii. Antimicrob. Agents Chemother. 57, 2121-2126. doi: 10.1128/AAC.02413-12

Higgins, P. G., Poirel, L., Lehmann, M., Nordmann, P., and Seifert, H. (2009). OXA-143, a novel carbapenem-hydrolyzing class D $\beta$-lactamase in Acinetobacter baumannii. Antimicrob. Agents Chemother. 53, 5035-5038. doi: 10.1128/AAC.00856-09

Higgins, P. G., Wisplinghoff, H., Stefanik, D., and Seifert, H. (2004). Selection of topoisomerase mutations and overexpression of adeB mRNA transcripts during an outbreak of Acinetobacter baumannii. J. Antimicrob. Chemother. 54, 821-823. doi: $10.1093 / \mathrm{jac} / \mathrm{dkh} 427$

Hiraki, Y., Yoshida, M., Masuda, Y., Inoue, D., Tsuji, Y., Kamimura, H., et al. (2013). Successful treatment of skin and soft tissue infection due to carbapenem-resistant Acinetobacter baumannii by ampicillin-sulbactam and meropenem combination therapy. Int. J. Infect. Dis. 17, e1234-e1236. doi: 10.1016/j.ijid.2013.05.002
Hogg, G. M., Barr, J. G., and Webb, C. H. (1998). In-vitro activity of the combination of colistin and rifampicin against multidrug-resistant strains of Acinetobacter baumannii. J Antimicrob Chemother. 41, 494-495.

Hong, S. B., Shin, K. S., Ha, J., and Han, K. (2013). Co-existence of bla OXA-23 and armA in multidrug-resistant Acinetobacter baumannii isolated from a hospital in South Korea. J. Med. Microbiol. 62, 836-844. doi: 10.1099/jmm.0.055384-0

Hong, Y. K., Lee, J. Y., Wi, Y. M., and Ko, K. S. (2016). High rate of colistin dependence in Acinetobacter baumannii. J. Antimicrob. Chemother. 71, 2346-2348. doi: 10.1093/jac/dkw121

Hood, M. I., Jacobs, A. C., Sayood, K., Dunman, P. M., and Skaar, E. P. (2010). Acinetobacter baumannii increases tolerance to antibiotics in response to monovalent cations. Antimicrob. Agents Chemother. 54, 1029-1041. doi: 10.1128/AAC.00963-09

Hood, M. I., Mortensen, B. L., Moore, J. L., Zhang, Y., Kehl-Fie, T. E., Sugitani, N., et al. (2012). Identification of an Acinetobacter baumannii zinc acquisition system that facilitates resistance to calprotectin-mediated zinc sequestration. PLoS Pathog. 8:e1003068. doi: 10.1371/journal.ppat.1003068

Hornsey, M., Ellington, M. J., Doumith, M., Thomas, C. P., Gordon, N. C., Wareham, D. W., et al. (2010). AdeABC-mediated efflux and tigecycline MICs for epidemic clones of Acinetobacter baumannii. J. Antimicrob. Chemother. 65, 1589-1593. doi: 10.1093/jac/dkq218

Hornsey, M., Loman, N., Wareham, D. W., Ellington, M. J., Pallen, M. J., Turton, J. F., et al. (2011). Whole-genome comparison of two Acinetobacter baumannii isolates from a single patient, where resistance developed during tigecycline therapy. J. Antimicrob. Chemother. 66, 1499-1503. doi: 10.1093/jac/dkr168

Hornsey, M., and Wareham, D. W. (2011). In vivo efficacy of glycopeptide-colistin combination therapies in a Galleria mellonella model of Acinetobacter baumannii infection. Antimicrob. Agents Chemother. 55, 3534-3537. doi: 10.1128/AAC.00230-11

Hou, C., and Yang, F. (2015). Drug-resistant gene of blaXX-23, bla OXA-24, bla $a_{\mathrm{OXA}-51}$ and bla $a_{\mathrm{OXA}-58}$ in Acinetobacter baumannii. Int. J. Clin. Exp. Med. 8, 13859-13863.

Houang, E. T., Chu, Y. W., Chu, K. Y., Ng, K. C., Leung, C. M., and Cheng, A. F. (2003). Significance of genomic DNA group delineation in comparative studies of antimicrobial susceptibility of Acinetobacter spp. Antimicrob. Agents Chemother. 47, 1472-1475. doi: 10.1128/AAC.47.4.1472-1475.2003

Hu, D., Liu, B., Dijkshoorn, L., Wang, L., and Reeves, P. R. (2013). Diversity in the major polysaccharide antigen of Acinetobacter baumannii assessed by DNA sequencing, and development of a molecular serotyping scheme. PLoS ONE 8:e70329. doi: 10.1371/journal.pone.0070329

Hu, W. S., Yao, S. M., Fung, C. P., Hsieh, Y. P., Liu, C. P., and Lin, J. F. (2007). An OXA-66/OXA-51-like carbapenemase and possibly an efflux pump are associated with resistance to imipenem in Acinetobacter baumannii. Antimicrob. Agents Chemother. 51, 3844-3852. doi: 10.1128/AAC.01512-06

Huang, W., Yao, Y., Long, Q., Yang, X., Sun, W., Liu, C., et al. (2014). Immunization against multidrug-resistant Acinetobacter baumannii effectively protects mice in both pneumonia and sepsis models. PLoS ONE 9:e100727. doi: 10.1371/journal.pone.0100727

Huang, W., Yao, Y., Wang, S., Xia, Y., Yang, X., Long, Q., et al. (2016). Immunization with a $22-\mathrm{kDa}$ outer membrane protein elicits protective immunity to multidrug-resistant Acinetobacter baumannii. Sci. Rep. 6:20724. doi: $10.1038 /$ srep20724

Hujer, K. M., Hamza, N. S., Hujer, A. M., Perez, F., Helfand, M. S., Bethel, C. R., et al. (2005). Identification of a new allelic variant of the Acinetobacter baumannii cephalosporinase, ADC-7 $\beta$-lactamase: defining a unique family of class C enzymes. Antimicrob. Agents Chemother. 49, 2941-2948. doi: 10.1128/AAC.49.7.2941-2948.2005

Iwashkiw, J. A., Seper, A., Weber, B. S., Scott, N. E., Vinogradov, E., Stratilo, C., et al. (2012). Identification of a general O-linked protein glycosylation system in Acinetobacter baumannii and its role in virulence and biofilm formation. PLoS Pathog. 8:e1002758. doi: 10.1371/journal.ppat. 1002758

Jacobs, A. C., Hood, I., Boyd, K. L., Olson, P. D., Morrison, J. M., Carson, S., et al. (2010). Inactivation of phospholipase D diminishes Acinetobacter baumannii pathogenesis. Infect. Immun. 78, 1952-1962. doi: 10.1128/IAI.00889-09

Jara, L. M., Perez-Varela, M., Corral, J., Arch, M., Cortes, P., Bou, G., et al. (2015). Novobiocin inhibits the antimicrobial resistance acquired through DNA damage-induced mutagenesis in Acinetobacter baumannii. Antimicrob. Agents Chemother. 60, 637-639. doi: 10.1128/AAC.01810-15 
Jaruratanasirikul, S., Wongpoowarak, W., Wattanavijitkul, T., Sukarnjanaset, W., Samaeng, M., Nawakitrangsan, M., et al. (2016). Population pharmacokinetics and pharmacodynamics modeling to optimize dosage regimens of sulbactam in critically ill patients with severe sepsis caused by Acinetobacter baumannii. Antimicrob. Agents Chemother. 60, 7236-7244. doi: 10.1128/AAC.01669-16

Jeon, J. H., Lee, J. H., Lee, J. J., Park, K. S., Karim, A. M., Lee, C. R., et al. (2015). Structural basis for carbapenem-hydrolyzing mechanisms of carbapenemases conferring antibiotic resistance. Int. J. Mol. Sci. 16, 9654-9692. doi: 10.3390/ijms16059654

Jeon, J., Ryu, C. M., Lee, J. Y., Park, J. H., Yong, D., and Lee, K. (2016). In vivo application of bacteriophage as a potential therapeutic agent to control OXA-66-like carbapenemase-producing Acinetobacter baumannii strains belonging to sequence type 357. Appl. Environ. Microbiol. 82, 4200-4208. doi: 10.1128/AEM.00526-16

Jeong, H. W., Cheong, H. J., Kim, W. J., Kim, M. J., Song, K. J., Song, J. W., et al. (2009). Loss of the 29-kilodalton outer membrane protein in the presence of OXA-51-like enzymes in Acinetobacter baumannii is associated with decreased imipenem susceptibility. Microb. Drug Resist. 15, 151-158. doi: $10.1089 / \mathrm{mdr} .2009 .0828$

Jeong, S. H., Bae, I. K., Kwon, S. B., Lee, K., Yong, D., Woo, G. J., et al. (2005). Investigation of a nosocomial outbreak of Acinetobacter baumannii producing PER-1 extended-spectrum $\beta$-lactamase in an intensive care unit. J. Hosp. Infect. 59, 242-248. doi: 10.1016/j.jhin.2004.09.025

Jin, J. S., Kwon, S. O., Moon, D. C., Gurung, M., Lee, J. H., Kim, S. I., et al. (2011). Acinetobacter baumannii secretes cytotoxic outer membrane protein A via outer membrane vesicles. PLoS ONE 6:e17027. doi: 10.1371/journal.pone.0017027

Johnson, T. L., Waack, U., Smith, S., Mobley, H., and Sandkvist, M. (2015). Acinetobacter baumannii is dependent on the type II secretion system and its substrate LipA for lipid utilization and in vivo fitness. J. Bacteriol. 198, 711-719. doi: 10.1128/JB.00622-15

Jones, C. L., Clancy, M., Honnold, C., Singh, S., Snesrud, E., Onmus-Leone, F., et al. (2015). Fatal outbreak of an emerging clone of extensively drugresistant Acinetobacter baumannii with enhanced virulence. Clin. Infect. Dis. 61, 145-154. doi: 10.1093/cid/civ225

Jun, S. H., Lee, J. H., Kim, B. R., Kim, S. I., Park, T. I., Lee, J. C., et al. (2013). Acinetobacter baumannii outer membrane vesicles elicit a potent innate immune response via membrane proteins. PLOS ONE 8:e71751. doi: 10.1371/journal.pone.0071751

Juttukonda, L. J., Chazin, W. J., and Skaar, E. P. (2016). Acinetobacter baumannii coordinates urea metabolism with metal import to resist host-mediated metal limitation. MBio 7:e01475-16. doi: 10.1128/mBio.01475-16

Kalin, G., Alp, E., Akin, A., Coskun, R., and Doganay, M. (2014). Comparison of colistin and colistin/sulbactam for the treatment of multidrug resistant Acinetobacter baumannii ventilator-associated pneumonia. Infection. 42, 37-42. doi: 10.1007/s15010-013-0495-y

Kaplan, J. B. (2011). Antibiotic-induced biofilm formation. Int. J. Artif. Organs. 34, 737-751. doi: 10.5301/ijao.5000027

Karthikeyan, K., Thirunarayan, M. A., and Krishnan, P. (2010). Coexistence of bla $a_{\mathrm{OXA}-23}$ with $b a_{\mathrm{NDM}-1}$ and armA in clinical isolates of Acinetobacter baumannii from India. J. Antimicrob. Chemother. 65, 2253-2254. doi: $10.1093 / \mathrm{jac} / \mathrm{dkq} 273$

Kenyon, J. J., and Hall, R. M. (2013). Variation in the complex carbohydrate biosynthesis loci of Acinetobacter baumannii genomes. PLoS ONE 8:e62160. doi: 10.1371/journal.pone.0062160

Kim, C. K., Lee, Y., Lee, H., Woo, G. J., Song, W., Kim, M. N., et al. (2010). Prevalence and diversity of carbapenemases among imipenem-nonsusceptible Acinetobacter isolates in Korea: emergence of a novel OXA-182. Diagn. Microbiol. Infect. Dis. 68, 432-438. doi: 10.1016/j.diagmicrobio.2010.07.014

Kim, S. W., Choi, C. H., Moon, D. C., Jin, J. S., Lee, J. H., Shin, J. H., et al. (2009). Serum resistance of Acinetobacter baumannii through the binding of factor $\mathrm{H}$ to outer membrane proteins. FEMS Microbiol. Lett. 301, 224-231. doi: 10.1111/j.1574-6968.2009.01820.x

Kim, Y. J., Kim, S. I., Kim, Y. R., Hong, K. W., Wie, S. H., Park, Y. J., et al. (2012). Carbapenem-resistant Acinetobacter baumannii: diversity of resistant mechanisms and risk factors for infection. Epidemiol. Infect. 140, 137-145. doi: $10.1017 /$ S0950268811000744

Knight, D., Dimitrova, D. D., Rudin, S. D., Bonomo, R. A., and Rather, P. N. (2016). Mutations decreasing intrinsic $\beta$-lactam resistance are linked to cell division in the nosocomial pathogen Acinetobacter baumannii. Antimicrob. Agents Chemother. 60, 3751-3758. doi: 10.1128/AAC.00361-16

Kobayashi, N., Nishino, K., and Yamaguchi, A. (2001). Novel macrolide-specific ABC-type efflux transporter in Escherichia coli. J. Bacteriol. 183, 5639-5644. doi: 10.1128/JB.183.19.5639-5644.2001

Koeleman, J. G., Stoof, J., Biesmans, D. J., Savelkoul, P. H., and VandenbrouckeGrauls, C. M. (1998). Comparison of amplified ribosomal DNA restriction analysis, random amplified polymorphic DNA analysis, and amplified fragment length polymorphism fingerprinting for identification of Acinetobacter genomic species and typing of Acinetobacter baumannii. J. Clin. Microbiol. 36, 2522-2529.

Koeleman, J. G., van der Bijl, M. W., Stoof, J., Vandenbroucke-Grauls, C. M., and Savelkoul, P. H. (2001). Antibiotic resistance is a major risk factor for epidemic behavior of Acinetobacter baumannii. Infect. Control Hosp Epidemiol. 22, 284-288. doi: 10.1086/501901

Koenigs, A., Stahl, J., Averhoff, B., Gottig, S., Wichelhaus, T. A., Wallich, R., et al. (2016). CipA of Acinetobacter baumannii is a novel plasminogen binding and complement inhibitory protein. J. Infect. Dis. 213, 1388-1399. doi: 10.1093/infdis/jiv601

Koenigs, A., Zipfel, P. F., and Kraiczy, P. (2015). Translation elongation factor Tuf of Acinetobacter baumannii is a plasminogen-binding protein. PLOS ONE 10:e0134418. doi: 10.1371/journal.pone.0134418

Koh, T. H., Sng, L. H., Wang, G. C., Hsu, L. Y., and Zhao, Y. (2007). IMP4 and OXA beta-lactamases in Acinetobacter baumannii from Singapore. J. Antimicrob. Chemother. 59, 627-632. doi: 10.1093/jac/dkl544

Koh, T. H., Tan, T. T., Khoo, C. T., Ng, S. Y., Tan, T. Y., Hsu, L. Y., et al. (2012). Acinetobacter calcoaceticus-Acinetobacter baumannii complex species in clinical specimens in Singapore. Epidemiol. Infect. 140, 535-538. doi: $10.1017 /$ S0950268811001129

Kohlenberg, A., Brummer, S., Higgins, P. G., Sohr, D., Piening, B. C., de Grahl, C., et al. (2009). Outbreak of carbapenem-resistant Acinetobacter baumannii carrying the carbapenemase OXA-23 in a German university medical centre. J. Med. Microbiol. 58, 1499-1507. doi: 10.1099/jmm.0.012302-0

Konstantinidis, T., Kambas, K., Mitsios, A., Panopoulou, M., Tsironidou, V., Dellaporta, E., et al. (2016). Immunomodulatory role of clarithromycin in Acinetobacter baumannii infection via formation of neutrophil extracellular traps. Antimicrob. Agents Chemother. 60, 1040-1048. doi: 10.1128/AAC.02063-15

Koomanachai, P., Kim, A., and Nicolau, D. P. (2009). Pharmacodynamic evaluation of tigecycline against Acinetobacter baumannii in a murine pneumonia model. J. Antimicrob. Chemother. 63, 982-987. doi: $10.1093 / \mathrm{jac} / \mathrm{dkp} 056$

Korotkov, K. V., Sandkvist, M., and Hol, W. G. (2012). The type II secretion system: biogenesis, molecular architecture and mechanism. Nat. Rev. Microbiol. 10, 336-351. doi: 10.1038/nrmicro2762

Kostoulias, X., Murray, G. L., Cerqueira, G. M., Kong, J. B., Bantun, F., Mylonakis, E., et al. (2015). Impact of a cross-kingdom signaling molecule of Candida albicans on Acinetobacter baumannii physiology. Antimicrob. Agents Chemother. 60, 161-167. doi: 10.1128/AAC.01540-15

Krizova, L., Poirel, L., Nordmann, P., and Nemec, A. (2013). TEM-1 $\beta$-lactamase as a source of resistance to sulbactam in clinical strains of Acinetobacter baumannii. J. Antimicrob. Chemother. 68, 2786-2791. doi: 10.1093/jac/ $\mathrm{dkt} 275$

Kulp, A., and Kuehn, M. J. (2010). Biological functions and biogenesis of secreted bacterial outer membrane vesicles. Annu. Rev. Microbiol. 64, 163-184. doi: 10.1146/annurev.micro.091208.073413

Kumar, M. (2016). Identification of a novel NDM variant, $b l a_{N D M-3}$, from a multidrug-resistant Acinetobacter baumannii. Infect. Control. Hosp. Epidemiol. 37, 747-748. doi: 10.1017/ice.2016.66

Kuo, H. Y., Hsu, P. J., Chen, J. Y., Liao, P. C., Lu, C. W., Chen, C. H., et al. (2016). Clonal spread of bla $\mathrm{OXA}_{-72}$-carrying Acinetobacter baumannii sequence type 512 in Taiwan. Int. J. Antimicrob. Agents 48, 111-113. doi: 10.1016/j.ijantimicag.2016.04.020

Kuo, H. Y., Yang, C. M., Lin, M. F., Cheng, W. L., Tien, N., and Liou, M. L. (2010). Distribution of bla OXA-carrying imipenem-resistant Acinetobacter spp. in 3 hospitals in Taiwan. Diagn. Microbiol. Infect. Dis. 66, 195-199. doi: 10.1016/j.diagmicrobio.2009.09.013

Kuo, L. C., Lai, C. C., Liao, C. H., Hsu, C. K., Chang, Y. L., Chang, C. Y., et al. (2007). Multidrug-resistant Acinetobacter baumannii bacteraemia: 
clinical features, antimicrobial therapy and outcome. Clin. Microbiol. Infect. 13, 196-198. doi: 10.1111/j.1469-0691.2006.01601.x

Kuo, S. C., Chang, S. C., Wang, H. Y., Lai, J. F., Chen, P. C., Shiau, Y. R., et al. (2012). Emergence of extensively drug-resistant Acinetobacter baumannii complex over 10 years: nationwide data from the Taiwan Surveillance of Antimicrobial Resistance (TSAR) program. BMC Infect Dis. 12:200. doi: 10.1186/1471-2334-12-200

Kusradze, I., Karumidze, N., Rigvava, S., Dvalidze, T., Katsitadze, M., Amiranashvili, I., et al. (2016). Characterization and testing the efficiency of Acinetobacter baumannii phage $v B-G E C \_A b-M-G 7$ as an antibacterial agent. Front. Microbiol. 7:1590. doi: 10.3389/fmicb.2016.01590

Kwon, S. O., Gho, Y. S., Lee, J. C., and Kim, S. I. (2009). Proteome analysis of outer membrane vesicles from a clinical Acinetobacter baumannii isolate. FEMS Microbiol. Lett. 297, 150-156. doi: 10.1111/j.1574-6968.2009.01669.x

La Scola, B., Gundi, V. A., Khamis, A., and Raoult, D. (2006). Sequencing of the $r p o B$ gene and flanking spacers for molecular identification of Acinetobacter species. J. Clin. Microbiol. 44, 827-832. doi: 10.1128/JCM.44.3.827-832.2006

Lee, C. H., Tang, Y. F., Su, L. H., Chien, C. C., and Liu, J. W. (2008). Antimicrobial effects of varied combinations of meropenem, sulbactam, and colistin on a multidrug-resistant Acinetobacter baumannii isolate that caused meningitis and bacteremia. Microb. Drug Resist. 14, 233-237. doi: 10.1089/mdr.2008.0840

Lee, C. R., Cho, I. H., Jeong, B. C., and Lee, S. H. (2013a). Strategies to minimize antibiotic resistance. Int. J. Environ. Res. Public Health. 10, 4274-4305. doi: 10.3390/ijerph10094274

Lee, C. R., Lee, J. H., Jeong, B. C., and Lee, S. H. (2013b). Lipid a biosynthesis of multidrug-resistant pathogens - a novel drug target. Curr. Pharm. Des. 19, 6534-6550. doi: 10.2174/13816128113199990494

Lee, C. R., Lee, J. H., Park, K. S., Jeong, B. C., and Lee, S. H. (2015). Quantitative proteomic view associated with resistance to clinically important antibiotics in Gram-positive bacteria: a systematic review. Front. Microbiol. 6:828. doi: 10.3389/fmicb.2015.00828

Lee, C. R., Lee, J. H., Park, K. S., Kim, Y. B., Jeong, B. C., and Lee, S. H. (2016). Global Dissemination of Carbapenemase-Producing Klebsiella pneumoniae: epidemiology, Genetic Context, Treatment Options, and Detection Methods. Front. Microbiol. 7:895. doi: 10.3389/fmicb.2016.00895

Lee, J. H., Choi, C. H., Kang, H. Y., Lee, J. Y., Kim, J., Lee, Y. C., et al. (2007). Differences in phenotypic and genotypic traits against antimicrobial agents between Acinetobacter baumannii and Acinetobacter genomic species 13TU. J. Antimicrob. Chemother. 59, 633-639. doi: 10.1093/jac/dkm007

Lee, J. H., Lee, J. J., Park, K. S., and Lee, S. H. (2015). Urgent need for $\beta$-lactam- $\beta$-lactamase inhibitors. Lancet Infect. Dis. $15,876-877$. doi: 10.1016/S1473-3099(15)00143-7

Lee, J. H., Park, K. S., Karim, A. M., Lee, C. R., and Lee, S. H. (2016). How to minimise antibiotic resistance. Lancet Infect. Dis. 16, 17-18. doi: 10.1016/S1473-3099(15)00467-3

Lee, J. S., Choi, C. H., Kim, J. W., and Lee, J. C. (2010). Acinetobacter baumannii outer membrane protein A induces dendritic cell death through mitochondrial targeting. J. Microbiol. 48, 387-392. doi: 10.1007/s12275-010-0155-1

Lee, K., Yum, J. H., Yong, D., Lee, H. M., Kim, H. D., Docquier, J. D., et al. (2005). Novel acquired metallo- $\beta$-lactamase gene, $b l a_{S I M-1}$, in a class 1 integron from Acinetobacter baumannii clinical isolates from Korea. Antimicrob. Agents Chemother. 49, 4485-4491. doi: 10.1128/AAC.49.11.4485-4491.2005

Lee, M. F., Peng, C. F., Hsu, H. J., and Chen, Y. H. (2008). Molecular characterisation of the metallo- $\beta$-lactamase genes in imipenem-resistant Gramnegative bacteria from a university hospital in southern Taiwan. Int. J. Antimicrob. Agents 32, 475-480. doi: 10.1016/j.ijantimicag.2008.07.009

Lee, Y., Kim, C. K., Lee, H., Jeong, S. H., Yong, D., and Lee, K. (2011). A novel insertion sequence, ISAba10, inserted into ISAbal adjacent to the bla $_{\mathrm{OXA}-23}$ gene and disrupting the outer membrane protein gene carO in Acinetobacter baumannii. Antimicrob. Agents Chemother. 55, 361-363. doi: 10.1128/AAC.01672-09

Lee, Y. T., Tsao, S. M., and Hsueh, P. R. (2013). Clinical outcomes of tigecycline alone or in combination with other antimicrobial agents for the treatment of patients with healthcare-associated multidrug-resistant Acinetobacter baumannii infections. Eur. J. Clin. Microbiol Infect Dis. 32, 1211-1220. doi: 10.1007/s10096-013-1870-4

Lees-Miller, R. G., Iwashkiw, J. A., Scott, N. E., Seper, A., Vinogradov, E., Schild, S., et al. (2013). A common pathway for O-linked protein-glycosylation and synthesis of capsule in Acinetobacter baumannii. Mol. Microbiol. 89, 816-830. doi: $10.1111 / \mathrm{mmi} .12300$

Lenhard, J. R., Bulitta, J. B., Connell, T. D., King-Lyons, N., Landersdorfer, C. B., Cheah, S. E., et al. (2016a). High-intensity meropenem combinations with polymyxin B: new strategies to overcome carbapenem resistance in Acinetobacter baumannii. J. Antimicrob. Chemother. 72, 153-165. doi: 10.1093/jac/dkw355

Lenhard, J. R., Gall, J. S., Bulitta, J. B., Thamlikitkul, V., Landersdorfer, C. B., Forrest, A., et al. (2016b). Comparative pharmacodynamics of four different carbapenems in combination with polymyxin B against carbapenemresistant Acinetobacter baumannii. Int. J. Antimicrob. Agents 48, 719-724. doi: 10.1016/j.ijantimicag.2016.07.024

Li, L., Hassan, K. A., Brown, M. H., and Paulsen, I. T. (2016). Rapid multiplexed phenotypic screening identifies drug resistance functions for three novel efflux pumps in Acinetobacter baumannii. J. Antimicrob. Chemother. 71, 1223-1232. doi: $10.1093 / \mathrm{jac} / \mathrm{dkv} 460$

Li, X., Liu, L., Ji, J., Chen, Q., Hua, X., Jiang, Y., et al. (2015). Tigecycline resistance in Acinetobacter baumannii mediated by frameshift mutation in $p l s C$, encoding 1-acyl-sn-glycerol-3-phosphate acyltransferase. Eur. J. Clin. Microbiol. Infect. Dis. 34, 625-631. doi: 10.1007/s10096-014-2272-y

Li, X. M., Choi, J. A., Choi, I. S., Kook, J. K., Chang, Y. H., Park, G., et al. (2016). Development and evaluation of species-specific PCR for detection of nine Acinetobacter species. Ann. Clin. Lab. Sci. 46, 270-278.

Li, X., Quan, J., Yang, Y., Ji, J., Liu, L., Fu, Y., et al. (2016). Abrp, a new gene, confers reduced susceptibility to tetracycline, glycylcine, chloramphenicol and fosfomycin classes in Acinetobacter baumannii. Eur. J. Clin. Microbiol. Infect. Dis. 35, 1371-1375. doi: 10.1007/s10096-016-2674-0

Li, Y., Guo, Q., Wang, P., Zhu, D., Ye, X., Wu, S., et al. (2015). Clonal dissemination of extensively drug-resistant Acinetobacter baumannii producing an OXA-23 $\beta$-lactamase at a teaching hospital in Shanghai, China. J. Microbiol. Immunol. Infect. 48, 101-108. doi: 10.1016/j.jmii.2014.04.005

Li, Z. T., Zhang, R. L., Bi, X. G., Xu, L., Fan, M., Xie, D., et al. (2015). Outer membrane vesicles isolated from two clinical Acinetobacter baumannii strains exhibit different toxicity and proteome characteristics. Microb. Pathog. 81, 46-52. doi: 10.1016/j.micpath.2015.03.009

Liang, W., Liu, X. F., Huang, J., Zhu, D. M., Li, J., and Zhang, J. (2011). Activities of colistin- and minocycline-based combinations against extensive drug resistant Acinetobacter baumannii isolates from intensive care unit patients. BMC Infect. Dis. 11:109. doi: 10.1186/1471-2334-11-109

Liao, Y. T., Kuo, S. C., Chiang, M. H., Lee, Y. T., Sung, W. C., Chen, Y. H., et al. (2015). Acinetobacter baumannii extracellular OXA-58 is primarily and selectively released via outer membrane vesicles after Sec-dependent periplasmic translocation. Antimicrob. Agents Chemother. 59, 7346-7354. doi: 10.1128/AAC.01343-15

Lin, L., Tan, B., Pantapalangkoor, P., Ho, T., Baquir, B., Tomaras, A., et al. (2012). Inhibition of LpxC protects mice from resistant Acinetobacter baumannii by modulating inflammation and enhancing phagocytosis. MBio 3:e00312-12. doi: $10.1128 / \mathrm{mBio} .00312-12$

Lin, L., Tan, B., Pantapalangkoor, P., Ho, T., Hujer, A. M., Taracila, M. A., et al. (2013). Acinetobacter baumannii rOmpA vaccine dose alters immune polarization and immunodominant epitopes. Vaccine 31, 313-318. doi: 10.1016/j.vaccine.2012.11.008

Lin, M. F., Chang, K. C., Lan, C. Y., Chou, J., Kuo, J. W., Chang, C. K., et al. (2011a). Molecular epidemiology and antimicrobial resistance determinants of multidrug-resistant Acinetobacter baumannii in five proximal hospitals in Taiwan. Jpn. J. Infect. Dis. 64, 222-227.

Lin, M. F., Chang, K. C., Yang, C. Y., Yang, C. M., Xiao, C. C., Kuo, H. Y., et al. (2010). Role of integrons in antimicrobial susceptibility patterns of Acinetobacter baumannii. Jpn. J. Infect. Dis. 63, 440-443.

Lin, M. F., Kuo, H. Y., Yeh, H. W., Yang, C. M., Sung, C. H., Tu, C. C., et al. (2011b). Emergence and dissemination of bla $a_{\mathrm{OXA}-23}$-carrying imipenemresistant Acinetobacter sp. in a regional hospital in Taiwan. J. Microbiol. Immunol. Infect. 44, 39-44. doi: 10.1016/j.jmii.2011.01.008

Lin, M. F., and Lan, C. Y. (2014). Antimicrobial resistance in Acinetobacter baumannii: from bench to bedside. World J. Clin. Cases. 2, 787-814. doi: 10.12998/wjcc.v2.i12.787

Lin, M. F., Lin, Y. Y., and Lan, C. Y. (2015). The role of the twocomponent system BaeSR in disposing chemicals through regulating 
transporter systems in Acinetobacter baumannii. PLoS ONE 10:e0132843. doi: 10.1371/journal.pone.0132843

Lin, M. F., Lin, Y. Y., Yeh, H. W., and Lan, C. Y. (2014). Role of the BaeSR two-component system in the regulation of Acinetobacter baumannii adeAB genes and its correlation with tigecycline susceptibility. BMC Microbiol. 14:119. doi: 10.1186/1471-2180-14-119

Lin, M. F., Liou, M. L., Tu, C. C., Yeh, H. W., and Lan, C. Y. (2013). Molecular epidemiology of integron-associated antimicrobial gene cassettes in the clinical isolates of Acinetobacter baumannii from northern Taiwan. Ann. Lab. Med. 33, 242-247. doi: 10.3343/alm.2013.33.4.242

Liou, M. L., Soo, P. C., Ling, S. R., Kuo, H. Y., Tang, C. Y., and Chang, K. C. (2014). The sensor kinase BfmS mediates virulence in Acinetobacter baumannii. J. Microbiol. Immunol. Infect. 47, 275-281. doi: 10.1016/j.jmii.2012.12.004

Liu, C. C., Kuo, H. Y., Tang, C. Y., Chang, K. C., and Liou, M. L. (2014). Prevalence and mapping of a plasmid encoding a type IV secretion system in Acinetobacter baumannii. Genomics. 104, 215-223. doi: 10.1016/j.ygeno.2014.07.011

Liu, D., Liu, Z. S., Hu, P., Cai, L., Fu, B. Q., Li, Y. S., et al. (2016). Characterization of surface antigen protein 1 (SurA1) from Acinetobacter baumannii and its role in virulence and fitness. Vet. Microbiol. 186, 126-138. doi: 10.1016/j.vetmic.2016.02.018

Liu, Q., Li, W., Feng, Y., and Tao, C. (2014). Efficacy and safety of polymyxins for the treatment of Acinectobacter baumannii infection: a systematic review and meta-analysis. PLoS ONE 9:e98091. doi: 10.1371/journal.pone.0098091

Liu, X., Zhao, M., Chen, Y., Bian, X., Li, Y., Shi, J., et al. (2016). Synergistic killing by meropenem and colistin combination of carbapenem-resistant Acinetobacter baumannii isolates from Chinese patients in an in vitro pharmacokinetic/pharmacodynamic model. Int. J. Antimicrob. Agents 48, 559-563. doi: 10.1016/j.ijantimicag.2016.07.018

Liu, Y., and Liu, X. (2015). Detection of AmpC $\beta$-lactamases in Acinetobacter baumannii in the Xuzhou region and analysis of drug resistance. Exp. Ther. Med. 10, 933-936. doi: 10.3892/etm.2015.2612

Lolans, K., Rice, T. W., Munoz-Price, L. S., and Quinn, J. P. (2006). Multicity outbreak of carbapenem-resistant Acinetobacter baumannii isolates producing the carbapenemase OXA-40. Antimicrob. Agents Chemother. 50, 2941-2945. doi: 10.1128/AAC.00116-06

Lomovskaya, O., and Lewis, K. (1992). Emr, an Escherichia coli locus for multidrug resistance. Proc. Natl. Acad. Sci. U.S.A. 89, 8938-8942.

Luke, N. R., Sauberan, S. L., Russo, T. A., Beanan, J. M., Olson, R., Loehfelm, T. W., et al. (2010). Identification and characterization of a glycosyltransferase involved in Acinetobacter baumannii lipopolysaccharide core biosynthesis. Infect. Immun. 78, 2017-2023. doi: 10.1128/IAI.00016-10

Luo, G., Lin, L., Ibrahim, A. S., Baquir, B., Pantapalangkoor, P., Bonomo, R. A., et al. (2012). Active and passive immunization protects against lethal, extreme drug resistant-Acinetobacter baumannii infection. PLoS ONE 7:e29446. doi: 10.1371/journal.pone.0029446

Lu, P. L., Doumith, M., Livermore, D. M., Chen, T. P., and Woodford, N. (2009). Diversity of carbapenem resistance mechanisms in Acinetobacter baumannii from a Taiwan hospital: spread of plasmid-borne OXA-72 carbapenemase. J. Antimicrob. Chemother. 63, 641-647. doi: 10.1093/jac/dkn553

Magnet, S., Courvalin, P., and Lambert, T. (2001). Resistance-nodulationcell division-type efflux pump involved in aminoglycoside resistance in Acinetobacter baumannii strain BM4454. Antimicrob. Agents Chemother. 45, 3375-3380. doi: 10.1128/AAC.45.12.3375-3380.2001

Mak, J. K., Kim, M. J., Pham, J., Tapsall, J., and White, P. A. (2009). Antibiotic resistance determinants in nosocomial strains of multidrugresistant Acinetobacter baumannii. J. Antimicrob. Chemother. 63, 47-54. doi: $10.1093 / \mathrm{jac} / \mathrm{dkn} 454$

Marchand, I., Damier-Piolle, L., Courvalin, P., and Lambert, T. (2004). Expression of the RND-type efflux pump AdeABC in Acinetobacter baumannii is regulated by the AdeRS two-component system. Antimicrob. Agents Chemother. 48, 3298-3304. doi: 10.1128/AAC.48.9.3298-3304.2004

Martinez-Guitian, M., Vazquez-Ucha, J. C., Odingo, J., Parish, T., Poza, M., Waite, R. D., et al. (2016). Synergy between colistin and the signal peptidase inhibitor MD3 is dependent on the mechanism of colistin resistance in Acinetobacter baumannii. Antimicrob. Agents Chemother. 60, 4375-4379. doi: 10.1128/AAC.00510-16

Martinez, T., Martinez, I., Vazquez, G. J., Aquino, E. E., and Robledo, I. E. (2016). Genetic environment of the KPC gene in Acinetobacter baumannii ST2 clone from Puerto Rico and genomic insights into its drug resistance. J. Med. Microbiol. 65, 784-792. doi: 10.1099/jmm.0.000289

McConnell, M. J., Actis, L., and Pachon, J. (2013). Acinetobacter baumannii: human infections, factors contributing to pathogenesis and animal models. FEMS Microbiol. Rev. 37, 130-155. doi: 10.1111/j.1574-6976.2012.00344.x

McConnell, M. J., Rumbo, C., Bou, G., and Pachon, J. (2011). Outer membrane vesicles as an acellular vaccine against Acinetobacter baumannii. Vaccine 29, 5705-5710. doi: 10.1016/j.vaccine.2011.06.001

McQueary, C. N., Kirkup, B. C., Si, Y., Barlow, M., Actis, L. A., Craft, D. W., et al. (2012). Extracellular stress and lipopolysaccharide modulate Acinetobacter baumannii surface-associated motility. J. Microbiol. 50, 434-443. doi: 10.1007/s12275-012-1555-1

Megeed, A. A., Hayssam, M. A., Salem, M. Z., El-Shikh, M. S., Talea, I. A., and Alogaibi, Y. A. (2016). Investigation of the virulence factors and molecular characterization of the clonal relations of multidrug-resistant Acinetobacter baumannii isolates. J. AOAC Int. doi: 10.5740/jaoacint.16-0139. [Epub ahead of print].

Mendes, R. E., Bell, J. M., Turnidge, J. D., Castanheira, M., and Jones, R. N. (2009). Emergence and widespread dissemination of OXA-23, -24/40 and 58 carbapenemases among Acinetobacter spp. in Asia-Pacific nations: report from the SENTRY Surveillance Program. J. Antimicrob. Chemother. 63, 55-59. doi: $10.1093 / \mathrm{jac} / \mathrm{dkn} 434$

Mendes, R. E., Farrell, D. J., Sader, H. S., and Jones, R. N. (2010). Comprehensive assessment of tigecycline activity tested against a worldwide collection of Acinetobacter spp. (2005-2009). Diagn. Microbiol. Infect. Dis. 68, 307-311. doi: 10.1016/j.diagmicrobio.2010.07.003

Menegucci, T. C., Albiero, J., Migliorini, L. B., Alves, J. L., Viana, G. F., Mazucheli, J., et al. (2016). Strategies for the treatment of polymyxin B-resistant Acinetobacter baumannii infections. Int. J. Antimicrob. Agents 47, 380-385. doi: 10.1016/j.ijantimicag.2016.02.007

Merino, M., Acosta, J., Poza, M., Sanz, F., Beceiro, A., Chaves, F., et al. (2010). OXA-24 carbapenemase gene flanked by XerC/XerD-like recombination sites in different plasmids from different Acinetobacter species isolated during a nosocomial outbreak. Antimicrob. Agents Chemother. 54, 2724-2727. doi: 10.1128/AAC.01674-09

Moffatt, J. H., Harper, M., Harrison, P., Hale, J. D., Vinogradov, E., Seemann, T., et al. (2010). Colistin resistance in Acinetobacter baumannii is mediated by complete loss of lipopolysaccharide production. Antimicrob. Agents Chemother. 54, 4971-4977. doi: 10.1128/AAC.00834-10

Moland, E. S., Craft, D. W., Hong, S. G., Kim, S. Y., Hachmeister, L., Sayed, S. D., et al. (2008). In vitro activity of tigecycline against multidrug-resistant Acinetobacter baumannii and selection of tigecycline-amikacin synergy. Antimicrob. Agents Chemother. 52, 2940-2942. doi: 10.1128/AAC.01581-07

Montero, A., Ariza, J., Corbella, X., Domenech, A., Cabellos, C., Ayats, J., et al. (2004). Antibiotic combinations for serious infections caused by carbapenemresistant Acinetobacter baumannii in a mouse pneumonia model. J. Antimicrob. Chemother. 54, 1085-1091. doi: 10.1093/jac/dkh485

Moon, D. C., Choi, C. H., Lee, J. H., Choi, C. W., Kim, H. Y., Park, J. S., et al. (2012). Acinetobacter baumannii outer membrane protein A modulates the biogenesis of outer membrane vesicles. J. Microbiol. 50, 155-160. doi: 10.1007/s12275-012-1589-4

Mosqueda, N., Espinal, P., Cosgaya, C., Viota, S., Plasensia, V., Alvarez-Lerma, F., et al. (2013). Globally expanding carbapenemase finally appears in Spain: nosocomial outbreak of Acinetobacter baumannii producing plasmid-encoded OXA-23 in Barcelona, Spain. Antimicrob. Agents Chemother. 57, 5155-5157. doi: 10.1128/AAC.01486-13

Motaouakkil, S., Charra, B., Hachimi, A., Nejmi, H., Benslama, A., Elmdaghri, N., et al. (2006). Colistin and rifampicin in the treatment of nosocomial infections from multiresistant Acinetobacter baumannii. J. Infect. 53, 274-278. doi: $10.1016 /$ j.jinf.2005.11.019

Moubareck, C., Bremont, S., Conroy, M. C., Courvalin, P., and Lambert, T. (2009). GES-11, a novel integron-associated GES variant in Acinetobacter baumannii. Antimicrob. Agents Chemother. 53, 3579-3581. doi: 10.1128/AAC.00072-09

Mougous, J. D., Cuff, M. E., Raunser, S., Shen, A., Zhou, M., Gifford, C. A., et al. (2006). A virulence locus of Pseudomonas aeruginosa encodes a protein secretion apparatus. Science 312, 1526-1530. doi: 10.1126/science.1128393

Moya, B., Juan, C., Alberti, S., Perez, J. L., and Oliver, A. (2008). Benefit of having multiple $\operatorname{ampD}$ genes for acquiring $\beta$-lactam resistance without losing fitness 
and virulence in Pseudomonas aeruginosa. Antimicrob. Agents Chemother. 52, 3694-3700. doi: 10.1128/AAC.00172-08

Mugnier, P. D., Poirel, L., Naas, T., and Nordmann, P. (2010). Worldwide dissemination of the bla $a_{\mathrm{OXA}-23}$ carbapenemase gene of Acinetobacter baumannii. Emerg. Infect. Dis. 16, 35-40. doi: 10.3201/eid1601.090852

Mussi, M. A., Limansky, A. S., and Viale, A. M. (2005). Acquisition of resistance to carbapenems in multidrug-resistant clinical strains of Acinetobacter baumannii: natural insertional inactivation of a gene encoding a member of a novel family of b-barrel outer membrane proteins. Antimicrob. Agents Chemother. 49, 1432-1440. doi: 10.1128/AAC.49.4.1432-1440.2005

Mussi, M. A., Relling, V. M., Limansky, A. S., and Viale, A. M. (2007). CarO, an Acinetobacter baumannii outer membrane protein involved in carbapenem resistance, is essential for L-ornithine uptake. FEBS Lett. 581, 5573-5578. doi: 10.1016/j.febslet.2007.10.063

Muthusamy, D., Sudhishnaa, S., and Boppe, A. (2016). In vitro activities of polymyxins and rifampicin against carbapenem resistant Acinetobacter baumannii at a tertiary care hospital from south India. J. Clin.Diagn. Res. 10, DC15-DC18. doi: 10.7860/JCDR/2016/19968.8535

Mutlu Yilmaz, E., Sunbul, M., Aksoy, A., Yilmaz, H., Guney, A. K., and Guvenc, T. (2012). Efficacy of tigecycline/colistin combination in a pneumonia model caused by extensively drug-resistant Acinetobacter baumannii. Int. J. Antimicrob. Agents 40, 332-336. doi: 10.1016/j.ijantimicag.2012.06.003

Naas, T., Coignard, B., Carbonne, A., Blanckaert, K., Bajolet, O., Bernet, C., et al. (2006). VEB-1 Extended-spectrum $\beta$-lactamase-producing Acinetobacter baumannii, France. Emerg. Infect. Dis. 12, 1214-1222. doi: 10.3201/eid1208. 051547

Naas, T., Levy, M., Hirschauer, C., Marchandin, H., and Nordmann, P. (2005). Outbreak of carbapenem-resistant Acinetobacter baumannii producing the carbapenemase OXA-23 in a tertiary care hospital of Papeete, French Polynesia. J. Clin. Microbiol. 43, 4826-4829. doi: 10.1128/JCM.43.9.4826-4829.2005

Naas, T., Namdari, F., Reglier-Poupet, H., Poyart, C., and Nordmann, P. (2007). Panresistant extended-spectrum $\beta$-lactamase SHV-5-producing Acinetobacter baumannii from New York City. J. Antimicrob. Chemother. 60, 1174-1176. doi: 10.1093/jac/dkm366

Nagano, N., Nagano, Y., Cordevant, C., Shibata, N., and Arakawa, Y. (2004). Nosocomial transmission of CTX-M-2 $\beta$-lactamase-producing Acinetobacter baumannii in a neurosurgery ward. J. Clin. Microbiol. 42, 3978-3984. doi: 10.1128/JCM.42.9.3978-3984.2004

Nairn, B. L., Lonergan, Z. R., Wang, J., Braymer, J. J., Zhang, Y., Calcutt, M. W., et al. (2016). The Response of Acinetobacter baumannii to Zinc Starvation. Cell Host Microbe. 19, 826-836. doi: 10.1016/j.chom.2016.05.007

Navia, M. M., Ruiz, J., and Vila, J. (2002). Characterization of an integron carrying a new class D $\beta$-lactamase (OXA-37) in Acinetobacter baumannii. Microb. Drug Resist. 8, 261-265. doi: 10.1089/10766290260469516

Navon-Venezia, S., Leavitt, A., and Carmeli, Y. (2007). High tigecycline resistance in multidrug-resistant Acinetobacter baumannii. J. Antimicrob. Chemother. 59, 772-774. doi: $10.1093 / \mathrm{jac} / \mathrm{dkm} 018$

Nemec, A., Dolzani, L., Brisse, S., van den Broek, P., and Dijkshoorn, L. (2004). Diversity of aminoglycoside-resistance genes and their association with class 1 integrons among strains of pan-European Acinetobacter baumannii clones. J. Med. Microbiol. 53, 1233-1240. doi: 10.1099/jmm.0.45716-0

Nepka, M., Perivolioti, E., Kraniotaki, E., Politi, L., Tsakris, A., and Pournaras, S. (2016). In vitro bactericidal activity of trimethoprim-sulfamethoxazole alone and in combination with colistin, against carbapenem-resistant Acinetobacter baumannii clinical isolates. Antimicrob. Agents Chemother. doi: 10.1128/AAC.01082-16

Ni, W., Li, Y., Guan, J., Zhao, J., Cui, J., Wang, R., et al. (2016). Effects of efflux pump inhibitors on colistin resistance in multidrug-resistant Gram-negative gacteria. Antimicrob. Agents Chemother. 60, 3215-3218. doi: 10.1128/AAC.00248-16

Norton, M. D., Spilkia, A. J., and Godoy, V. G. (2013). Antibiotic resistance acquired through a DNA damage-inducible response in Acinetobacter baumannii. J. Bacteriol. 195, 1335-1345. doi: 10.1128/JB.02176-12

Nowak-Zaleska, A., Wieczor, M., Czub, J., Nierzwicki, L., Kotlowski, R., Mikucka, A., et al. (2016). Correlation between the number of Pro-Ala repeats in the EmrA homologue of Acinetobacter baumannii and resistance to netilmicin, tobramycin, imipenem and ceftazidime. J. Glob. Antimicrob. Resist. 7, 145-149. doi: 10.1016/j.jgar.2016.09.004
Ozbek, B., and Senturk, A. (2010). Postantibiotic effects of tigecycline, colistin sulfate, and levofloxacin alone or tigecycline-colistin sulfate and tigecyclinelevofloxacin combinations against Acinetobacter baumannii. Chemotherapy 56, 466-471. doi: 10.1159/000321015

Pachon-Ibanez, M. E., Docobo-Perez, F., Lopez-Rojas, R., Dominguez-Herrera, J., Jimenez-Mejias, M. E., Garcia-Curiel, A., et al. (2010). Efficacy of rifampin and its combinations with imipenem, sulbactam, and colistin in experimental models of infection caused by imipenem-resistant Acinetobacter baumannii. Antimicrob. Agents Chemother. 54, 1165-1172. doi: 10.1128/AAC.00367-09

Pachon-Ibanez, M. E., Jimenez-Mejias, M. E., Pichardo, C., Llanos, A. C., and Pachon, J. (2004). Activity of tigecycline (GAR-936) against Acinetobacter baumannii strains, including those resistant to imipenem. Antimicrob. Agents Chemother. 48, 4479-4481. doi: 10.1128/AAC.48.11.4479-4481.2004

Pailhories, H., Kempf, M., Belmonte, O., Joly-Guillou, M. L., and Eveillard, M. (2016). First case of OXA-24-producing Acinetobacter baumannii in cattle from Reunion Island, France. Int. J. Antimicrob. Agents 48, 763-764. doi: 10.1016/j.ijantimicag.2016.09.005

Pankuch, G. A., Lin, G., Seifert, H., and Appelbaum, P. C. (2008). Activity of meropenem with and without ciprofloxacin and colistin against Pseudomonas aeruginosa and Acinetobacter baumannii. Antimicrob. Agents Chemother. 52, 333-336. doi: 10.1128/AAC.00689-07

Pannek, S., Higgins, P. G., Steinke, P., Jonas, D., Akova, M., Bohnert, J. A., et al. (2006). Multidrug efflux inhibition in Acinetobacter baumannii: comparison between 1-(1-naphthylmethyl)-piperazine and phenyl-arginineb-naphthylamide. J. Antimicrob. Chemother. 57, 970-974. doi: 10.1093/jac/ dkl081

Pantopoulou, A., Giamarellos-Bourboulis, E. J., Raftogannis, M., Tsaganos, T., Dontas, I., Koutoukas, P., et al. (2007). Colistin offers prolonged survival in experimental infection by multidrug-resistant Acinetobacter baumannii: the significance of co-administration of rifampicin. Int. J. Antimicrob. Agents 29, 51-55. doi: 10.1016/j.ijantimicag.2006.09.009

Papa, A., Koulourida, V., and Souliou, E. (2009). Molecular epidemiology of carbapenem-resistant Acinetobacter baumannii in a newly established Greek hospital. Microb. Drug Resist. 15, 257-260. doi: 10.1089/mdr.2009.0060

Park, Y. K., and Ko, K. S. (2015). Effect of carbonyl cyanide 3chlorophenylhydrazone (CCCP) on killing Acinetobacter baumannii by colistin. J. Microbiol. 53, 53-59. doi: 10.1007/s12275-015-4498-5

Parra Millan, R., Jimenez Mejias, M. E., Sanchez Encinales, V., Ayerbe Algaba, R., Gutierrez Valencia, A., Pachon Ibanez, M. E., et al. (2016). Efficacy of lysophosphatidylcholine in combination with antimicrobial agents against Acinetobacter baumannii in experimental murine peritoneal sepsis and pneumonia models. Antimicrob. Agents Chemother. 60, 4464-4470. doi: 10.1128/AAC.02708-15

Pasteran, F., Rapoport, M., Petroni, A., Faccone, D., Corso, A., Galas, M., et al. (2006). Emergence of PER-2 and VEB-1a in Acinetobacter baumannii strains in the Americas. Antimicrob. Agents Chemother. 50, 3222-3224. doi: 10.1128/AAC.00284-06

Peck, K. R., Kim, M. J., Choi, J. Y., Kim, H. S., Kang, C. I., Cho, Y. K., et al. (2012). In vitro time-kill studies of antimicrobial agents against blood isolates of imipenem-resistant Acinetobacter baumannii, including colistin- or tigecycline-resistant isolates. J. Med. Microbiol. 61, 353-360. doi: 10.1099/jmm.0.036939-0

Peleg, A. Y., Adams, J., and Paterson, D. L. (2007). Tigecycline efflux as a mechanism for nonsusceptibility in Acinetobacter baumannii. Antimicrob. Agents Chemother. 51, 2065-2069. doi: 10.1128/AAC.01198-06

Peleg, A. Y., Seifert, H., and Paterson, D. L. (2008). Acinetobacter baumannii: emergence of a successful pathogen. Clin. Microbiol. Rev. 21, 538-582. doi: 10.1128/CMR.00058-07

Pelletier, M. R., Casella, L. G., Jones, J. W., Adams, M. D., Zurawski, D. V., Hazlett, K. R., et al. (2013). Unique structural modifications are present in the lipopolysaccharide from colistin-resistant strains of Acinetobacter baumannii. Antimicrob. Agents Chemother. 57, 4831-4840. doi: 10.1128/AAC.00865-13

Penwell, W. F., Arivett, B. A., and Actis, L. A. (2012). The Acinetobacter baumannii entA gene located outside the acinetobactin cluster is critical for siderophore production, iron acquisition and virulence. PLOS ONE 7:e36493. doi: 10.1371/journal.pone.0036493

Perez, A., Merino, M., Rumbo-Feal, S., Alvarez-Fraga, L., Vallejo, J. A., Beceiro, A., et al. (2016). The FhaB/FhaC two-partner secretion system is involved 
in adhesion of Acinetobacter baumannii AbH12O-A2 strain. Virulence. doi: 10.1080/21505594.2016.1262313. [Epub ahead of print].

Perez, F., Hujer, A. M., Hujer, K. M., Decker, B. K., Rather, P. N., and Bonomo, R. A. (2007). Global challenge of multidrug-resistant Acinetobacter baumannii. Antimicrob. Agents Chemother. 51, 3471-3484. doi: 10.1128/AAC.01464-06

Petrosillo, N., Chinello, P., Proietti, M. F., Cecchini, L., Masala, M., Franchi, C., et al. (2005). Combined colistin and rifampicin therapy for carbapenem-resistant Acinetobacter baumannii infections: clinical outcome and adverse events. Clin. Microbiol. Infect. 11, 682-683. doi: 10.1111/j.1469-0691.2005.01198.x

Pfeifer, Y., Wilharm, G., Zander, E., Wichelhaus, T. A., Gottig, S., Hunfeld, K. P., et al. (2011). Molecular characterization of bla $a_{\mathrm{NDM}-1}$ in an Acinetobacter baumannii strain isolated in Germany in 2007. J. Antimicrob. Chemother. 66, 1998-2001. doi: 10.1093/jac/dkr256

Phee, L. M., Betts, J. W., Bharathan, B., and Wareham, D. W. (2015). Colistin and fusidic acid, a novel potent synergistic combination for treatment of multidrugresistant Acinetobacter baumannii infections. Antimicrob. Agents Chemother. 59, 4544-4550. doi: 10.1128/AAC.00753-15

Pichardo, C., Pachon-Ibanez, M. E., Docobo-Perez, F., Lopez-Rojas, R., JimenezMejias, M. E., Garcia-Curiel, A., et al. (2010). Efficacy of tigecycline vs. imipenem in the treatment of experimental Acinetobacter baumannii murine pneumonia. Eur. J. Clin. Microbiol. Infect. Dis. 29, 527-531. doi: 10.1007/s10096-010-0890-6

Pires, J., Siriwardena, T. N., Stach, M., Tinguely, R., Kasraian, S., Luzzaro, F., et al. (2015). In vitro activity of the novel antimicrobial peptide dendrimer G3KL against multidrug-resistant Acinetobacter baumannii and Pseudomonas aeruginosa. Antimicrob. Agents Chemother. 59, 7915-7918. doi: 10.1128/AAC.01853-15

Ploy, M. C., Giamarellou, H., Bourlioux, P., Courvalin, P., and Lambert, T. (1994). Detection of $a a c\left(6^{\prime}\right)$-I genes in amikacin-resistant Acinetobacter spp. by PCR. Antimicrob. Agents Chemother. 38, 2925-2928.

Poirel, L., Cabanne, L., Vahaboglu, H., and Nordmann, P. (2005a). Genetic environment and expression of the extended-spectrum $\beta$-lactamase $b a_{\mathrm{PER}-1}$ gene in gram-negative bacteria. Antimicrob. Agents Chemother. 49, 1708-1713. doi: 10.1128/AAC.49.5.1708-1713.2005

Poirel, L., Corvec, S., Rapoport, M., Mugnier, P., Petroni, A., Pasteran, F., et al. (2007). Identification of the novel narrow-spectrum $\beta$-lactamase SCO1 in Acinetobacter spp. from Argentina. Antimicrob. Agents Chemother. 51, 2179-2184. doi: 10.1128/AAC.01600-06

Poirel, L., Mansour, W., Bouallegue, O., and Nordmann, P. (2008). Carbapenemresistant Acinetobacter baumannii isolates from Tunisia producing the OXA58-like carbapenem-hydrolyzing oxacillinase OXA-97. Antimicrob. Agents Chemother. 52, 1613-1617. doi: 10.1128/AAC.00978-07

Poirel, L., Marque, S., Heritier, C., Segonds, C., Chabanon, G., and Nordmann, P. (2005b). OXA-58, a novel class D $\beta$-lactamase involved in resistance to carbapenems in Acinetobacter baumannii. Antimicrob. Agents Chemother. 49, 202-208. doi: 10.1128/AAC.49.1.202-208.2005

Poirel, L., Mugnier, P. D., Toleman, M. A., Walsh, T. R., Rapoport, M. J., Petroni, A., et al. (2009). ISCR2, another vehicle for bla $a_{\mathrm{VEB}}$ gene acquisition. Antimicrob. Agents Chemother. 53, 4940-4943. doi: 10.1128/AAC.00414-09

Pongpech, P., Amornnopparattanakul, S., Panapakdee, S., Fungwithaya, S., Nannha, P., Dhiraputra, C., et al. (2010). Antibacterial activity of carbapenembased combinations againts multidrug-resistant Acinetobacter baumannii. J. Med. Assoc. Thai. 93, 161-171.

Potron, A., Munoz-Price, L. S., Nordmann, P., Cleary, T., and Poirel, L. (2011). Genetic features of CTX-M-15-producing Acinetobacter baumannii from Haiti. Antimicrob. Agents Chemother. 55, 5946-5948. doi: 10.1128/AAC.05124-11

Potron, A., Poirel, L., Croize, J., Chanteperdrix, V., and Nordmann, P. (2009). Genetic and biochemical characterization of the first extended-spectrum CARB-type b-lactamase, RTG-4, from Acinetobacter baumannii. Antimicrob. Agents Chemother. 53, 3010-3016. doi: 10.1128/AAC.01164-08

Pournaras, S., Markogiannakis, A., Ikonomidis, A., Kondyli, L., Bethimouti, K., Maniatis, A. N., et al. (2006). Outbreak of multiple clones of imipenem-resistant Acinetobacter baumannii isolates expressing OXA-58 carbapenemase in an intensive care unit. J. Antimicrob. Chemother. 57, 557-561. doi: 10.1093/jac/dkl004

Principe, L., Capone, A., Mazzarelli, A., D’Arezzo, S., Bordi, E., Di Caro, A., et al. (2013). In vitro activity of doripenem in combination with various antimicrobials against multidrug-resistant Acinetobacter baumannii: possible options for the treatment of complicated infection. Microb. Drug Resist. 19, 407-414. doi: $10.1089 / \mathrm{mdr} .2012 .0250$

Principe, L., D'Arezzo, S., Capone, A., Petrosillo, N., and Visca, P. (2009). In vitro activity of tigecycline in combination with various antimicrobials against multidrug resistant Acinetobacter baumannii. Ann. Clin. Microbiol. Antimicrob. 8:18. doi: $10.1186 / 1476-0711-8-18$

Principe, L., Piazza, A., Giani, T., Bracco, S., Caltagirone, M. S., Arena, F., et al. (2014). Epidemic diffusion of OXA-23-producing Acinetobacter baumannii isolates in Italy: results of the first cross-sectional countrywide survey. J. Clin. Microbiol. 52, 3004-3010. doi: 10.1128/JCM.00291-14

Pukatzki, S., Ma, A. T., Sturtevant, D., Krastins, B., Sarracino, D., Nelson, W. C., et al. (2006). Identification of a conserved bacterial protein secretion system in Vibrio cholerae using the Dictyostelium host model system. Proc. Natl. Acad. Sci. U.S.A. 103, 1528-1533. doi: 10.1073/pnas.0510322103

Qi, C., Malczynski, M., Parker, M., and Scheetz, M. H. (2008). Characterization of genetic diversity of carbapenem-resistant Acinetobacter baumannii clinical strains collected from 2004 to 2007. J. Clin. Microbiol. 46, 1106-1109. doi: 10.1128/JCM.01877-07

Quale, J., Bratu, S., Landman, D., and Heddurshetti, R. (2003). Molecular epidemiology and mechanisms of carbapenem resistance in Acinetobacter baumannii endemic in New York City. Clin. Infect. Dis. 37, 214-220. doi: $10.1086 / 375821$

Quinteira, S., Grosso, F., Ramos, H., and Peixe, L. (2007). Molecular epidemiology of imipenem-resistant Acinetobacter haemolyticus and Acinetobacter baumannii isolates carrying plasmid-mediated OXA-40 from a Portuguese hospital. Antimicrob. Agents Chemother. 51, 3465-3466. doi: 10.1128/AAC.00267-07

Rafailidis, P. I., Ioannidou, E. N., and Falagas, M. E. (2007). Ampicillin/sulbactam: current status in severe bacterial infections. Drugs 67, 1829-1849. doi: 10.2165/00003495-200767130-00003

Rajamohan, G., Srinivasan, V. B., and Gebreyes, W. A. (2010). Molecular and functional characterization of a novel efflux pump, AmvA, mediating antimicrobial and disinfectant resistance in Acinetobacter baumannii. J. Antimicrob. Chemother. 65, 1919-1925. doi: 10.1093/jac/dkq195

Rakin, A., Schneider, L., and Podladchikova, O. (2012). Hunger for iron: the alternative siderophore iron scavenging systems in highly virulent Yersinia. Front. Cell. Infect. Microbiol. 2:151. doi: 10.3389/fcimb.2012.00151

Ramirez, M. S., Don, M., Merkier, A. K., Bistue, A. J., Zorreguieta, A., Centron, D., et al. (2010a). Naturally competent Acinetobacter baumannii clinical isolate as a convenient model for genetic studies. J. Clin. Microbiol. 48, 1488-1490. doi: 10.1128/JCM.01264-09

Ramirez, M. S., Pineiro, S., Argentinian Integron Study Group, and Centron, D. (2010b). Novel insights about class 2 integrons from experimental and genomic epidemiology. Antimicrob. Agents Chemother. 54, 699-706. doi: 10.1128/AAC.01392-08

Rao, G. G., Ly, N. S., Bulitta, J. B., Soon, R. L., San Roman, M. D., Holden, P. N., et al. (2016a). Polymyxin B in combination with doripenem against heteroresistant Acinetobacter baumannii: pharmacodynamics of new dosing strategies. J. Antimicrob. Chemother. 71, 3148-3156. doi: 10.1093/jac/ dkw293

Rao, G. G., Ly, N. S., Diep, J., Forrest, A., Bulitta, J. B., Holden, P. N., et al. (2016b). Combinatorial pharmacodynamics of polymyxin B and tigecycline against heteroresistant Acinetobacter baumannii. Int. J. Antimicrob. Agents 48, 331-336. doi: 10.1016/j.ijantimicag.2016.06.006

Ravasi, P., Limansky, A. S., Rodriguez, R. E., Viale, A. M., and Mussi, M. A. (2011). ISAba825, a functional insertion sequence modulating genomic plasticity and blaXA-58 expression in Acinetobacter baumannii. Antimicrob. Agents Chemother. 55, 917-920. doi: 10.1128/AAC.00491-10

Reid, G., Food and Agricultural Organization of the United Nation and the WHO (2005). The importance of guidelines in the development and application of probiotics. Curr. Pharm. Des. 11, 11-16. doi: 10.2174/1381612053382395

Repizo, G. D., Gagne, S., Foucault-Grunenwald, M. L., Borges, V., Charpentier, X., Limansky, A. S., et al. (2015). Differential Role of the T6SS in Acinetobacter baumannii Virulence. PLoS ONE 10:e0138265. doi: 10.1371/journal.pone. 0138265

Ribera, A., Roca, I., Ruiz, J., Gibert, I., and Vila, J. (2003a). Partial characterization of a transposon containing the tet $(A)$ determinant in a clinical 
isolate of Acinetobacter baumannii. J. Antimicrob. Chemother. 52, 477-480. doi: $10.1093 / \mathrm{jac} / \mathrm{dkg} 344$

Ribera, A., Ruiz, J., and Vila, J. (2003b). Presence of the Tet M determinant in a clinical isolate of Acinetobacter baumannii. Antimicrob. Agents Chemother. 47, 2310-2312. doi: 10.1128/AAC.47.7.2310-2312.2003

Riccio, M. L., Franceschini, N., Boschi, L., Caravelli, B., Cornaglia, G., Fontana, R., et al. (2000). Characterization of the metallo- $\beta$-lactamase determinant of Acinetobacter baumannii AC-54/97 reveals the existence of bla $a_{\mathrm{IMP}}$ allelic variants carried by gene cassettes of different phylogeny. Antimicrob. Agents Chemother. 44, 1229-1235. doi: 10.1128/AAC.44.5.1229-1235.2000

Ritchie, D. J., and Garavaglia-Wilson, A. (2014). A review of intravenous minocycline for treatment of multidrug-resistant Acinetobacter infections. Clin. Infect. Dis. 59 (Suppl. 6), S374-S380. doi: 10.1093/cid/ciu613

Robledo, I. E., Aquino, E. E., Sante, M. I., Santana, J. L., Otero, D. M., Leon, C. F., et al. (2010). Detection of KPC in Acinetobacter spp. in Puerto Rico. Antimicrob. Agents Chemother. 54, 1354-1357. doi: 10.1128/AAC.00899-09

Roca, I., Marti, S., Espinal, P., Martinez, P., Gibert, I., and Vila, J. (2009). CraA, a major facilitator superfamily efflux pump associated with chloramphenicol resistance in Acinetobacter baumannii. Antimicrob. Agents Chemother. 53, 4013-4014. doi: 10.1128/AAC.00584-09

Rodriguez-Bano, J., Marti, S., Soto, S., Fernandez-Cuenca, F., Cisneros, J. M., Pachon, J., et al. (2008). Biofilm formation in Acinetobacter baumannii: associated features and clinical implications. Clin. Microbiol. Infect. 14, 276-278. doi: 10.1111/j.1469-0691.2007.01916.x

Rodriguez, C. H., De Ambrosio, A., Bajuk, M., Spinozzi, M., Nastro, M., Bombicino, K., et al. (2010). In vitro antimicrobials activity against endemic Acinetobacter baumannii multiresistant clones. J. Infect. Dev. Ctries. 4, 164-167. doi: 10.3855 /jidc. 604

Rodriguez, C. H., Nastro, M., Vay, C., and Famiglietti, A. (2015). In vitro activity of minocycline alone or in combination in multidrugresistant Acinetobacter baumannii isolates. J. Med. Microbiol. 64, 1196-1200. doi: $10.1099 / \mathrm{jmm} .0 .000147$

Rodriguez-Rubio, L., Chang, W. L., Gutierrez, D., Lavigne, R., Martinez, B., Rodriguez, A., et al. (2016). 'Artilysation' of endolysin lambdaSa2lys strongly improves its enzymatic and antibacterial activity against streptococci. Sci. Rep. 6:35382. doi: 10.1038/srep35382

Rosenfeld, N., Bouchier, C., Courvalin, P., and Perichon, B. (2012). Expression of the resistance-nodulation-cell division pump AdeIJK in Acinetobacter baumannii is regulated by AdeN, a TetR-type regulator. Antimicrob. Agents Chemother. 56, 2504-2510. doi: 10.1128/AAC.06422-11

Ruiz, F. M., Santillana, E., Spinola-Amilibia, M., Torreira, E., Culebras, E., and Romero, A. (2015). Crystal Structure of Hcp from Acinetobacter baumannii: a Component of the Type VI Secretion System. PLoS ONE 10:e0129691. doi: 10.1371/journal.pone.0129691

Ruiz, M., Marti, S., Fernandez-Cuenca, F., Pascual, A., and Vila, J. (2007). High prevalence of carbapenem-hydrolysing oxacillinases in epidemiologically related and unrelated Acinetobacter baumannii clinical isolates in Spain. Clin. Microbiol. Infect. 13, 1192-1198. doi: 10.1111/j.1469-0691.2007.01825.x

Rumbo, C., Fernandez-Moreira, E., Merino, M., Poza, M., Mendez, J. A., Soares, N. C., et al. (2011). Horizontal transfer of the OXA-24 carbapenemase gene via outer membrane vesicles: a new mechanism of dissemination of carbapenem resistance genes in Acinetobacter baumannii. Antimicrob. Agents Chemother. 55, 3084-3090. doi: 10.1128/AAC.00929-10

Rumbo, C., Tomas, M., Fernandez Moreira, E., Soares, N. C., Carvajal, M., Santillana, E., et al. (2014). The Acinetobacter baumannii Omp3336 porin is a virulence factor that induces apoptosis and modulates autophagy in human cells. Infect. Immun. 82, 4666-4680. doi: 10.1128/IAI. 02034-14

Rumbo, C., Vallejo, J. A., Cabral, M. P., Martinez-Guitian, M., Perez, A., Beceiro, A., et al. (2016). Assessment of antivirulence activity of several D-amino acids against Acinetobacter baumannii and Pseudomonas aeruginosa. J. Antimicrob. Chemother. 71, 3473-3481. doi: 10.1093/jac/dkw342

Russo, T. A., Beanan, J. M., Olson, R., MacDonald, U., Cox, A. D., St. Michael, F., et al. (2013). The K1 capsular polysaccharide from Acinetobacter baumannii is a potential therapeutic target via passive immunization. Infect. Immun. 81, 915-922. doi: 10.1128/IAI.01184-12

Russo, T. A., Luke, N. R., Beanan, J. M., Olson, R., Sauberan, S. L., MacDonald, U., et al. (2010). The K1 capsular polysaccharide of Acinetobacter baumannii strain 307-0294 is a major virulence factor. Infect. Immun. 78, 3993-4000. doi: 10.1128/IAI.00366-10
Russo, T. A., MacDonald, U., Beanan, J. M., Olson, R., MacDonald, I. J., Sauberan, S. L., et al. (2009). Penicillin-binding protein $7 / 8$ contributes to the survival of Acinetobacter baumannii in vitro and in vivo. J. Infect. Dis. 199, 513-521. doi: $10.1086 / 596317$

Russo, T. A., Manohar, A., Beanan, J. M., Olson, R., MacDonald, U., Graham, J., et al. (2016). The response regulator $\mathrm{BfmR}$ is a potential drug target for Acinetobacter baumannii. mSphere 1:e00082-16. doi: $10.1128 / \mathrm{mSphere} .00082-16$

Ruzin, A., Keeney, D., and Bradford, P. A. (2007). AdeABC multidrug efflux pump is associated with decreased susceptibility to tigecycline in Acinetobacter calcoaceticus-Acinetobacter baumannii complex. J. Antimicrob. Chemother. 59, 1001-1004. doi: 10.1093/jac/dkm058

Saha, R., Saha, N., Donofrio, R. S., and Bestervelt, L. L. (2013). Microbial siderophores: a mini review. J. Basic Microbiol. 53, 303-317. doi: 10.1002/jobm.201100552

Sahly, H., Navon-Venezia, S., Roesler, L., Hay, A., Carmeli, Y., Podschun, R., et al. (2008). Extended-spectrum $\beta$-lactamase production is associated with an increase in cell invasion and expression of fimbrial adhesins in Klebsiella pneumoniae. Antimicrob. Agents Chemother. 52, 3029-3034. doi: 10.1128/AAC.00010-08

Sakoulas, G., Rose, W., Berti, A., Olson, J., Mungia, J., Nonejuie, P., et al. (2016). Classical $\beta$-lactamase inhibitors potentiate the activity of daptomycin against methicillin-resistant Staphylococcus aureus and colistin against Acinetobacter baumannii. Antimicrob. Agents Chemother. 61:e01745-16. doi: 10.1128/AAC.01745-16

Sandri, A. M., Landersdorfer, C. B., Jacob, J., Boniatti, M. M., Dalarosa, M. G., Falci, D. R., et al. (2013). Population pharmacokinetics of intravenous polymyxin B in critically ill patients: implications for selection of dosage regimens. Clin. Infect. Dis. 57, 524-531. doi: 10.1093/cid/cit334

Santimaleeworagun, W., Wongpoowarak, P., Chayakul, P., Pattharachayakul, S., Tansakul, P., and Garey, K. W. (2011). In vitro activity of colistin or sulbactam in combination with fosfomycin or imipenem against clinical isolates of carbapenem-resistant Acinetobacter baumannii producing OXA23 carbapenemases. Southeast Asian J. Trop. Med. Public Health. 42, 890-900.

Schroder, W., Goerke, C., and Wolz, C. (2013). Opposing effects of aminocoumarins and fluoroquinolones on the SOS response and adaptability in Staphylococcus aureus. J. Antimicrob. Chemother. 68, 529-538. doi: 10.1093/ jac/dks456

Sechi, L. A., Karadenizli, A., Deriu, A., Zanetti, S., Kolayli, F., Balikci, E., et al. (2004). PER-1 type $\beta$-lactamase production in Acinetobacter baumannii is related to cell adhesion. Med. Sci. Monit. 10, BR180-BR184.

Segal, H., Nelson, E. C., and Elisha, B. G. (2004). Genetic environment and transcription of $a m p C$ in an Acinetobacter baumannii clinical isolate. Antimicrob. Agents Chemother. 48, 612-614. doi: 10.1128/AAC.48.2.612-614. 2004

Sharma, A., Sharma, R., Bhattacharyya, T., Bhando, T., and Pathania, R. (2016). Fosfomycin resistance in Acinetobacter baumannii is mediated by efflux through a major facilitator superfamily (MFS) transporter-AbaF. J. Antimicrob. Chemother. 72, 68-74. doi: 10.1093/jac/dkw382

Sheng, W. H., Wang, J. T., Li, S. Y., Lin, Y. C., Cheng, A., Chen, Y. C., et al. (2011). Comparative in vitro antimicrobial susceptibilities and synergistic activities of antimicrobial combinations against carbapenemresistant Acinetobacter species: Acinetobacter baumannii versus Acinetobacter genospecies 3 and 13TU. Diagn. Microbiol. Infect. Dis. 70, 380-386. doi: 10.1016/j.diagmicrobio.2011.03.003

Shin, B., and Park, W. (2015). Synergistic effect of oleanolic acid on aminoglycoside antibiotics against Acinetobacter baumannii. PLoS ONE 10:e0137751. doi: 10.1371/journal.pone.0137751

Shneider, M. M., Buth, S. A., Ho, B. T., Basler, M., Mekalanos, J. J., and Leiman, P. G. (2013). PAAR-repeat proteins sharpen and diversify the type VI secretion system spike. Nature 500, 350-353. doi: 10.1038/nature12453

Siroy, A., Molle, V., Lemaitre-Guillier, C., Vallenet, D., Pestel-Caron, M., Cozzone, A. J., et al. (2005). Channel formation by CarO, the carbapenem resistance-associated outer membrane protein of Acinetobacter baumannii. Antimicrob. Agents Chemother. 49, 4876-4883. doi: 10.1128/AAC.49.12.48764883.2005

Skalweit, M. J., and Li, M. (2016). Bulgecin A as a $\beta$-lactam enhancer for carbapenem-resistant Pseudomonas aeruginosa and carbapenem-resistant Acinetobacter baumannii clinical isolates containing various resistance 
mechanisms. Drug Des. Devel. Ther. 10, 3013-3020. doi: 10.2147/DDDT.S 110193

Smani, Y., Dominguez-Herrera, J., and Pachon, J. (2013). Association of the outer membrane protein Omp33 with fitness and virulence of Acinetobacter baumannii. J. Infect. Dis. 208, 1561-1570. doi: 10.1093/infdis/jit386

Smani, Y., Fabrega, A., Roca, I., Sanchez-Encinales, V., Vila, J., and Pachon, J. (2014). Role of OmpA in the multidrug resistance phenotype of Acinetobacter baumannii. Antimicrob. Agents Chemother. 58, 1806-1808. doi: 10.1128/AAC.02101-13

Smani, Y., McConnell, M. J., and Pachon, J. (2012). Role of fibronectin in the adhesion of Acinetobacter baumannii to host cells. PLOS ONE 7:e33073. doi: 10.1371/journal.pone.0033073

Smith, S. G., Mahon, V., Lambert, M. A., and Fagan, R. P. (2007). A molecular Swiss army knife: OmpA structure, function and expression. FEMS Microbiol. Lett. 273, 1-11. doi: 10.1111/j.1574-6968.2007.00778.x

Smolyakov, R., Borer, A., Riesenberg, K., Schlaeffer, F., Alkan, M., Porath, A., et al. (2003). Nosocomial multi-drug resistant Acinetobacter baumannii bloodstream infection: risk factors and outcome with ampicillin-sulbactam treatment. J. Hosp. Infect. 54, 32-38. doi: 10.1016/S0195-6701(03) 00046-X

Songer, J. G. (1997). Bacterial phospholipases and their role in virulence. Trends Microbiol. 5, 156-161. doi: 10.1016/S0966-842X(97)01005-6

Song, J. Y., Lee, J., Heo, J. Y., Noh, J. Y., Kim, W. J., Cheong, H. J., et al. (2008). Colistin and rifampicin combination in the treatment of ventilator-associated pneumonia caused by carbapenem-resistant Acinetobacter baumannii. Int. J. Antimicrob. Agents 32, 281-284. doi: 10.1016/j.ijantimicag.2008.04.013

Srinivasan, V. B., Rajamohan, G., and Gebreyes, W. A. (2009). Role of AbeS, a novel efflux pump of the SMR family of transporters, in resistance to antimicrobial agents in Acinetobacter baumannii. Antimicrob. Agents Chemother. 53, 5312-5316. doi: 10.1128/AAC.00748-09

Srinivasan, V. B., Venkataramaiah, M., Mondal, A., and Rajamohan, G. (2015). Functional characterization of AbeD, an RND-type membrane transporter in antimicrobial resistance in Acinetobacter baumannii. PLOS ONE 10:e141314. doi: 10.1371/journal.pone.0141314

Stahl, J., Bergmann, H., Gottig, S., Ebersberger, I., and Averhoff, B. (2015). Acinetobacter baumannii virulence is mediated by the concerted action of three phospholipases D. PLOS ONE 10:e0138360. doi: 10.1371/journal.pone. 0138360

Stoeva, T., Higgins, P. G., Bojkova, K., and Seifert, H. (2008). Clonal spread of carbapenem-resistant OXA-23-positive Acinetobacter baumannii in a Bulgarian university hospital. Clin. Microbiol. Infect. 14, 723-727. doi: 10.1111/j.1469-0691.2008.02018.x

Su, C. H., Wang, J. T., Hsiung, C. A., Chien, L. J., Chi, C. L., Yu, H. T., et al. (2012). Increase of carbapenem-resistant Acinetobacter baumannii infection in acute care hospitals in Taiwan: association with hospital antimicrobial usage. PLoS ONE 7:e37788. doi: 10.1371/journal.pone.0037788

Sugawara, E., and Nikaido, H. (2012). OmpA is the principal nonspecific slow porin of Acinetobacter baumannii. J. Bacteriol. 194, 4089-4096. doi: 10.1128/JB.00435-12

Sun, J. R., Jeng, W. Y., Perng, C. L., Yang, Y. S., Soo, P. C., Chiang, Y. S., et al. (2016). Single amino acid substitution Gly186Val in AdeS restores tigecycline susceptibility of Acinetobacter baumannii. J. Antimicrob. Chemother. 71, 1488-1492. doi: 10.1093/jac/dkw002

Sun, J. R., Perng, C. L., Chan, M. C., Morita, Y., Lin, J. C., Su, C. M., et al. (2012). A truncated AdeS kinase protein generated by ISAbal insertion correlates with tigecycline resistance in Acinetobacter baumannii. PLoS ONE 7:e49534. doi: 10.1371/journal.pone.0049534

Su, X. Z., Chen, J., Mizushima, T., Kuroda, T., and Tsuchiya, T. (2005). AbeM, an $\mathrm{H}^{+}$-coupled Acinetobacter baumannii multidrug efflux pump belonging to the MATE family of transporters. Antimicrob. Agents Chemother. 49, 4362-4364. doi: 10.1128/AAC.49.10.4362-4364.2005

Tada, T., Miyoshi-Akiyama, T., Shimada, K., Shimojima, M., and Kirikae, T. (2014). Dissemination of 16S rRNA methylase ArmA-producing Acinetobacter baumannii and emergence of OXA-72 carbapenemase coproducers in Japan. Antimicrob. Agents Chemother. 58, 2916-2920. doi: 10.1128/AAC. 01212-13

Taitt, C. R., Leski, T. A., Stockelman, M. G., Craft, D. W., Zurawski, D. V., Kirkup, B. C., et al. (2014). Antimicrobial resistance determinants in Acinetobacter baumannii isolates taken from military treatment facilities. Antimicrob. Agents Chemother. 58, 767-781. doi: 10.1128/AAC.01897-13

Thandar, M., Lood, R., Winer, B. Y., Deutsch, D. R., Euler, C. W., and Fischetti, V. A. (2016). Novel engineered peptides of a phage lysin as effective antimicrobials against multidrug-resistant Acinetobacter baumannii. Antimicrob. Agents Chemother. 60, 2671-2679. doi: 10.1128/AAC.02972-15

Thummeepak, R., Kitti, T., Kunthalert, D., and Sitthisak, S. (2016). Enhanced antibacterial activity of Acinetobacter baumannii bacteriophage OABP-01 endolysin (LysABP-01) in combination with colistin. Front. Microbiol. 7:1402. doi: 10.3389/fmicb.2016.01402

Timurkaynak, F., Can, F., Azap, O. K., Demirbilek, M., Arslan, H., and Karaman, S. O. (2006). In vitro activities of non-traditional antimicrobials alone or in combination against multidrug-resistant strains of Pseudomonas aeruginosa and Acinetobacter baumannii isolated from intensive care units. Int. J. Antimicrob. Agents 27, 224-228. doi: 10.1016/j.ijantimicag.2005.10.012

Tipton, K. A., and Rather, P. N. (2016). An ompR/envZ two-component system ortholog regulates phase variation, osmotic tolerance, motility, and virulence in Acinetobacter baumannii strain AB5075. J. Bacteriol. doi: 10.1128/JB.00705-16. [Epub ahead of print].

Tognim, M. C., Gales, A. C., Penteado, A. P., Silbert, S., and Sader, H. S. (2006). Dissemination of IMP-1 metallo- beta -lactamase-producing Acinetobacter species in a Brazilian teaching hospital. Infect. Control Hosp. Epidemiol. 27, 742-747. doi: 10.1086/504356

Tomaras, A. P., Dorsey, C. W., Edelmann, R. E., and Actis, L. A. (2003). Attachment to and biofilm formation on abiotic surfaces by Acinetobacter baumannii: involvement of a novel chaperone-usher pili assembly system. Microbiology 149, 3473-3484. doi: 10.1099/mic.0.26541-0

Tomaras, A. P., Flagler, M. J., Dorsey, C. W., Gaddy, J. A., and Actis, L. A. (2008). Characterization of a two-component regulatory system from Acinetobacter baumannii that controls biofilm formation and cellular morphology. Microbiology 154, 3398-3409. doi: 10.1099/mic.0.2008/019471-0

Touchon, M., Cury, J., Yoon, E. J., Krizova, L., Cerqueira, G. C., Murphy, C., et al. (2014). The genomic diversification of the whole Acinetobacter genus: origins, mechanisms, and consequences. Genome Biol. Evol. 6, 2866-2882. doi: 10.1093/gbe/evu225

Traglia, G. M., Chua, K., Centron, D., Tolmasky, M. E., and Ramirez, M. S. (2014). Whole-genome sequence analysis of the naturally competent Acinetobacter baumannii clinical isolate A118. Genome Biol. Evol. 6, 2235-2239. doi: $10.1093 / g b e /$ evu176

Traglia, G. M., Quinn, B., Schramm, S. T., Soler-Bistue, A., and Ramirez, M. S. (2016). Serum Albumin and $\mathrm{Ca}^{2+}$ Are Natural Competence Inducers in the Human Pathogen Acinetobacter baumannii. Antimicrob. Agents Chemother. 60, 4920-4929. doi: 10.1128/AAC.00529-16

Trebosc, V., Gartenmann, S., Royet, K., Manfredi, P., Totzl, M., Schellhorn, B., et al. (2016). A novel genome-editing platform for drug-resistant Acinetobacter baumannii reveals an AdeR-unrelated tigecycline resistance mechanism. Antimicrob. Agents Chemother. 60, 7263-7271. doi: 10.1128/AAC.01275-16

Tsakris, A., Ikonomidis, A., Poulou, A., Spanakis, N., Vrizas, D., Diomidous, M., et al. (2008). Clusters of imipenem-resistant Acinetobacter baumannii clones producing different carbapenemases in an intensive care unit. Clin. Microbiol. Infect. 14, 588-594. doi: 10.1111/j.1469-0691.2008.01996.x

Tsakris, A., Ikonomidis, A., Pournaras, S., Tzouvelekis, L. S., Sofianou, D., Legakis, N. J., et al. (2006). VIM-1 metallo- $\beta$-lactamase in Acinetobacter baumannii. Emerg. Infect. Dis. 12, 981-983. doi: 10.3201/eid1206.051097

Tsakris, A., Ikonomidis, A., Spanakis, N., Pournaras, S., and Bethimouti, K. (2007). Identification of a novel $b l a_{\text {OXA-51 }}$ variant, $b l a_{\text {OXA-92 }}$, from a clinical isolate of Acinetobacter baumannii. Clin. Microbiol. Infect. 13, 348-349. doi: 10.1111/j.1469-0691.2006.01598.x

Tsuji, B. T., Landersdorfer, C. B., Lenhard, J. R., Cheah, S. E., Thamlikitkul, V., Rao, G. G., et al. (2016). Paradoxical effect of polymyxin B: high drug exposure amplifies resistance in Acinetobacter baumannii. Antimicrob. Agents Chemother. 60, 3913-3920. doi: 10.1128/AAC.02831-15

Turner, P. J., Greenhalgh, J. M., and MYSTIC Study Group (Europe) (2003). The activity of meropenem and comparators against Acinetobacter strains isolated from European hospitals, 1997-2000. Clin. Microbiol. Infect. 9, 563-567. doi: 10.1046/j.1469-0691.2003.00591.x

Turton, J. F., Ward, M. E., Woodford, N., Kaufmann, M. E., Pike, R., Livermore, D. M., et al. (2006a). The role of ISAbal in expression of OXA 
carbapenemase genes in Acinetobacter baumannii. FEMS Microbiol. Lett. 258, 72-77. doi: 10.1111/j.1574-6968.2006.00195.x

Turton, J. F., Woodford, N., Glover, J., Yarde, S., Kaufmann, M. E., and Pitt, T. L. (2006b). Identification of Acinetobacter baumannii by detection of the bla $a_{\text {OXA-51-like }}$ carbapenemase gene intrinsic to this species. J. Clin Microbiol. 44, 2974-2976. doi: 10.1128/JCM.01021-06

Umland, T. C., Schultz, L. W., MacDonald, U., Beanan, J. M., Olson, R., and Russo, T. A. (2012). In vivo-validated essential genes identified in Acinetobacter baumannii by using human ascites overlap poorly with essential genes detected on laboratory media. MBio. 3:e00113-12. doi: 10.1128/mBio.00113-12

Vahaboglu, H., Budak, F., Kasap, M., Gacar, G., Torol, S., Karadenizli, A., et al. (2006). High prevalence of OXA-51-type class D $\beta$-lactamases among ceftazidime-resistant clinical isolates of Acinetobacter spp.: co-existence with OXA-58 in multiple centres. J. Antimicrob. Chemother. 58, 537-542. doi: $10.1093 / \mathrm{jac} / \mathrm{dkl} 273$

Valenzuela, J. K., Thomas, L., Partridge, S. R., van der Reijden, T., Dijkshoorn, L., and Iredell, J. (2007). Horizontal gene transfer in a polyclonal outbreak of carbapenem-resistant Acinetobacter baumannii. J. Clin. Microbiol. 45, 453-460. doi: 10.1128/JCM.01971-06

Vijayakumar, S., Gopi, R., Gunasekaran, P., Bharathy, M., Walia, K., Anandan, S., et al. (2016). Molecular characterization of invasive carbapenem-resistant Acinetobacter baumannii from a tertiary care hospital in south India. Infect. Dis. Ther. 5, 379-387. doi: 10.1007/s40121-016-0125-y

Vilacoba, E., Almuzara, M., Gulone, L., Traglia, G. M., Figueroa, S. A., Sly, G., et al. (2013). Emergence and spread of plasmid-borne tet(B)::ISCR2 in minocyclineresistant Acinetobacter baumannii isolates. Antimicrob. Agents Chemother. 57, 651-654. doi: 10.1128/AAC.01751-12

Vila, J., Navia, M., Ruiz, J., and Casals, C. (1997). Cloning and nucleotide sequence analysis of a gene encoding an OXA-derived $\beta$-lactamase in Acinetobacter baumannii. Antimicrob. Agents Chemother. 41, 2757-2759.

Vila, J., Ruiz, J., Goni, P., Marcos, A., and Jimenez de Anta, T. (1995). Mutation in the gyrA gene of quinolone-resistant clinical isolates of Acinetobacter baumannii. Antimicrob. Agents Chemother. 39, 1201-1203.

Vincent, J. L., Rello, J., Marshall, J., Silva, E., Anzueto, A., Martin, C. D., et al. (2009). International study of the prevalence and outcomes of infection in intensive care units. JAMA 302, 2323-2329. doi: 10.1001/jama.2009.1754

Voulgari, E., Politi, L., Pitiriga, V., Dendrinos, J., Poulou, A., Georgiadis, G., et al. (2016). First report of an NDM-1 metallo- $\beta$-lactamase-producing Acinetobacter baumannii clinical isolate in Greece. Int. J. Antimicrob. Agents 48, 761-762. doi: 10.1016/j.ijantimicag.2016.09.006

Wang, H., Guo, P., Sun, H., Wang, H., Yang, Q., Chen, M., et al. (2007). Molecular epidemiology of clinical isolates of carbapenem-resistant Acinetobacter spp. from Chinese hospitals. Antimicrob. Agents Chemother. 51, 4022-4028. doi: 10.1128/AAC.01259-06

Wang, N., Ozer, E. A., Mandel, M. J., and Hauser, A. R. (2014). Genome-wide identification of Acinetobacter baumannii genes necessary for persistence in the lung. MBio 5, e01163-14. doi: 10.1128/mBio.01163-14

Wareham, D. W., Gordon, N. C., and Hornsey, M. (2011). In vitro activity of teicoplanin combined with colistin versus multidrug-resistant strains of Acinetobacter baumannii. J. Antimicrob. Chemother. 66, 1047-1051. doi: $10.1093 / \mathrm{jac} / \mathrm{dkr} 069$

Weber, B. S., Harding, C. M., and Feldman, M. F. (2015a). Pathogenic Acinetobacter: from the Cell Surface to Infinity and Beyond. J. Bacteriol. 198, 880-887. doi: 10.1128/JB.00906-15

Weber, B. S., Ly, P. M., Irwin, J. N., Pukatzki, S., and Feldman, M. F. (2015b). A multidrug resistance plasmid contains the molecular switch for type VI secretion in Acinetobacter baumannii. Proc. Natl.Acad. Sci. U.S.A. 112, 9442-9447. doi: 10.1073/pnas.1502966112

Weber, B. S., Miyata, S. T., Iwashkiw, J. A., Mortensen, B. L., Skaar, E. P., Pukatzki, S., et al. (2013). Genomic and functional analysis of the type VI secretion system in Acinetobacter. PLoS ONE 8:e55142. doi: 10.1371/journal.pone.0055142

Wormser, G. P., Keusch, G. T., and Heel, R. C. (1982). Co-trimoxazole (trimethoprim-sulfamethoxazole): an updated review of its antibacterial activity and clinical efficacy. Drugs 24, 459-518.
Wright, M. S., Haft, D. H., Harkins, D. M., Perez, F., Hujer, K. M., Bajaksouzian, S. et al. (2014). New insights into dissemination and variation of the health careassociated pathogen Acinetobacter baumannii from genomic analysis. MBio 5, e00963-e00913. doi: 10.1128/mBio.00963-13

Wu, X., Chavez, J. D., Schweppe, D. K., Zheng, C., Weisbrod, C. R., Eng, J. K., et al. (2016). In vivo protein interaction network analysis reveals porin-localized antibiotic inactivation in Acinetobacter baumannii strain AB5075. Nat. Commun. 7:13414. doi: 10.1038/ncomms 13414

Yamamoto, M., Nagao, M., Matsumura, Y., Matsushima, A., Ito, Y., Takakura, S., et al. (2011). Interspecies dissemination of a novel class 1 integron carrying bla $a_{\mathrm{IMP}-19}$ among Acinetobacter species in Japan. J. Antimicrob. Chemother. 66, 2480-2483. doi: 10.1093/jac/dkr336

Yang, H., Wang, M., Yu, J., and Wei, H. (2015). Antibacterial activity of a novel peptide-modified lysin against Acinetobacter baumannii and Pseudomonas aeruginosa. Front. Microbiol. 6:1471. doi: 10.3389/fmicb.2015.01471

Yang, Y. S., Lee, Y., Tseng, K. C., Huang, W. C., Chuang, M. F., Kuo, S. C., et al. (2016). In vivo and in vitro efficacy of minocycline-based combination therapy for minocycline-resistant Acinetobacter baumannii. Antimicrob. Agents Chemother. 60, 4047-4054. doi: 10.1128/AAC.02994-15

Yokoyama, Y., Matsumoto, K., Ikawa, K., Watanabe, E., Morikawa, N., and Takeda, Y. (2015). Population pharmacokinetic-pharmacodynamic target attainment analysis of sulbactam in patients with impaired renal function: dosing considerations for Acinetobacter baumannii infections. J. Infect. Chemother. 21, 284-289. doi: 10.1016/j.jiac.2014.12.005

Yum, J. H., Yi, K., Lee, H., Yong, D., Lee, K., Kim, J. M., et al. (2002). Molecular characterization of metallo- $\beta$-lactamase-producing Acinetobacter baumannii and Acinetobacter genomospecies 3 from Korea: identification of two new integrons carrying the bla $a_{\mathrm{VIM}-2}$ gene cassettes. J. Antimicrob. Chemother. 49, 837-840. doi: 10.1093/jac/dkf043

Yu, Y. S., Zhou, H., Yang, Q., Chen, Y. G., and Li, L. J. (2007). Widespread occurrence of aminoglycoside resistance due to ArmA methylase in imipenemresistant Acinetobacter baumannii isolates in China. J. Antimicrob. Chemother. 60, 454-455. doi: 10.1093/jac/dkm208

Zavascki, A. P., Goldani, L. Z., Li, J., and Nation, R. L. (2007). Polymyxin B for the treatment of multidrug-resistant pathogens: a critical review. J. Antimicrob. Chemother. 60, 1206-1215. doi: 10.1093/jac/dkm357

Zhang, X., Yang, T., Cao, J., Sun, J., Dai, W., and Zhang, L. (2016). Mucosal immunization with purified OmpA elicited protective immunity against infections caused by multidrug-resistant Acinetobacter baumannii. Microb. Pathog. 96, 20-25. doi: 10.1016/j.micpath.2016.04.019

Zhu, J., Wang, C., Wu, J., Jiang, R., Mi, Z., and Huang, Z. (2009). A novel aminoglycoside-modifying enzyme gene $a a c\left(6^{\prime}\right)-I b$ in a pandrugresistant Acinetobacter baumannii strain. J. Hosp. Infect. 73, 184-185. doi: 10.1016/j.jhin.2009.05.012

Zimbler, D. L., Park, T. M., Arivett, B. A., Penwell, W. F., Greer, S. M., Woodruff, T. M., et al. (2012). Stress response and virulence functions of the Acinetobacter baumannii NfuA Fe-S scaffold protein. J. Bacteriol. 194, 2884-2893. doi: 10.1128/JB.00213-12

Zoued, A., Brunet, Y. R., Durand, E., Aschtgen, M. S., Logger, L., Douzi, B., et al. (2014). Architecture and assembly of the Type VI secretion system. Biochim. Biophys. Acta 1843, 1664-1673. doi: 10.1016/j.bbamcr.2014.03.018

Conflict of Interest Statement: The authors declare that the research was conducted in the absence of any commercial or financial relationships that could be construed as a potential conflict of interest.

Copyright (c) 2017 Lee, Lee, Park, Park, Bae, Kim, Cha, Jeong and Lee. This is an open-access article distributed under the terms of the Creative Commons Attribution License (CC BY). The use, distribution or reproduction in other forums is permitted, provided the original author(s) or licensor are credited and that the original publication in this journal is cited, in accordance with accepted academic practice. No use, distribution or reproduction is permitted which does not comply with these terms. 